Universidad de Lima

Facultad de Comunicación

Carrera de Psicología

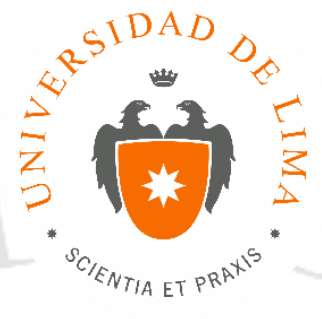

\title{
ADAPTACIÓN Y PROPIEDADES PSICOMÉTRICAS DEL INVENTARIO DE ANSIEDAD ANTE EL DESEMPEÑO MUSICAL DE KENNY (IADM-K)
}

Tesis para optar el título profesional de Licenciado en Psicología

\section{Álvaro Mario Chang Arana}

Código 20080232

\author{
Asesor \\ Andrés Burga León \\ Lima - Perú
}

Diciembre de 2015 
A la memoria de Jorge Arana;

mi perenne ejemplo.

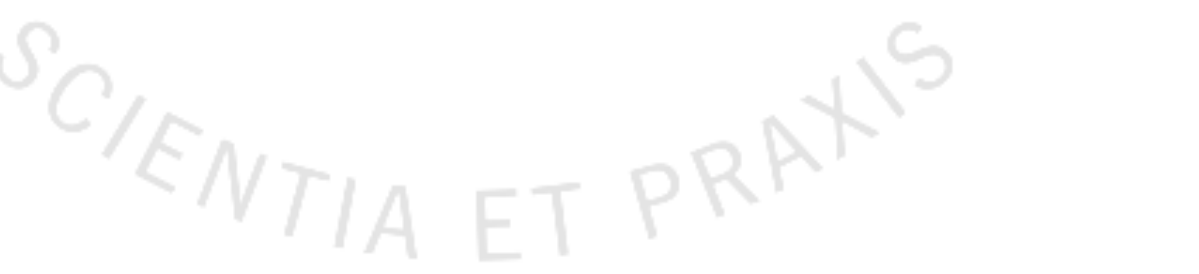




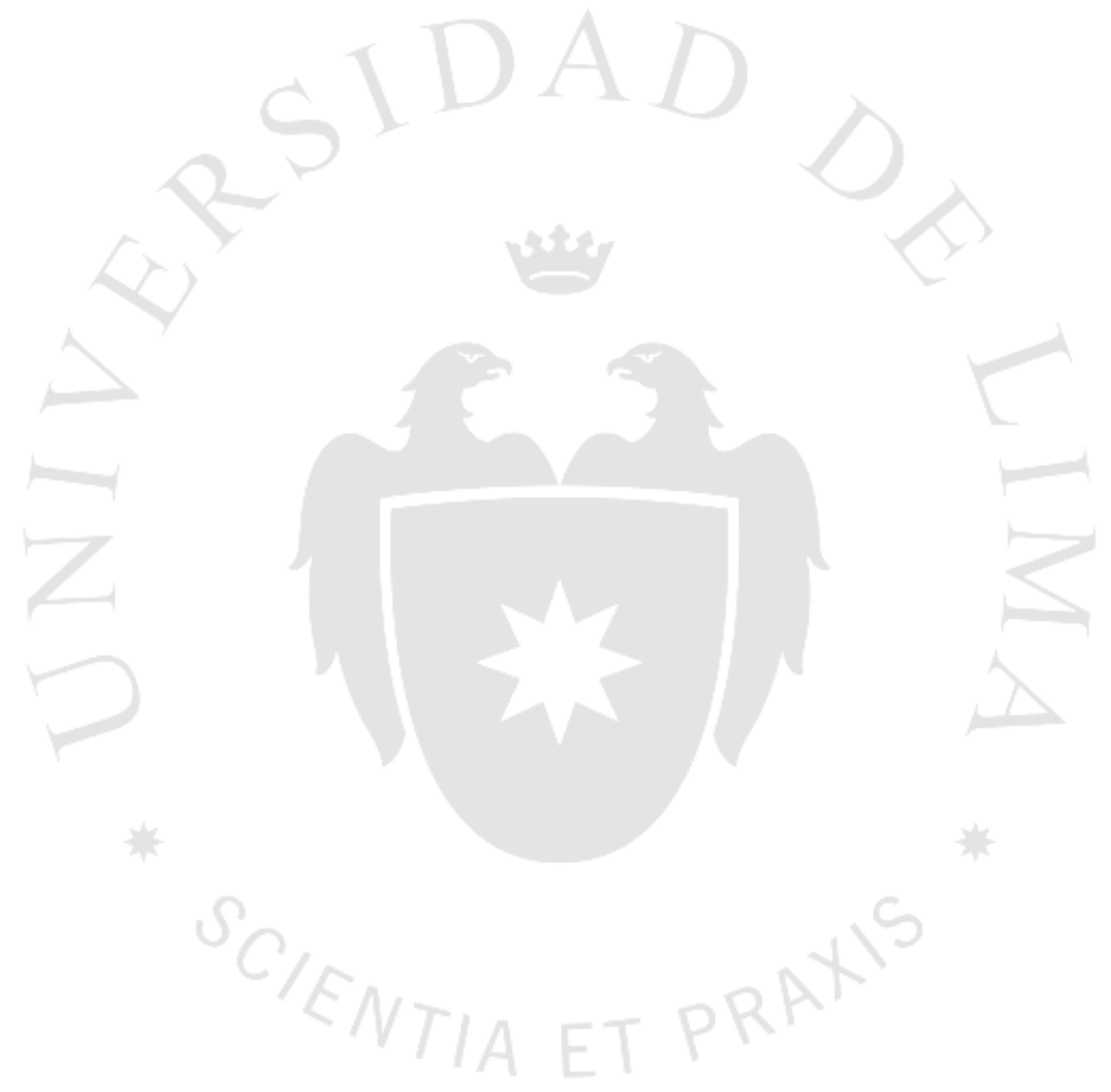




\section{AGRADECIMIENTOS}

El estudio de la ansiedad ante el desempeño musical nació durante los últimos ciclos del pregrado. Mi interés por la intersección entre la psicología y la música me llevaron a profundizar en un fenómeno que afecta a muchos estudiantes de música y músicos profesionales. Si bien en un primer momento busqué diseñar un programa instruccional para regular la ansiedad ante el desempeño musical en estudiantes de música de nivel profesional, el proyecto devino en una investigación psicométrica. Esta evolución fue posible gracias a un conjunto de personas que me apoyaron durante diversas etapas del proceso.

Empezando por las etapas germinales de la investigación, quiero agradecer particularmente a los profesores Norma Reátegui, Alberto Alegre, Edwin Salas, Cipriano Olivera y Noemí Salazar quienes me motivaron y guiaron en el proceso de exploración del tema. Asimismo, valoro el esfuerzo de mis compañeras María Jesús Escobar, Yanira Jiménez y Josefina Navarrete, quienes formaron parte de las primeras búsquedas de información durante el transcurso de la asignatura de Psicología Instruccional. A mi maestro, Pablo Sabat le estaré siempre agradecido por nutrir mi abnegada vocación hacia la música: principal motor de mis esfuerzos.

A la profesora Sandra Inurritegui también le agradezco por encaminar este proyecto de investigación hacia una adaptación y estimación de las propiedades psicométricas del Inventario de Ansiedad ante el Desempeño Musical diseñado por Dianna Kenny, psicóloga y pianista australiana. Gracias a su guía pude formular un proyecto más viable en términos de capacidad y tiempo.

Al profesor Andrés Burga le estoy agradecido por haber sido mi asesor de investigación y ser un ejemplar facilitador social del aprendizaje, sugiriendo nuevas ideas y lecturas que tuve que explorar en el camino a lo largo del proyecto. Por su guía pude construir un conocimiento que hoy atesoro.

También quiero reconocer a otros agentes que apoyaron en la logística de la investigación. A los maestros Carlos Sayán, Lyscenia Durazo y Fernando De Lucchi, directores de las instituciones educativas que generosamente me abrieron sus puertas, les debo mi gratitud, así como a cada uno de los docentes que me otorgaron minutos de sus clases para cumplir con mis objetivos. Gracias a Anna Lucía Campos, fundadora de Cerebrum, quien me permitió ausentarme de mis funciones laborales con el propósito de avanzar mi investigación. Durante las sesiones de aplicación, colegas y amigos me apoyaron 
en la recolección de las pruebas: muchas gracias a Lidia Calderón, Víctor Talavera, Omar Rodas, Rodrigo Álvarez y Rodrigo Flores.

Por último, extiendo el mayor de mis agradecimientos a mi padres, quienes con su esfuerzo y sacrificio me otorgaron las mejores oportunidades a su alcance. Espero que esta investigación sea un gesto al menos justo ante los años de entrega de sus vidas. 


\section{ADAPTACIÓN Y PROPIEDADES PSICOMÉTRICAS DEL INVENTARIO DE ANSIEDAD ANTE EL DESEMPEÑO MUSICAL DE KENNY (IADM-K)}




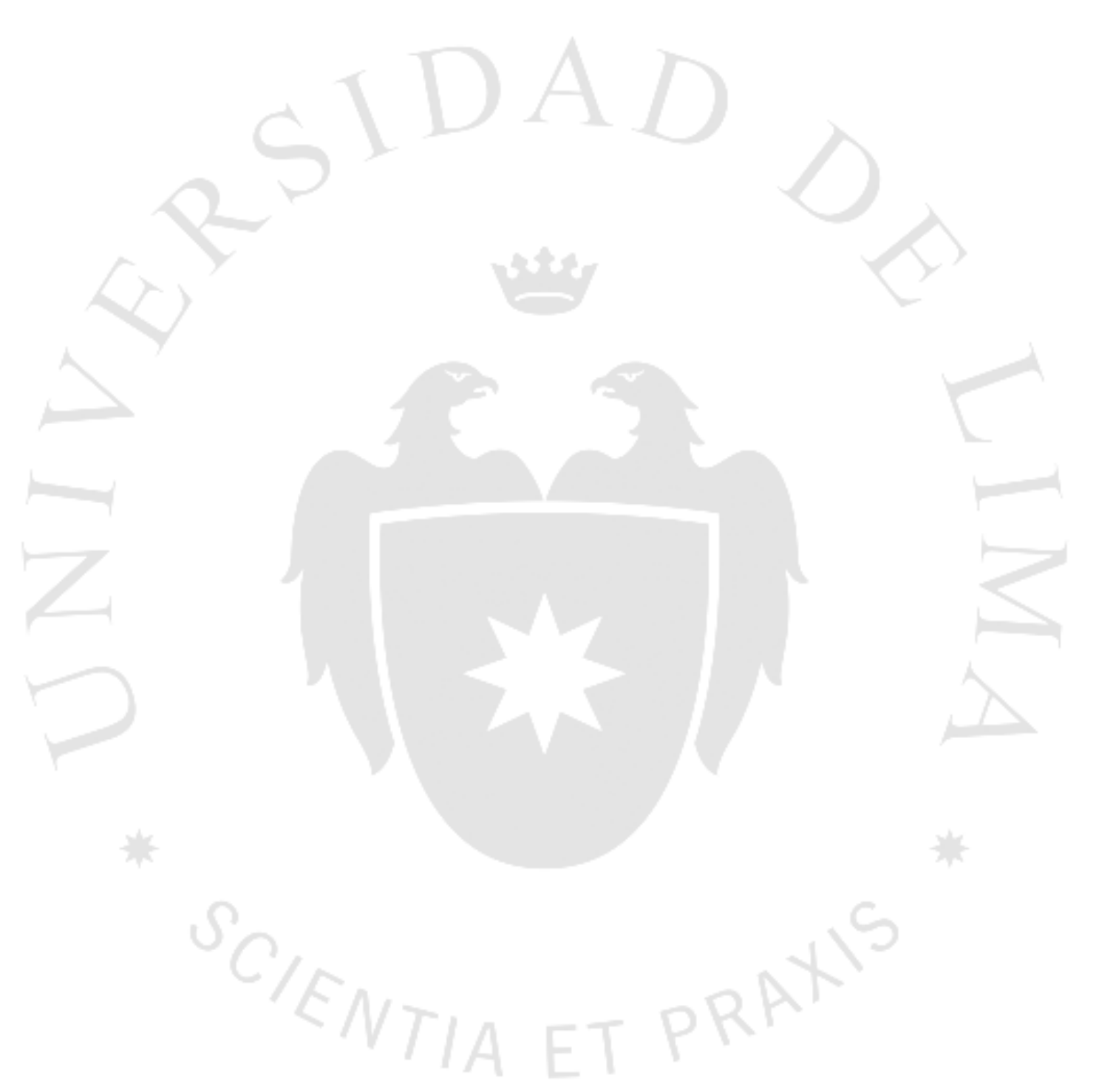




\section{TABLA DE CONTENIDOS}

\section{CAPÍTULO I: PLANTEAMIENTO DEL PROBLEMA}

1.1 Descripción del problema

1.2 Justificación y relevancia

1.3 Limitaciones

CAPÍTULO II: MARCO TEÓRICO

2.1 Ansiedad

2.2 Ansiedad estado y ansiedad rasgo

2.3 Trastorno de ansiedad

2.3.1 Fobia social (ansiedad social)

2.3.2 Fobia social y la ansiedad ante el desempeño

\subsubsection{Fobia social y ansiedad ante el desempeño} musical

2.4 Investigaciones previas vinculadas a la ansiedad ante el desempeño musical

2.5 Definición conceptual de la ansiedad ante el desempeño musical

2.6 Componentes de la ansiedad ante el desempeño musical

2.6.1 Componentes fisiológicos de la ansiedad ante el desempeño musical

2.6.2 Componentes conductuales de la ansiedad ante el desempeño musical

2.6.3 Componentes cognitivos de la ansiedad ante

el desempeño musical

2.6.4 Componentes afectivos de la ansiedad ante

el desempeño musical

2.7 Consecuencias profesionales y personales de la 
ansiedad ante el desempeño musical

2.8 Teoría de la ansiedad de Barlow

2.9 Facilitación social

2.10 Instrumentos de medición empleados para

evaluar la ansiedad ante el desempeño musical

2.11 Investigaciones previas relacionadas con

alternativas de solución a la ansiedad ante el

desempeño musical

CAPÍTULO III: OBJETIVOS

3.1 Objetivo general 36

3.1.1 Objetivos específicos 36

3.2 Definición de variables

3.2.1 Definición conceptual de ansiedad ante el desempeño musical

3.2.2 Definición operacional de ansiedad ante el desempeño musical

4.1 Tipo y diseño de investigación

4.2 Participantes

4.3 Técnicas de recolección de datos

4.3.1 Inventario de Ansiedad Ante el Desempeño

Musical de Kenny (IADM-K)

4.3.2 Inventario de Ansiedad Rasgo-Estado

(IDARE)

4.3.3 Inventario de Ansiedad de Beck (IAB)

4.4 Procedimiento

\section{CAPÍTULO V: RESULTADOS}

5.1 Adaptación del IADM-K

5.2 Evidencias de validez vinculadas al contenido

5.3 Evidencias de validez vinculadas a la estructura interna 
5.4 Estimación de la confiabilidad a partir de las puntuaciones derivadas de la aplicación de los ítems que conforman al IADM-K

5.5 Evidencias de validez vinculadas a la relación con otras variables

5.6 Elaboración de baremos

6.1 Adaptación y propiedades psicométricas

6.2 Estándares para la Evaluación Educativa y Psicológica (AERA, APA y NCME, 2014)

6.2.1 Estándares para la validez

6.2.2 Estándares para la confiabilidad

6.2.3 Estándares para el diseño y desarrollo de la prueba

6.2.5 Estándares para la administración, puntuación, reporte e interpretación

Conclusiones 86

Recomendaciones 88

Referencias 


\section{ÍNDICE DE TABLAS}

Tabla 2.1 Similitudes y diferencias entre la ADM y la fobia social

Tabla 4.1 Distribución poblacional de los estudiantes de música de Lima Metropolitana en las seis instituciones de formación musical más representativas

Tabla 4.2 Distribución muestral de los estudiantes de música de Lima Metropolitana en tres instituciones de formación musical

Tabla 5.1 Coeficiente V de Aiken para los ítems del IADM-K 52

Tabla 5.2 Matriz de factores rotados ortogonalmente para los ítems del IADM-K

Tabla 5.3 Análisis factorial exploratorio de segundo orden de los ítems del IADM-K con

la solución Schmid-Leiman con tres factores de primer orden rotados

oblicuamente

Tabla 5.4 Matriz de correlación entre los puntajes del IADM-K, y los puntajes del F1, F2, y F3

Tabla 5.5 Análisis factorial exploratorio de segundo orden de los ítems del IADM-K con la solución Schmid-Leiman con dos factores de primer orden rotados oblicuamente

Tabla 5.6 Alfa de Cronbach, alfa ordinal y EEM para las puntuaciones derivadas del factor $\mathrm{G}$ y de los factores de primer orden

Tabla 5.7 Alfa de Cronbach, alfa ordinal y EEM para las puntuaciones derivadas del factor $\mathrm{G}$ y de los factores de primer orden para el grupo de hombres

Tabla 5.8 Alfa ordinal y EEM para las puntuaciones derivadas del factor G y de los factores de primer orden para el grupo de mujeres

Tabla 5.9 Prueba K-Z de bondad de ajuste a la curva normal para el IADM-K, IDARE 62 
Estado, IDARE Rasgo y IAB

Tabla 5.10 Matriz de correlación entre los puntajes del IADM-K, IDARE Estado, IDARE Rasgo y el IAB

Tabla 5.11 Percentiles globales para las puntuaciones obtenidas a partir del IADM-K 66

Tabla 5.12 Percentiles globales para las puntuaciones obtenidas a partir del F1 (ansiedad ante el desempeño musical)

Tabla 5.13 Percentiles globales para las puntuaciones obtenidas a partir del F2 (componentes depresivos)

Tabla 5.14 Estadísticos descriptivos y prueba Shapiro-Wilk de bondad de ajuste a la curva normal para las instituciones educativas privadas A y $\mathrm{B}$; y para la institución educativa estatal

Tabla 5.15 Media y desviación estándar para F1 y F2 de acuerdo a la institución educativa de pertenencia

Tabla 5.16 Análisis de varianza, tamaño del efecto y potencia estadística de las puntuaciones obtenidas de F1 y F2 para las tres instituciones educativas

Tabla 5.17 Percentiles de acuerdo al sexo de los participantes para las puntuaciones obtenidas a partir del IADM-K

Tabla 5.18 Percentiles de acuerdo al sexo de los participantes para las puntuaciones obtenidas a partir del F1 (ansiedad ante el desempeño musical) 


\section{ÍNDICE DE FIGURAS}

Figura 2.1 Aproximación teórica a la ansiedad ante el desempeño musical 6

Figura 5.1 Histograma de las puntuaciones del IDARE-Estado 63

Figura 5.2 Histograma de las puntuaciones del IADRE-Rasgo $\quad 64$

Figura 5.3 Histograma de las puntuaciones del IAB $\quad 64$ 


\section{ÍNDICE DE ANEXOS}

Anexo 1: Ficha Sociodemográfica 96

Anexo 2: IADM-K

Anexo 3: K-MPAI-R 100

Anexo 4: Ficha Técnica y Propuesta de Prueba 103

Anexo 5: IDARE-Ansiedad Estado $\quad 106$

Anexo 6: IDARE-Ansiedad Rasgo 107

Anexo 7:IAB 108

Anexo 8: Criterio de Jueces 109

Anexo 9: Consentimiento Informado 114

Anexo 10: Protocolo de Aplicación $\quad 115$ 


\section{RESUMEN}

La ansiedad ante el desempeño musical es un fenómeno que afecta a los músicos instrumentistas independientemente del género, años de entrenamiento, estilo, etc.; y que puede deteriorar el desarrollo profesional de los músicos. No obstante, no existen pruebas específicas para estudiantes de música peruanos. La presente investigación adaptó y estimó las propiedades psicométricas del Inventario de Ansiedad ante el Desempeño Musical (IADM-K) de Kenny en 455 estudiantes profesionales de música de tres escuelas musicales de enseñanza superior. Tras una contratraducción del instrumento, la autora de la prueba reconoció a la versión traducida como la oficial en español. Se encontraron evidencias de validez vinculadas al contenido por medio del criterio de ocho de jueces. Al analizar las evidencias de validez vinculadas a la estructura interna, se optó por un modelo unidimensional $(\alpha$ ordinal $=.97, \mathrm{EEM}=4.87$ ). Adicionalmente se identificaron dos factores de primer orden: "ansiedad ante el desempeño musical" ( $\alpha$ ordinal $=.93, \mathrm{EEM}=6.11)$ y “componentes depresivos ( $\alpha$ ordinal $=.92, \mathrm{SEM}=3.01$ ). A raíz de la nueva estructura, se propuso un nuevo Inventario de Afectividad Negativa Ante el Desempeño Musical (IANDM). Por último, las evidencias de validez vinculadas a las relaciones con otras variables señalan que a un nivel $p<.001$, el IADM-K correlaciona de manera estadísticamente significativa, tanto con el Inventario de Ansiedad Rasgo-Ansiedad Estado (IDARE), como con el Inventario de Ansiedad de Beck (IAB), siendo dichas correlaciones altas. Los resultados permitieron concluir que las interpretaciones y decisiones que se tomen a partir de las puntuaciones obtenidas mediante la adaptación del IADM-K presentan evidencias de validez y confiabilidad en estudiantes de música de nivel superior de Lima metropolitana.

Palabras clave: ansiedad ante el desempeño musical, IADM-K, adaptación, contratraducción, evidencias de validez, confiabilidad, afectividad negativa ante el desempeño musical, INADM. 


\begin{abstract}
Music performance anxiety is a condition that affects instrumentalist musicians independently of gender, years of training, music style, etc.; and can deteriorate their professional development. Nevertheless, there are no specific tests for Peruvian music students. The aim of this research was to adapt and estimate the psychometric properties of the Kenny Music Performance Anxiety Inventory (K-MPAI) on a sample of 455 professional music students from three professional music institutions. After back translating the test, the author of the English test recognized it as the official Spanish version. Appropriate validity evidence based on test content was estimated by eight subject matter experts. Validity evidence based on internal structure was estimated by a second-order exploratory factor analysis with the Schmid-Leiman solution which showed a unidimensional structure (ordinal $\alpha=.97$, SEM = 4.87). Additionally, two first order factors: "music performance anxiety" (ordinal $\alpha=.93$, $\mathrm{SEM}=6.11$ ) and "depressive components" (ordinal $\alpha=.92, \mathrm{SEM}=3.01$ ) were identified. Based on the new structure, a Negative Affectivity Towards Music Performance Inventory (NAMPI) was proposed. Finally, with a $p<.001$, the K-MPAI presented high and significant correlational values with STAI and BAI and, thus, appropriate validity evidence based on the relation with other variables. Results showed that interpretations and decisions based on the scores obtained through the adaptation of the K-MPAI present validity and reliability evidence for professional music students of Metropolitan Lima.
\end{abstract}

Key words: music performance anxiety, K-MPAI, adaptation, back translation, validity evidence, reliability, negative affectivity towards music performance, NAMPI. 


\section{INTRODUCCIÓN}

Esta investigación tiene como objetivo adaptar y determinar las propiedades psicométricas del IADM-K en una muestra de 455 estudiantes de instituciones de enseñanza musical de Lima Metropolitana.

El Capítulo 1 de la tesis abarca el Planteamiento del Problema, el cual incluye la presentación del tema, la viabilidad y las limitaciones. En esa sección se argumenta la relevancia de esta investigación psicométrica en una población desatendida por la psicología en el contexto peruano.

En el Capítulo 2 se presenta el Marco Teórico, en el cual se presenta entre otras consideraciones teóricas, la definición de ansiedad ante el desempeño musical según Kenny (2011), así como la teoría de la ansiedad de Barlow (2000). Asimismo, el capítulo contiene investigaciones antecedentes sobre la ansiedad ante el desempeño musical, los instrumentos de medición que se han utilizado para este propósito y las alternativas de solución reportadas en la literatura.

El tercer capítulo contiene los objetivos de la tesis y la definición conceptual y operacional de la ansiedad ante el desempeño musical; y el cuarto detalla la metodología escogida, donde se ha procurado ahondar en detalles que permitan evaluar la calidad de la investigación y permitir futuras ampliaciones o replicaciones.

El Capítulo 5 reporta los resultados de la investigación. En esta sección se encuentran seis subcapítulos, cada uno de ellos acorde a los objetivos específicos planteados en el Capítulo 3.

La discusión de los resultados puede hallarse en el Capítulo 6. En esta sección se interpretan las propiedades psicométricas halladas en la sección anterior, se presenta una nueva propuesta de prueba a partir del modelo tripartito de la ansiedad y depresión (Anderson y Hope, 2008; Brown, Chorpita y Barlow, 1998; Clark y Watson, 1991) y se finaliza cotejando los estándares de calidad con los que cuenta esta investigación psicométrica a partir de los Estándares para la Evaluación Educativa y Psicológica (American Educational Research Association [AERA], American Psychological Association [APA] y National Council on Measurement in Education [NCME], 2014).

Por último, podrán consultarse las conclusiones que resumen los principales hallazgos, así como las recomendaciones planteadas para futuras investigaciones. También se presenta 
una sección de Anexos donde pueden consultarse diversos documentos utilizados para la elaboración de esta tesis. 


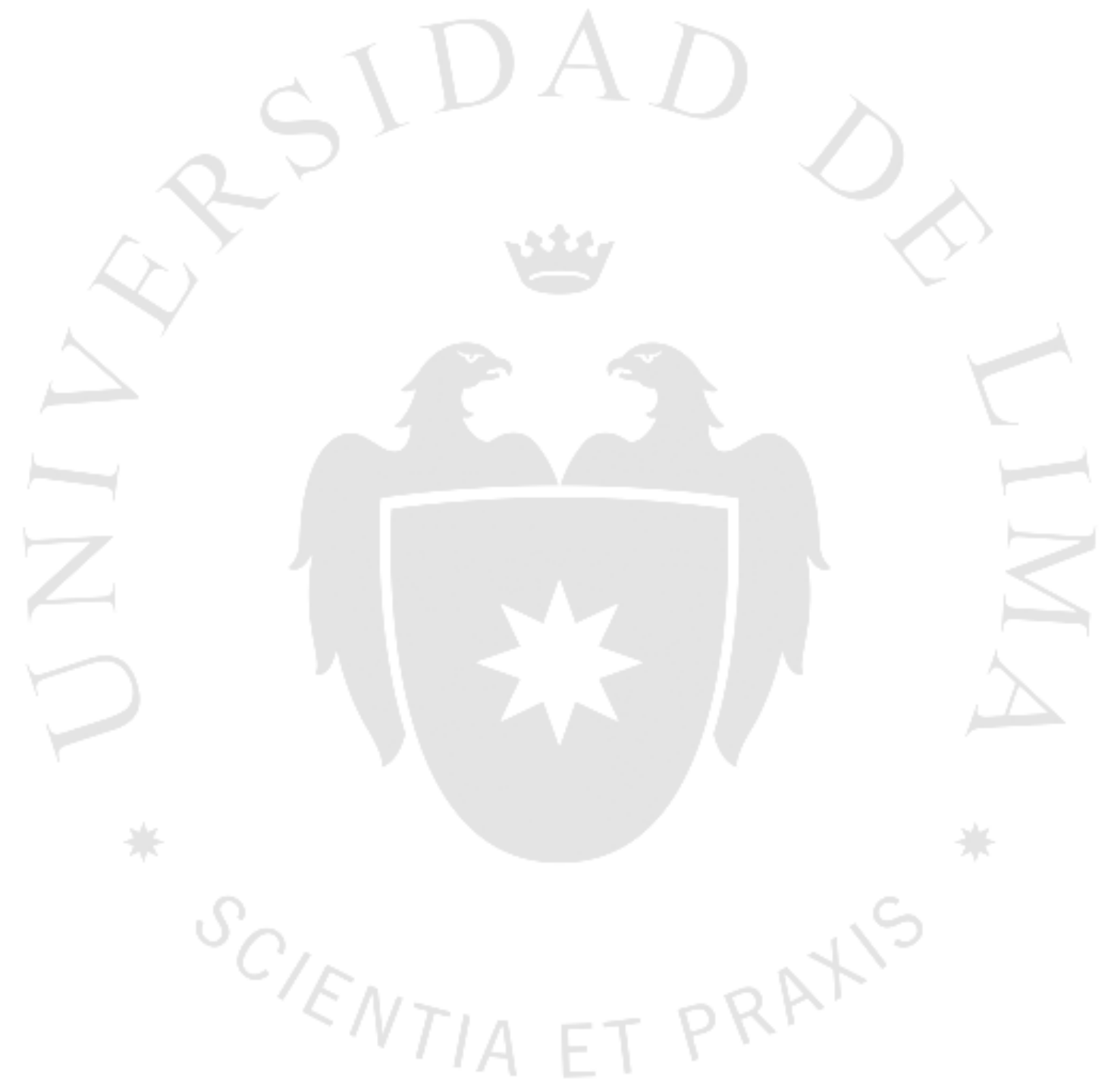




\section{CAPÍTULO I: PLANTEAMIENTO DEL PROBLEMA}

\subsection{Descripción del problema}

Un problema recurrente que se observa entre músicos profesionales y entre estudiantes de música es que conforme se acerca el momento final de la ejecución musical en una presentación pública o con fines de evaluación en el caso de los estudiantes, el nivel de ansiedad, entendida como una "emoción que se caracteriza por la aprensión y síntomas somáticos de tensión en que un individuo anticipa un peligro, catástrofe o desgracia inminente" (American Psychological Association [APA], 2010a, p. 32), se incrementa. Este fenómeno puede llegar incluso a incapacitar a la persona y perjudicar la calidad de la presentación o los resultados de la evaluación; es decir, la ansiedad está íntimamente relacionada con la ejecución de una conducta y su grado de eficacia.

No obstante, también es cierto que un grado leve de ansiedad puede facilitar el desempeño óptimo de un intérprete (Martínez y Paterna, 2010). De acuerdo a lo señalado por Craske y Craig (1984), la presencia de cierto grado de ansiedad en estudiantes de piano resulta en una evaluación más positiva por parte de un jurado frente a una situación en la que se cuenta con un público (e.g. una audición), en comparación con una carente de público (e.g. un ensayo individual). En otras palabras, cuando un grupo de pianistas tenía que tocar frente a un jurado, este calificó como superior al desempeño mostrado en la audición frente a una situación de ensayo individual grabada (sin presencia de un público).

Sin embargo, el incremento incontrolado de la ansiedad puede generar sintomatologías de tipo fisiológicas, conductuales, cognitivas y afectivas que pueden representar un problema para la plena ejecución musical del o de los intérpretes. La exacerbación de dichos componentes puede tener efectos inesperados y perjudiciales para el desarrollo personal y profesional de los músicos.

Por componentes fisiológicos se entienden manifestaciones medibles relacionadas con la actividad del sistema nervioso periférico. Algunos de los componentes fisiológicos vinculados al fenómeno de la ansiedad ante la ejecución son la aceleración del ritmo cardíaco, aumento del ritmo de sudoración, mayor actividad electromiográfica (actividad eléctrica medible, producida por los músculos 
esqueléticos), el mayor nivel de co-contracción muscular de los brazos o la disminución de la temperatura de los dedos (Yoshie, Kudo, Murakoshi y Ohtsuki, 2009).

Las manifestaciones conductuales tienden a ser la modificación involuntaria del tempo de ejecución, contraer los hombros, presencia de temblores en las manos o errores en la coordinación motora fina (Yoshie et al., 2008; Yoshie et al., 2009). Sin embargo, pueden variar de acuerdo a cada instrumento, así las conductas vinculadas a la ansiedad en pianistas no tienen por qué ser iguales a las manifestadas por oboístas, por ejemplo.

Los componentes cognitivos identificados de la ansiedad ante alguna presentación musical son: cogniciones catastróficas (e.g. "tengo que ser el mejor", "no debo de equivocarme", si no hago esto bien mi carrera está terminada", etc.), creencias irracionales (e.g. "nunca seré un concertista", "todos piensan que toco mal”, “jamás alcanzaré el éxito como músico", etc.), diálogos internos negativos, autocrítica destructiva o ausencia de correspondencia entre el nivel de interpretación percibido y el estándar asignado por el músico (Deniz, 2007; Kirchner, Bloom y Skutnick-Henley, 2008; Ortiz, 2011a).

En lo que respecta a los componentes afectivos, estos tienden a caracterizarse por lo siguiente: aprehensión y tensión subjetivas, miedo al fracaso o culpa (Ortiz, 2011a; Kirchner, et al., 2008; Nagel, 2010; Spielberger y Díaz-Guerrero, 1970). De hecho, Taylor y Wasley (2004), dan cuenta de testimonios de músicos acerca de sus hábitos para calmarse antes de una presentación. Uno de ellos señala: "antes de la ejecución, algunas veces acudía al alcohol o a tomar tranquilizantes” (p. 172). La cita anterior es un indicio de inadecuadas estrategias de afrontamiento para la modulación de las emociones en estudiantes de música.

Por otro lado, la adaptación de instrumentos psicométricos y la estimación de las propiedades psicométricas derivadas de las puntuaciones obtenidas tras la aplicación de estas herramientas es una actividad científica aplicada de gran relevancia. Permiten generar nuevas tecnologías para el estudio estadístico y objetivo de diferentes fenómenos psicológicos, enmarcados dentro de un contexto y grupo humano en particular. Los instrumentos psicológicos son procedimientos de evaluación que permiten futuras intervenciones o de producción de conocimiento en investigaciones de tipo básicas. 
A pesar de que se cuenta con instrumentos psicológicos para medir la ansiedad en términos más genéricos, se carece de instrumentos diseñados específicamente para medir a la ansiedad ante el desempeño musical (ADM). Por ello, el Inventario de Ansiedad Ante el Desempeño Musical de Kenny (IADM-K) creado por Dianna Kenny (2009), es un instrumento de una utilidad potencial que debe ser adaptado al contexto peruano.

En función a lo expuesto anteriormente, la presente investigación pretender responder a las siguientes interrogantes:

¿Las interpretaciones y decisiones que se tomen a partir de las puntuaciones obtenidas mediante el IADM-K presentan evidencias de validez en estudiantes de música de instrucción superior de Lima Metropolitana?

¿Las interpretaciones y decisiones que se tomen a partir de las puntuaciones obtenidas mediante el IADM-K presentan confiabilidad en estudiantes de música de instrucción superior de Lima Metropolitana?

¿Qué características presentarán los baremos necesarios para tomar las interpretaciones y decisiones a partir de las puntuaciones obtenidas mediante el IADM-K en estudiantes de música de instrucción superior de Lima Metropolitana?

\subsection{Justificación y relevancia}

Es importante adaptar y estimar las propiedades psicométricas de un instrumento psicológico por ser una tecnología que permite identificar y evaluar posibles problemáticas existentes para una futura intervención sistemáticamente planeada en un contexto particular. En el caso de la presente investigación, la adaptación implica una serie de procesos que no se limitan al de la traducción del instrumento extranjero a la cultura peruana y a los códigos lingüísticos que se emplean en un grupo humano en un momento determinado. También comprende analizar si la versión adaptada sigue midiendo el mismo constructo, modificar el fraseo de los ítems, escoger a los traductores, etc. (Hambleton, 1996). Hérnandez, Fernández y Baptista (2010) coinciden con lo planteado por Hambleton (1996) y sostienen que el proceso de traducción es un primer paso necesario, mas no suficiente, para construir un argumento de validez que sustente el empleo de un instrumento para un fin determinado (Sireci y Padilla, 2014).

Asimismo, estudiar la ansiedad ante el desempeño en músicos es importante por las consecuencias que tiene en ellos a nivel físico, psicológico y profesional. Por 
ejemplo, la literatura consultada da cuenta de conductas mal adaptativas para afrontar esta ansiedad y que son un peligro para la salud física de los estudiantes de música. Entre ellas, está el consumo de drogas, tales como alcohol u otras ilegales; el consumo de betabloqueadores y fumar (Ortiz, 2011; Taylor y Wasley, 2004; West, 2004).

El consumo de drogas no es una conducta que se presente necesariamente en todos los músicos como consecuencia de la ansiedad, puesto que es solo una manera más para afrontarla, si bien perjudicial para la salud. Sin embargo, la presencia de este fenómeno psicológico puede afectar a un músico de cualquier nivel de experiencia o educación musical, así como también a cualquier grupo de edad. Por ejemplo, Karspen y Gotestam (como se citó en Kenny, 2011) hallaron que de 126 estudiantes de un conservatorio noruego, el 36.5\% reportó que la ADM que experimentaban era tan alto que manifestaban la necesidad de que los ayuden a regularla.

A nivel psicológico, el fracaso en una presentación como consecuencia de una ansiedad no modulada adaptativamente puede causar frustración, enojo, autocrítica destructiva y otros pensamientos negativos que afectan el autoconcepto de los estudiantes de música.

A nivel profesional, la ADM puede tener consecuencias graves en el futuro de los estudiantes de música. Meses de preparación pueden verse estropeados a los pocos minutos de iniciada una presentación.

Sin embargo, la aparición de la ADM puede darse en diferentes grupos de intérpretes sin importar la edad, ya sea en niños, adolescentes o músicos adultos. Esta ansiedad también puede manifestarse sin importar el nivel de experiencia, pues puede afectar a músicos aficionados o profesionales, con o sin experiencia, como solistas o en conjunto, cantante o instrumentista (Kenny, 2011).

Una justificación sociológica para adaptar y validar este instrumento psicológico está en la reciente aparición de nuevas facultades de música en diferentes universidades privadas, la formación de nuevas orquestas y el creciente desarrollo de la actividad musical en el país. Con respecto a las facultades de música, existen al menos dos instituciones educativas privadas que se han sumado a otras (privadas y estatales) en la formación profesional de músicos. Asimismo, existen por lo menos dos orquestas sinfónicas nuevas en Lima, en las cuales la población de músicos 
jóvenes es mayor; estas son la Orquesta Sinfónica Nacional Juvenil del Ministerio de Cultura y la Orquesta Sinfónica Juvenil "Sinfonía por el Perú".

$\mathrm{Al}$ existir una mayor demanda por espectáculos musicales, los músicos pueden encontrar más posibilidades de ejecutar en público. Esto, a su vez, es una fuente potencial de ansiedad que puede afectarlos en mayor o menor medida. Por ello es importante aportar una herramienta que pueda ser el inicio de futuras intervenciones que busquen brindarles más herramientas que complementen su formación personal y profesional.

Finalmente, la adaptación y validación del IADM-K al contexto peruano es una iniciativa original en su campo, dado que no se tiene conocimiento de antecedentes nacionales similares. Por ello, puede ser el inicio de futuras investigaciones e intervenciones vinculadas a la formación musical.

\subsection{Limitaciones}

De acuerdo a Kenny (2011) la ADM comparte características con la ansiedad social. Por ello, como parte de la estimación de las evidencias de validez vinculadas a la relación con otras variables, la inclusión de una escala de ansiedad social habría sido una fuente de evidencias convergentes importante. No obstante, no se tuvo acceso a una escala de este tipo. 


\section{CAPÍTULO II: MARCO TEÓRICO}

Esta sección tiene el propósito de discutir conceptualmente la ADM. Para ello, la estrategia que se seguirá es presentar una breve definición de ansiedad, para luego enmarcarla dentro de un tipo de trastorno específico que es la fobia social. A continuación, se elaborará una discusión acerca de la ansiedad ante el desempeño en líneas generales para concluir con la ADM. Como parte de la explicación de este último constructo, se presentarán investigaciones previas, definiciones conceptuales, otras teorías que complementen su entendimiento, instrumentos de medición y estrategias de solución a niveles altos de ADM. La figura 1 ilustra cómo se llevará a cabo la aproximación teórica.

Figura 2.1

Aproximación teórica a la ansiedad ante el desempeño musical.

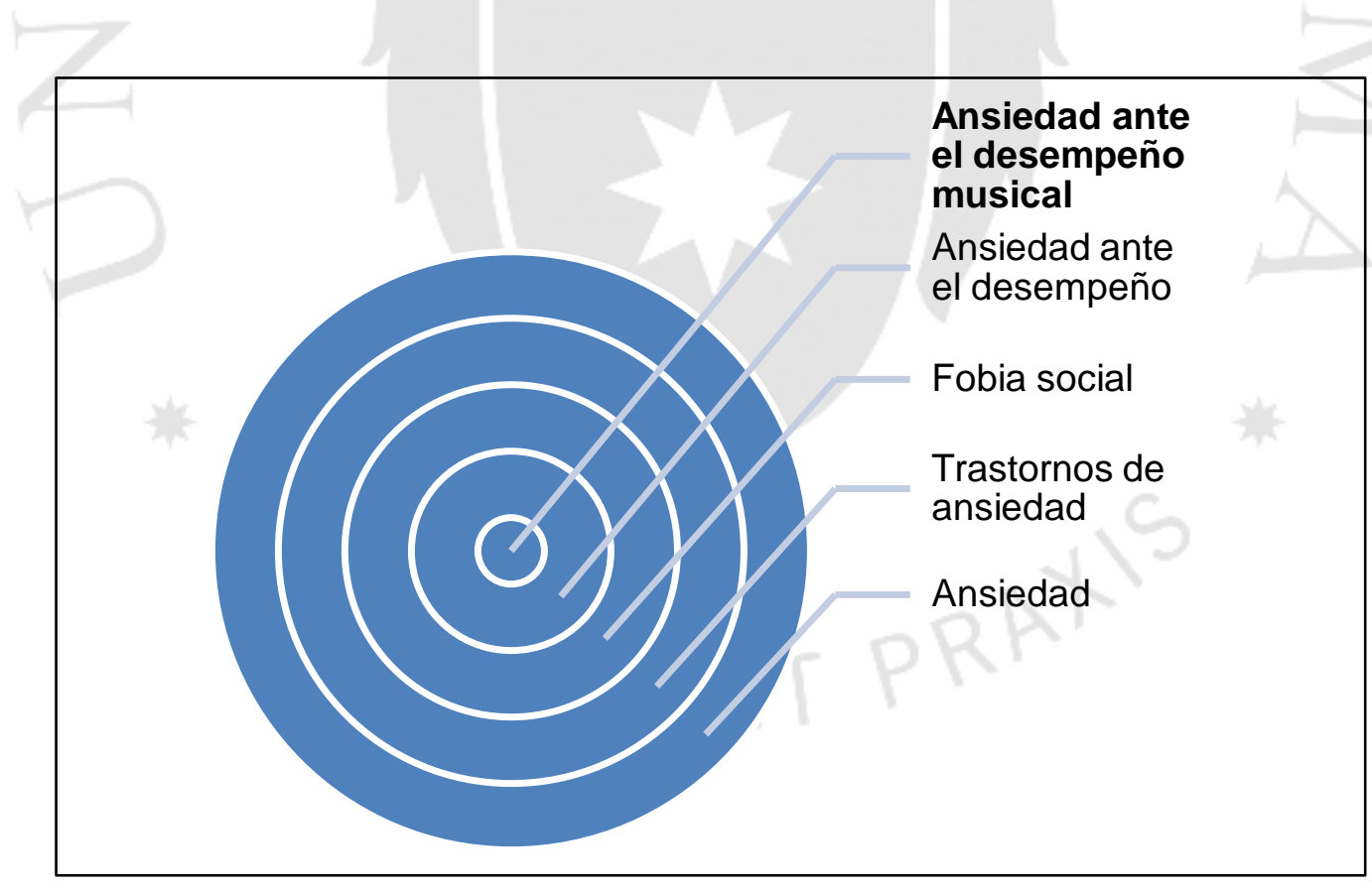

Nota: Elaboración propia del autor. 


\subsection{Ansiedad}

La ansiedad es definida por el diccionario conciso de psicología de la APA (2010a) como una

Emoción que se caracteriza por la aprensión y síntomas somáticos de tensión en que un individuo anticipa un peligro, catástrofe o desgracia inminente. El cuerpo a menudo se moviliza para enfrentar la amenaza percibida: los músculos se tensan, la respiración se acelera y el corazón late con mayor rapidez (p. 32).

Esta definición expresa los componentes de la ansiedad que suelen ser objeto de estudio: fisiológicos, conductuales, cognitivos y afectivos. Cuando se sostiene que un individuo 'anticipa un peligro, catástrofe o desgracia inminente', se hace referencia a componentes cognitivos que van acompañados de componentes afectivos de malestar (como la aprensión). La tensión de músculos, la respiración acelerada y el aumento del ritmo cardíaco son componentes fisiológicos que bien pueden ocasionar cambios conductuales (temblores en las manos, o fallas en la coordinación motora fina, por ejemplo).

Otro aspecto importante a señalar en la definición de la ansiedad es el diferenciarla de otros conceptos con los cuales se confunde comúnmente. Uno de estos es el miedo o temor. En el diccionario de la APA, se esclarece la diferencia fundamental entre ambos conceptos:

La ansiedad puede distinguirse del temor a nivel tanto conceptual como fisiológico, aunque ambos términos se usan a menudo como sinónimos. La primera se considera como una respuesta desproporcionada a una amenaza vaga y no identificada, mientras que el segundo es una respuesta apropiada a una amenaza específica y claramente identificable (p. 32).

Habría que preguntarse, no obstante, si acaso puede definirse al miedo como una respuesta 'apropiada' y no desproporcionada a una amenaza específica. Si se toma como ejemplo al miedo escénico, es cierto que sentir un temor hacia la evaluación del público o jurado es un miedo que puede considerarse normal, dado que uno se expone frente a otra persona y pone en muestra sus capacidades y destrezas en alguna tarea determinada. Sin embargo, la manifestación extrema de dicho miedo, es decir, la fobia, sería una respuesta desproporcionada a una amenaza específica y claramente definible, en la cual se manifestarían conductas inapropiadas o que interfieren con el funcionamiento esperado del individuo. 


\subsection{Ansiedad estado y ansiedad rasgo}

A continuación, se desarrollarán los dos tipos de ansiedad identificados por Spielberger y Díaz-Guerrero (1970), a saber, la ansiedad estado y la ansiedad rasgo. Es importante definir estos conceptos puesto que pueden ayudar a la comprensión de la $\mathrm{ADM}$ y porque serán parte del proceso de recolección de datos.

De un lado, Spielberger y Díaz-Guerrero (1970) definen a la ansiedad estado como

Una condición o estado emocional transitorio del organismo humano, que se caracteriza por sentimientos de tensión y de aprensión subjetivos conscientemente percibidos, y por un aumento de la actividad del sistema nervioso autónomo. Los estados de ansiedad pueden variar en intensidad y fluctuar a través del tiempo (p. 1).

Es decir, es un tipo de ansiedad temporal y que se activa en circunstancias específicas. Normalmente, la sintomatología es conscientemente percibida por la persona. Quizá una manera más sencilla de entender este concepto es comparándolo con otro fenómeno similar: el miedo (Kenny, 2011).

Por otro lado, la ansiedad rasgo se define como

Las diferencias individuales, relativamente estables, en la propensión a la ansiedad, es decir, a las diferencias entre las personas en la tendencia a responder a situaciones percibidas como amenazantes con elevaciones en la intensidad de la ansiedad rasgo. (Spielberger y Díaz-Guerrero, 1970, p. 1).

En otras palabras, la ansiedad rasgo es "la propensión de la persona a sentirse crónicamente preocupado o aprehensivo" (Kenny, 2011, p. 25). Dada esta definición, sería esperable encontrar que en individuos con mayores niveles de ansiedad rasgo se encuentren mayores medidas de ansiedad estado, puesto que habrá mayor predisposición genética a responder con ansiedad.

Si la ansiedad estado podía presentarse como una analogía al miedo, la ansiedad rasgo se asemejaría más a la concepción de ansiedad presentada en la definición de ansiedad; a saber, como la propensión general de una persona a generar una respuesta de amenaza a un evento indeterminado o no delimitado. 


\subsection{Trastorno de ansiedad}

En la presente sección se definirá lo que es un trastorno de ansiedad y luego se desarrollarán los aspectos clínicos de la fobia social. Más adelante, se elaborará conceptualmente la ansiedad ante el desempeño.

La ADM no ha sido contemplada con igual atención que otros trastornos de ansiedad (Kenny, 2011). La duda acerca de su ubicación diagnóstica está en la comorbilidad. De acuerdo a Davey (2008), la comorbilidad es la co-ocurrencia de dos o más desórdenes distintos. Asimismo, Kenny (2011) la define como una condición en la cual los criterios que presenta se comparten con más de un desorden. Por ejemplo, según la misma autora, muchas psicopatologías se caracterizan por la persistencia disfuncional de ciertos pensamientos o conductas (e.g. preocupaciones constantes, compulsiones o rumiaciones). Los mecanismos psicológicos que generan estas persistencias pueden ser comunes a varios desórdenes de ansiedad. Este ejemplo ilustra una preocupación crucial en la presente investigación. Si las personas que sufren de ADM presentan preocupaciones constantes o rumiaciones negativas acerca de su propio desempeño, por ejemplo, será más complicado determinar si es un fenómeno de ansiedad distinto a la fobia social o es una manifestación de otro desorden de ansiedad.

Davey (2008) define al trastorno de ansiedad como un "estado activado o excesivo caracterizados por sentimientos de aprensión, incertidumbre y miedo" (p. 118). Como puede observarse, el componente de aprensión coincide con lo señalado por Spielberger y Díaz-Guerrero (1970).

Davey (2008) da cuenta de tres conductas propias de una persona que sufre de un trastorno de ansiedad: primero, la persona puede responder en desproporción a la amenaza del evento o situación; segundo, la persona podría no atribuir su respuesta de ansiedad hacia una amenaza específica; y tercero, puede persistir crónicamente, impidiendo el desenvolvimiento cotidiano de la persona e interfiriendo con otras esferas de su vida, tales como el trabajo, amigos, pareja o familia. Habiendo delimitado conceptualmente al trastorno de ansiedad, a continuación se llevará a cabo la definición de la fobia social como el trastorno objeto de esta investigación. 


\subsubsection{Fobia social (ansiedad social)}

Antes de presentar los criterios diagnósticos de la fobia social es importante señalar que, de acuerdo al DSM-V, este concepto ha sido reemplazado por "desorden de ansiedad social". La razón del cambio se debe a que el nuevo concepto permite entender con mayor amplitud su manifestación en diferentes contextos sociales. Es decir, ahora es posible diagnosticar a una persona con este desorden en una variedad más amplia de situaciones y no únicamente en aquellas en las cuales una persona experimenta miedo extremo al ejecutar alguna actividad frente a otras personas.

No obstante, debido al mayor desarrollo teórico que existe en torno a la "fobia social", se tomará esta categoría como punto de discusión para analizar la relación que existe entre la fobia social y la ADM.

Davey (2008) define a la fobia social como "un miedo severo y persistente a las situaciones sociales o de desempeño" (p.128). Asimismo, agrega que las personas con fobia social tienden a evitar las situaciones sociales o aquellas en las cuales se sientan evaluados por su desempeño. Asimismo, Sandín y Chorot (2009) definen a la fobia social como una situación en la cual "el miedo está generado por situaciones sociales en las que la persona es expuesta a desconocidos o a la evaluación y escrutinio de los demás" (p. 77). Cuando una persona con fobia social es evaluada por otros, real o imaginariamente, puede sentir humillación o generar una respuesta de ansiedad.

A continuación se enlistarán algunos de los criterios diagnósticos de la fobia social, según el DSM-IV-TR (Sandín y Chorot, 2009, p. 77) y que son los más pertinentes para la presente investigación. Luego, se discutirá si acaso la ansiedad ante el desempeño y la ansiedad ante la ejecución musical son conceptos que merecen la pena diferenciarse de la fobia social, o si basta con este último para abordar el malestar que los músicos pueden experimentar.

a) Miedo elevado y persistente a una o más situaciones sociales o actuaciones en público en las que la persona se ve expuesta a otras que no pertenecen al ámbito familiar o a la posible evaluación por los demás. La persona tienen miedo a actuar de un modo (o mostrar componentes de ansiedad) que sea humillante o embarazoso. 
b) La exposición a la situación social temida provoca casi invariablemente una respuesta inmediata de ansiedad, que puede tomar la forma de un ataque de pánico situacional o predispuesto situacionalmente.

c) La persona reconoce que el miedo es excesivo o irracional.

d) Las situaciones sociales o las actuaciones en público temidas se evitan o bien se experimentan con ansiedad o malestar intensos.

e) La evitación, la anticipación ansiosa, o el malestar asociado a la situación social o actuación en público temidas interfiere significativamente en la rutina normal de la persona, en el funcionamiento laboral (académico) o en las actividades o relaciones sociales, o bien producen un malestar clínicamente significativo.

Si se toma en cuenta el criterio a), el ejecutar un instrumento o cantar frente a una audiencia parece ser una situación en la cual el músico podría experimentar un miedo elevado y persistente a la actuación en público, donde inevitablemente será evaluada por otras personas.

De acuerdo al criterio b), el estar expuesto a la situación social (concierto) puede provocar la respuesta de ansiedad, e incluso llegar al extremo de generar un ataque de pánico. Kenny (2001) cita el testimonio de Donny Osmond, cantante estadounidense, al respecto:

Una vez que el miedo a la humillación me tomaba, no podía escaparme de él. Era como si una gran irrealidad extraña y aterradora haya reemplazado todo aquello que era familiar o seguro. En la garra de mis miedos más salvajes, estaba paralizado, seguro de que si hacía un movimiento equivocado, literalmente moriría. Mientras más me esforzaba por recordar las palabras, más evasivas se volvían. Lo mejor que podía hacer era no desmayarme y continuar con el show repitiéndome varias veces "mantente consciente, mantente consciente". (p. 64).

Con respecto al criterio c), es claro que para aquellos músicos en los cuales la ansiedad no es facilitadora, sino perjudicial, la respuesta de ansiedad es excesiva y optarían por disminuirla.

La actuación en público a la cual están expuestos los músicos se experimenta con ansiedad o malestar intensos, llegando incluso a evitarlas (en los 
casos extremos en los cuales se abandona la profesión temporal o definitivamente). Estas características coinciden con el criterio d) expuesto anteriormente.

Finalmente, el criterio e) implica un obstáculo para el desarrollo profesional del músico, dado que las presentaciones en públicos o los concursos con jurado necesariamente conllevan a una ejecución en público que puede estar precedida por un miedo anticipatorio. Este miedo puede disminuir el desempeño esperado por el intérprete.

\subsubsection{Fobia social y la ansiedad ante el desempeño}

En esta sección se buscará delimitar conceptualmente los constructos de fobia social y ansiedad ante el desempeño. Para ello se mostrarán algunas definiciones de ambos constructos.

Por un lado, la fobia social fue definida en la sección anterior como "un miedo severo y persistente a las situaciones sociales o de ejecución" (Davey, 2008, p. 128). También, Sandín y Chorot mencionaron que en la fobia social existe un miedo a la "evaluación y escrutinio de los demás" (2009, p. 77). A estas definiciones vale la pena agregar la del DSM-IV-TR (2002), en la cual se señala que una persona con fobia social presentará preocupaciones por la calidad de su desempeño en situaciones sociales o actuaciones en público temidas (p. 502).

Por otro lado, la ansiedad ante el desempeño (que proviene del inglés performance anxiety) es definida como "un estado de ansiedad que solo ocurre en ciertas circunstancias y es percibido como la reacción a un estímulo" (Tolbert, 2009, p. 37). Asimismo, Kenny la define como "un desorden que afecta a los individuos en un amplio rango de tareas tales como: rendir exámenes, desempeño matemático, hablar en público, deportes, bailar, actuar y hacer música” (p. 47). De manera resumida, de acuerdo al DSM-IV-TR, las personas con ansiedad ante el desempeño presentarían: temor por aquellas situaciones sociales con un componente evaluativo (criterio a), respuestas de ansiedad ante la exposición a situaciones sociales temidas (criterio b), y malestar por actuar o exponerse a un público (criterio c, 2002, p. 509).

Sin embargo, la ansiedad ante el desempeño ha recibido poca atención en las taxonomías diagnósticas (Kenny, 2011). Es decir, existe una dificultad para distinguir conceptualmente a la ansiedad ante el desempeño y la fobia social 
(Kenny, 2011). Tanto Kenny, como Sandín y Chorot (2009) presentan una solución para la distinción teórica entre la fobia social y la ansiedad ante el desempeño.

De acuerdo a Kenny (2011), los subtipos de ansiedad ante el desempeño son: generalizada (como el tipo de ansiedad que se experimenta en las interacciones interpersonales en términos generales), no generalizada (la ansiedad experimentada solo en situaciones de evaluación), y específica (en la cual la respuesta de ansiedad se da en pocas situaciones de ejecución). Siguiendo esta clasificación, la ansiedad ante el desempeño sería un subtipo específico de la fobia social (Kenny, 2011).

La segunda solución, propuesta por Sandín y Chorot (2009), sigue una línea semejante a la planteada por Kenny. Ellos presentan tres subtipos de la fobia social. La primera es denominada "centro de atención (hablar/interaccionar formalmente)" (p. 77). Dentro de esta dimensión pueden distinguirse al temor de ser observado por otros y hablar en público. La segunda se denomina de "interacción social (hablar/interaccionar informalmente)" (p. 77). Esta dimensión contempla las interacciones que pueden darse con desconocidos y en fiestas. Finalmente, la tercera es llamada "interacción asertiva" (p. 77) y corresponde al temor a expresar el desacuerdo o desagrado con alguna situación.

Siguiendo esta clasificación, la ansiedad ante el desempeño se localizaría dentro de la primera dimensión, i.e. centro de atención, dado que el tocar en público, frente a un maestro o en una clase maestra (por poner algunos ejemplos) serían tipos de situaciones en las cuales existe una persona que es el foco de atención.

Por lo tanto, dada las similitudes y yuxtaposiciones en los criterios diagnósticos y definiciones conceptuales entre la fobia social y la ansiedad ante el desempeño, se considerará a la segunda como un subtipo específico de la primera.

\subsubsection{Fobia social y ansiedad ante el desempeño musical}

En esta sección se defenderá la postura de que la ADM es un tipo de fobia social que merece una elaboración teórica especializada. Por ello, no puede satisfacerse solamente con el conocimiento en torno a la ansiedad ante el desempeño en términos generales. La estrategia a seguirse será la siguiente: primero, se presentarán las similitudes entre la fobia social y la ADM; y segundo, se señalarán las diferencias teóricas entre ambos conceptos que justificarán la elaboración teórica especializada de la ADM. 
Kenny presenta los resultados de una investigación llevada a cabo por Clark y Agras (1991, citados en Kenny, 2011, p. 65), en la cual concluyen que el 95\% de la muestra de músicos adultos y de universidad que puntuaron alto en ADM calificaban para el diagnóstico de fobia social. Asimismo, Osborne y Kenny (2005) presentaron evidencias provenientes de músicos niños y adolescentes en los que aquellos que tenían ansiedad ante el desempeño más elevada, eran más propensos de ser diagnosticados con fobia social. Sobre la base de estas investigaciones y los criterios diagnósticos desarrollados anteriormente es legítimo preguntarse lo siguiente: ¿Merece hacerse una distinción teórica especializada para la ADM? En otras palabras, ¿para qué elaborar una discusión teórica específica para este tipo de ansiedad en músicos y no limitarlo a la ansiedad ante el desempeño?

Como se mencionó en la sección anterior, la ansiedad ante el desempeño (en términos generales) ha carecido de una definición consensuada, así como de un diagnóstico oficial del sistema psiquiátrico, con lo cual identificar la comorbilidad de este fenómeno con otros trastornos de ansiedad es complicado. Sin embargo, tal y como se ha elaborado en las secciones anteriores, la ADM es un tipo de fobia social específica.

Kenny afirma que la $\mathrm{ADM}$ ha sido poco estudiada y por ello recurre a la ansiedad a hablar en público como análogo a la musical. Kenny afirma que "dada la evidencia a favor de un subtipo de ansiedad ante el desempeño particular y muy común, uno puede extrapolarlo cautelosamente y plantear que el mismo subtipo existe para la ansiedad ante el desempeño musical” (p. 58). Presenta el testimonio de un violinista con 25 años de experiencia, en el cual se puede apreciar el carácter situacional y claramente definido que genera en él una respuesta de ansiedad:

Ejerzo mucho la docencia, la dirección y muchos conversatorios previos a conciertos y, extrañamente, no me pongo nervioso con nada de eso. Hablar en público no me genera nervios, tampoco me pongo nervioso al dirigir, o al menos solo un poco; pero solo experimento ataques de pánico cuando tengo que ejecutar... para mí, es casi una respuesta aprendida que no puedo eliminarla. El ejecutar puede perjudicarme, realmente abatirme. (p. 57).

La cita revela que existen experiencias de ansiedad altamente contextualizadas a circunstancias específicas. Más aún, estas respuestas de ansiedad no son dicotómicas (nada ansioso o muy ansioso), sino que parecen ser 
dimensionales, oscilando entre lo leve y lo grave, pero siempre delimitados a esos contextos particulares.

Sin embargo, Kenny (2011) también presenta diferencias importantes entre la fobia social y la ADM y que justificarán un tratamiento conceptual especializado de esta última:

- Aquellos con ADM son más propensos que aquellos con fobia social a tener mayores expectativas de ellos mismos. Esto se debe a la naturaleza de la profesión. Para un músico, es importante que su actuación pública tenga los mejores resultados posibles.

- Los que experimentan ADM tienen mayor miedo a la autoevaluación de su propia ejecución, en oposición al miedo que experimentan las personas con fobia social de la evaluación de los demás. La búsqueda de la perfección, si bien importante para la labor del músico, puede tener un costo perjudicial para él. Si el nivel de perfeccionismo es muy alto, se originan ideas rígidas de lo que constituye el éxito o fracaso, y se percibe al éxito en términos absolutos. Asimismo, es más probable que una ejecución musical se experimente como insatisfactoria, dañando la autoestima de la persona (Kenny, 2011).

En las personas con $\mathrm{ADM}$ existen mayores niveles de rumiación posteriores al evento. En otras palabras, un músico con alta ADM puede permanecer repasando los errores o imperfecciones ocurridos durante su ejecución.

- Otra diferencia fundamental está en la permanencia de un compromiso continuo con la situación de ejecución temida (a saber, tocar en público), frente a la posibilidad de evitación que tienen las personas con fobia social. Esta diferencia es fundamental, dado que si el músico acudiese a la evitación de las ejecuciones en público, su actividad profesional se vería claramente interrumpida. En términos de afrontamiento, el problema percibido, a saber, "tocar en público" no puede modificarse. Por ello, es importante desarrollar estrategias cognitivas y emocionales adaptativas para lidiar con las presentaciones públicas.

- $\quad$ Si bien es cierto que tanto en la fobia social como en la ADM existe miedo a la evaluación social, en la fobia social la tarea temida no es tan exigente cognitiva ni físicamente, asimismo, las conductas sometidas a la evaluación 
social ya están incorporadas en el repertorio de la persona y difícilmente presentarán déficits (por ejemplo, comer en un restaurant, entrar en contacto con otras personas en fiestas o reuniones de trabajo, $\mathrm{u}$ orinar en baños públicos son todas conductas que no requieren un dominio técnico complejo como puede ser tocar un instrumento). En cambio, las conductas de los músicos evaluadas socialmente requieren de un entrenamiento de alta exigencia. Son conductas de una compleja adquisición, demandan una interacción muy coordinada y concentrada entre lo motor, lo cognitivo y lo afectivo; y exigen una alta capacidad de memoria. Es decir, son actividades claramente distintas en términos de complejidad a las conductas que suelen temer las personas con fobia social.

- Con respecto a la evaluación por parte de otros, en la fobia social se tiende a experimentar un miedo imaginario a que otros los estén evaluando (del tipo: "todos se darán cuenta que no hablo en las fiestas"), mientras que un músico se encuentra claramente bajo la evaluación de una audiencia real, y es acertado pensar que los demás lo están evaluando.

- Otra diferencia está en que un músico con ADM será más propenso a preocuparse por su propia habilidad para desempeñar una tarea óptimamente y no tanto en la percepción de los otros acerca de su ejecución.

Previamente a concluir esta sección, se presenta una tabla en la cual se resumen las similitudes y diferencias entre la fobia social y la ADM. 
Tabla 2.1

Similitudes y diferencias entre la ADM y la fobia social

\begin{abstract}
Similitudes
El ejecutar un instrumento o cantar frente a una audiencia parece ser una situación en la cual el músico podría experimentar un miedo elevado y persistente a la actuación en público, donde inevitablemente será evaluada por otras personas.

El estar expuesto a la situación social (concierto) puede provocar la respuesta de ansiedad, e incluso llegar al extremo de generar un ataque de pánico.
\end{abstract}

La respuesta de ansiedad es excesiva y los músicos optarían por disminuirla.

La actuación en público a la cual están expuestos los músicos se experimenta con ansiedad o malestar intensos.

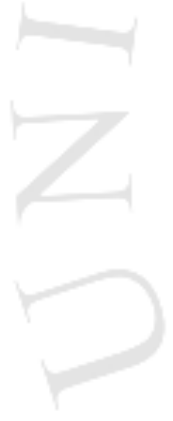

La ansiedad puede interferir significativamente en la rutina normal y profesional del músico.

\section{Diferencias}

Aquellos con ADM son más propensos que aquellos con fobia social a tener mayores expectativas de ellos mismos.

Los que experimentan ADM tienen mayor miedo a la autoevaluación de su propia ejecución, en oposición al miedo que experimentan las personas con fobia social de la evaluación de los demás.

En las personas con ADM existen mayores niveles de rumiación posteriores al evento.

En las personas con ADM existe un compromiso continuo con la situación de ejecución temida (a saber, tocar en público), frente a la posibilidad de evitación que tienen las personas con fobia social.

En la fobia social la tarea temida no es tan exigente cognitiva ni físicamente, asimismo, las conductas sometidas a la evaluación social ya están incorporadas en el repertorio conductual diario de la persona.

Las conductas de los músicos evaluadas socialmente requieren de un entrenamiento y habilidad de altos niveles.

Un músico se encuentra claramente bajo la evaluación de una audiencia real, y es acertado pensar que los demás lo están evaluando. Mientras que alguien con fobia social puede imaginar una evaluación por parte de otros.

Las personas con $\mathrm{ADM}$ serán más propensa a preocuparse por su propia habilidad para desempeñar una tarea óptimamente y no tanto en la percepción de los otros acerca de su ejecución como lo serían las personas con fobia social.

En suma, se ha aclarado que la $\mathrm{ADM}$ es un tipo específico de fobia social con la cual existen similitudes y diferencias a nivel conceptual. Por ello, se puede concluir que la ADM exige una aproximación conceptual especializada (si bien, no aislada de la fobia social) que no puede ser igualada a la categoría más amplia de 
“ansiedad ante el desempeño". En la siguiente sección se llevará a cabo el análisis conceptual especializado exigido.

\subsection{Investigaciones previas vinculadas a la ansiedad ante el desempeño musical}

Dentro de la investigación de la ADM, el estudio nacional de Fishbein y Middlestadt (1988) acerca de los problemas médicos en la International Conference of Symphony and Opera Musicians (ICSOM) es un referente básico en la literatura para iniciar el entendimiento de este tipo de ansiedad. Se llevó a cabo un estudio con 2212 músicos de orquestas profesionales, pertenecientes a la ICSOM, organización estadounidense que reúne a 4000 miembros entre EEUU y Puerto Rico.

Del total de encuestados, el $24 \%$ de la muestra sostuvo que el "miedo escénico" era un problema mayor. También se encontró que el $20 \%$ de la muestra empleaba beta-bloqueadores antes de presentaciones públicas importantes. Es decir, se identificaron dos problemas muy frecuentes en estos músicos: el miedo escénico y el uso de drogas no prescritas para calmar los componentes de la ansiedad.

Asimismo, existen otros estudios que datan de las décadas 1980 y 1990 y que se han llevado a cabo con poblaciones extensas de músicos. Kenny (2011) da cuenta de otros estudios tales como el de James (1998, citado en Kenny, 2011) en el cual encontró que, de un total de 56 orquestas, el $70 \%$ de los músicos reportaron experimentar niveles de ansiedad lo suficientemente altos como para perjudicar la calidad de su ejecución. El estudio de Steptoe (2001, citado en Kenny, 2011) abarcó una evaluación de 1639 músicos pertenecientes a la Fédération Internationale des Musiciens (FIM). En este estudio se identificó que el $70 \%$ de encuestados experimentaban niveles de ansiedad antes de sus presentaciones lo suficientemente fuerte como para disminuir la calidad de su desempeño. También se encontraron altos porcentajes en componentes vinculados a la ansiedad, tales como latidos cardíacos, sudoración en las manos, tensión muscular, entre otros. Finalmente, en 1981, Schulz (citado en Kenny, 2011) identificó que el 58\% de los integrantes de la Orquesta Sinfónica de Viena reportaron "nerviosismo" antes de presentarse y el 24\% reportó niveles altos de tensión antes de una presentación.

No obstante, experimentar ADM puede tener un efecto potenciador o facilitador en la calidad de la interpretación. De acuerdo a lo señalado por Craske y Craig (1984), la presencia de cierto grado de ansiedad en estudiantes de piano resulta en una evaluación más positiva por parte de un jurado frente a una situación en la que 
se cuenta con un público (p.e. una audición), en comparación con una carente de público (p.e. un ensayo individual). En otras palabras, cuando un grupo de pianistas tenía que tocar frente a un jurado, este calificó como superior al desempeño mostrado en la audición frente a una situación de ensayo individual grabada (sin presencia de un público).

Sin embargo, la ansiedad puede perder el carácter facilitador cuando aumenta a niveles que escapan del control de los músicos. Kirchner, Bloom y Skutnick-Henley (2008) examinaron la relación entre la ADM y la propensión al flow, por un lado; y por el otro, si existe una correlación negativa entre la ADM y la habilidad para interpretar sin presencia de autocrítica negativa y destructiva. Se trabajó con 90 estudiantes de música de pregrado (38 mujeres y 52 varones) y se recolectó la información por medio de dos instrumentos: el Inventario de Ansiedad ante el Desempeño Musical (Performance Anxiety Inventory) y el Inventario del Flow en la Música (Music in Flow Inventory). Se halló una correlación negativa entre la ansiedad ante la ejecución y la tendencia al flow, con un tamaño del efecto pequeño (Ellis, 2010), $r=-0.20, p=.034$, con prueba de una cola. Asimismo, la segunda hipótesis se vio corroborada: la habilidad para cantar o tocar sin autocrítica destructiva está negativa y significativamente correlacionada con la $\mathrm{ADM}(r=-0.39$, $p<.001$, una cola), presentando un tamaño del efecto mediano (Ellis, 2010). Así, pueden ocurrir dos escenarios: al desarrollar estrategias que propicien el estado de flow, se puede mitigar los efectos de la ADM; o al reducir la ansiedad es posible facilitar el flow.

En una línea similar a la anterior, Yoshie et al. (2008) evaluaron los efectos del estrés psicológico manipulado en situaciones de evaluación de la ejecución de pianistas. Se contó con 12 pianistas con una media de 15.8 años de experiencia tocando, quienes fueron divididos en un grupo de evaluación y otro en el cual no fueron evaluados. Cada grupo contaba con 100 puntos; la diferencia estaba en que en el grupo de evaluación, cada vez que un participante cometía algún error en la ejecución de una escala arpegiada, se le extraía un puntaje; mientras que en el grupo que no era evaluado, los participantes podían cometer errores en la ejecución de la escala sin que se les extraigan puntos.

El valor de esta investigación está en haber logrado medir los diferentes componentes del estrés en los participantes y de registrar cómo es que el organismo en su conjunto reacciona frente a una situación estresante. Sin embargo, Yoshie et al. 
(2008) no sugieren que tener un mayor nivel de estrés disminuye la calidad del desempeño musical, solo concluyen que la manipulación experimental de los niveles de estrés fue efectiva.

Más adelante, una investigación llevada a cabo por Yoshie, Kudo, Murakoshi y Ohtsuki (2009) en Tokio reportó los efectos del estrés sobre la calidad del desempeño musical. En esta investigación se contó con 18 pianistas con un promedio de 20.4 años de experiencia tocando. Ellos accedieron a ser evaluados en tres aspectos: las respuestas subjetivas, autonómicas y de estrés motor; además de ser calificados en su calidad interpretativa por parte de un jurado compuesto por cinco miembros. Las medidas se recogieron en dos situaciones: una de ensayo (sin público) y otra en una competencia real con jurado y con público. Se encontró que hubo una disminución estadísticamente significativa de la calidad de interpretación entre la situación de ensayo $(M=65.9, D E=13.3)$ y la situación de competencia $(M=59.3$, $D E=16.9)$, esto a pesar de contar con un tamaño del efecto pequeño y una potencia estadística inferior a .80 (Cohen, 1992), $t(17)=3.86, p<.01 . d=.43,1-\beta=.54$. La medida del Analog Mood Scale (VAS) mostró un aumento estadísticamente significativo de ansiedad estado entre la condición de ensayo $(M=44.4, D E=29.4)$ y la condición de competencia $(M=56.1, D E=29.1)$, también se reportó un tamaño del efecto pequeño y una potencia estadística superior a .80 (Cohen, 1992) que permite identificar un efecto real de la manipulación social en los niveles de estrés, $t(17)=2.87, p<.05, d=.39,1-\beta=.85$. El registro del ritmo cardíaco también varió entre la condición de ensayo $(M=112.4, D E=23.6)$ y la de competencia $(M=146.6$, $D E=19.2$ ) con un aumento significativo, un tamaño del efecto grande (Ellis, 2010) y una potencia estadística mayor a .80 (Cohen, 1992), $t(17)=9.47, p<.001, d=1.57$, $1-\beta=1$. Un resultado similar se registró con la taza de sudoración en la situación de ensayo $(M=0.23, D E=0.15)$ y la situación de competencia $(M=0.32, D E=0.12)$, obteniéndose diferencias estadísticamente significativas, un tamaño del efecto mediano (Ellis, 2010) y una potencia estadística superior a $.80($ Cohen, 1992), $t(17)=$ $3.40, p<.01, d=.64,1-\beta=.83$. Por lo tanto, el uso de una situación de evaluación real coincidió con lo teorizado: que un estrés más allá del nivel óptimo de funcionamiento lleva a una disminución en la calidad de la interpretación.

Finalmente, en cuanto a las diferencias de género, las mujeres tienden a presentar mayores niveles de ansiedad que los varones. Esto incluso se da en edades escolares. En el estudio llevado a cabo por Kaspersen y Gotestam (2002) se encontró 
que, de un total de 126 estudiantes noruegos de un conservatorio, las mujeres (56\%) solicitaron más ayuda para lidiar con la ansiedad que los hombres (11.8\%). Asimismo, en un estudio llevado a cabo por Osborne y Kenny (2005), se evaluaron a 296 músicos australianos entre los 11 y 19 años de edad que asistían a secundarias especializadas en las artes escénicas. Empleando el Inventario de Ansiedad Ante el Desempeño Musical para Adolescentes (IADM-A), se registraron puntuaciones de ansiedad mayores en el grupo de niñas $(M=46.27, D E=19.83)$ que en el grupo de niños $(M=38.23, D E=17.93), t(296)=-3.59, p<.001$. Asimismo, se registró un tamaño del efecto pequeño (Ellis, 2010) y una potencia estadística menor a .80 (Cohen, 1992), $d=.43,1-\beta=.69$.

\subsection{Definición conceptual de la ansiedad ante el desempeño musical}

En esta sección se presentarán las definiciones de la ADM de Yoshie et al. (2008); Nagel (2010); Ortiz (2011a); y Kenny (2011). Se analizará con más detalle la definición de Kenny desagregándola en seis puntos. Luego, se señalarán las similitudes compartidas entre todas y todos los autores citados.

De acuerdo a Yoshie et al. (2008), la ADM significa un "problema serio y frecuente para muchos músicos, algunas veces llevándolos a una interpretación insatisfactoria o incluso a abandonarla. Tal y como la ansiedad en general, esta ansiedad compromete una serie de sistemas cognitivos, fisiológicos y conductuales" (p. 120). Esta definición ilustra cómo la ADM puede afectar el desempeño musical en diferentes grados y está compuesta por cuatro factores. La siguiente definición a presentar agrega algunos datos novedosos.

Nagel (2010) define a la ADM como "una experiencia desconcertante para una cantidad numerosa de músicos intérpretes. La ansiedad ante el desempeño no considera ni edad, ni experiencia. Es experimentada tanto física como emocionalmente, y muchas veces impide la realización profesional y personal" (p.141). De esta definición se puede recoger el malestar físico y afectivo experimentado por la persona ejecutante, llegando al punto en el que su desempeño musical puede verse disminuido, afectando su desarrollo profesional. Asimismo, lo novedoso en esta definición es que ni la edad, ni la experiencia impiden la experimentación de la ADM. La tercera definición coincide en varios aspectos con los dos anteriores, pero también mostrará una tendencia más ambiental en la determinación de esta ansiedad. 
Ortiz (2011a) define al fenómeno como un tipo de ansiedad que "afecta a muchos individuos, independientemente de la edad, género, experiencia u horas de práctica" (p. 102). Asimismo, agrega que "es una experiencia de marcada y persistente aprensión ansiosa relacionada a la ejecución musical que ha sido producto de una serie de experiencias de ansiedad condicionada y que se manifiesta a través de combinaciones de componentes afectivos, cognitivos, somáticos y conductuales" (p. 102). Es decir, la ansiedad situacional que un músico puede sentir es producto de experiencias de condicionamiento aversivo y que parecen ser independientes de las horas de práctica y género de la persona. A continuación, se presenta la definición propuesta por Kenny y que constituye la definición más sistematizada que se encuentra hasta la fecha.

\section{Para Kenny, la ADM es}

La experiencia de una ansiedad aprensiva, marcada y persistente, que está vinculada a la ejecución musical y que puede originarse por vulnerabilidades biológicas o psicológicas, o por experiencias particulares de condicionamiento ansioso. Se manifiesta por una combinación de componentes afectivos, cognitivos, somáticos y conductuales. Puede ocurrir en diversos contextos de ejecución, pero suele ser más severa en contextos en los cuales hay mayor inversión del ego, existe la amenaza de ser evaluado (una audiencia), y en los cuales se tiene miedo al fracaso. Puede ser focal (i.e. presente solo en ejecuciones musicales), o ser comórbida con otros desórdenes de ansiedad, particularmente con la ansiedad social. Afecta a los músicos a lo largo de su vida y es parcialmente independiente de los años de entrenamiento, horas de práctica y nivel de logro musical. Puede o no perjudicar la calidad de la ejecución musical. (p. 61).

La definición anterior está compuesta por cinco elementos. El primero de estos elementos es acerca del origen de esta ansiedad. La autora reconoce que la ADM puede surgir como consecuencia de vulnerabilidades bio-psicológicas (es decir, congénitas a cada individuo), o bien puede surgir a causa de condicionamientos de miedo (es decir, como consecuencia de experiencias de alto temor asociadas a la presentación en público de las habilidades musicales). Para sustentar esta ontología, Kenny (2009) empleó un análisis factorial exploratorio con rotación ortogonal de tipo varimax, esperando encontrar independencia teórica entre 
las vulnerabilidades biológicas, psicológicas y de condicionamiento de miedo (Barlow, 2000). En la sección de Resultados se buscará replicar este modelo factorial.

El segundo elemento encontrado en esta definición es acerca de las manifestaciones de la ADM. Kenny presenta un modelo de ansiedad con cuatro manifestaciones: afectiva, cognitiva, somática y conductual. Estas son intercambiables con las manifestaciones empleadas en esta investigación: afectivas, cognitivas, fisiológicas y conductuales. Como puede observarse, al menos en este nivel, existe cierta concordancia entre diferentes autores, por lo que se justifica el empleo de esta manifestación cuádruple.

El tercer elemento que Kenny trae a discusión es el contexto situacional en el cual puede manifestarse la ansiedad. Como ella señala, la ansiedad puede darse en diferentes contextos (podría ser incluso algunos que aparentemente no tendrían por qué generar ansiedad, como por ejemplo, durante ensayos en solitario, en clases con la o el maestro, o ante grabaciones de piezas). Pero, claramente es más frecuente que se dé en las situaciones que ella enlista: aquellas en las cuales hay una mayor inversión de ego, una amenaza de evaluación (como con un público) y con miedo a fracasar. No obstante, el empleo del término ego debe ser discutido. Al ser un concepto perteneciente a la vertiente psicodinámica, no es contemplado en el marco de la presente investigación; por ello, el ego puede traducirse a una situación en la cual la o el artista ha invertido muchos recursos personales y en los cuales aspectos de su autoestima, autoeficacia y autoconcepto están enfocados en la correcta ejecución de su instrumento (en el caso de los cantantes, se tomará a la voz como un instrumento más).

El cuarto elemento está vinculado con la especificidad del dominio; es decir, si la ansiedad ante el desempeño es un tipo aislado de ansiedad (con características propias y distinguibles de otras), o perteneciente a un espectro mayor de esta. Para Kenny, es un fenómeno que bien puede enfocarse únicamente en la acción misma de ejecutar en público, o puede ser comórbida a otros fenómenos de ansiedad como los relacionados con la ansiedad social. En otras palabras, la ADM puede manifestarse de manera focal o como fobia social.

El quinto elemento sustraído de esta definición es el impacto generado en las y los músicos. La ADM "afecta a los músicos a lo largo de su vida y es parcialmente independiente de los años de entrenamiento, horas de práctica y nivel 
de logro musical. Puede o no perjudicar la calidad de la ejecución musical" (Kenny, 2011, p. 61). Al respecto, se puede tomar como ejemplo al reconocido pianista chileno, Claudio Arrau y su testimonio acerca de cómo afrontaba los errores en una presentación:

Creía que era el fin del mundo. Me podía tomar hasta meses recuperarme. Quería ser perfecto, divino, más allá de cualquier falla técnica o de error de memoria. Pero eso siempre produjo el efecto contrario. Ahora ya no me decepciono tanto... ¿Sabe qué hubiese pasado en mis años iniciales si es que algo salía mal? Me rendía. Seguía tocando, pero me rendía, como si lo demás no importara. (Conversaciones con Arrau, como se citó en Kenny, 2011, p. 10).

A partir de la cita, puede reconocerse cómo es que alguien del nivel musical de Arrau aún manifiesta serias manifestaciones de la ADM. Al parecer, ni el nivel de experiencia, horas de práctica y entrenamiento significaron mayores recursos para afrontar el estrés en el escenario. Por ello, Kenny sostiene que la ADM "puede o no medrar la calidad de la ejecución musical" (p. 61).

Es relevante agregar un último comentario con respecto a la definición de Kenny desde una perspectiva filosófica. Analizando el uso del término vulnerabilidades biológicas o psicológicas, uno debe preguntarse: ¿Acaso se refiere a dos fenómenos ontológicamente distintos? ¿Es el segundo resultado del primero? ¿Solo es una distinción de las propiedades biológicas y psicológicas? La autora, en ocasiones, tiende a expresar creencias dualistas, dando a entender que efectivamente existen dos cosas distintas. El dualismo de sustancias es altamente anticientífico y si ella no especifica su postura frente al problema mente-cuerpo, sus aseveraciones pueden perder cientificidad.

Una definición futura debe especificar una concepción materialista de la ansiedad, o, en su defecto, especificar que las propiedades psicológicas a las que se hace mención son producto de las biológicas, y no pertenecen a una categoría diferente. También, las futuras definiciones deben incorporar más datos desde las neurociencias, dado que, en último término, las funciones psicológicas son funciones cerebrales (Churchland, 1995). Sin embargo, la definición presentada por Kenny es la más completa con la que se cuenta en la actualidad.

Las definiciones de ADM antes presentadas comparten cuatro características en común. En primer lugar, está la mención acerca del sentimiento de aprensión subjetiva, introducido inicialmente por Spielberger y Díaz-Guerrero (1970). En 
segundo lugar, tal y como la ansiedad como fenómeno global, la ansiedad ante el desempeño se manifiesta a través de componentes cognitivos, conductuales, fisiológicos y afectivos. En tercer lugar, está la relativa independencia de la edad, años de experiencia u horas de preparación con la aparición de la ansiedad. En cuarto lugar, el constructo a estudiarse significa un problema serio para los músicos, puesto que puede tener un impacto negativo a nivel profesional y personal en ellos.

Al punto anterior, Kenny aporta tres elementos adicionales. Menciona las posibles causas de la ansiedad ante el desempeño (ya sean causas innatas o adquiridas), los contextos en los cuales puede aparecer con mayor severidad, y el grado de especificidad de esta ansiedad (en la cual existen casos que son focales a presentaciones en público, y otras que se asemejan más a la fobia social).

En suma, en esta sección se presentaron cuatro definiciones de la ADM provenientes de Yoshie et al. (2008), Nagel (2010), Ortiz (2011a) y Kenny (2011). Concluida la presentación de estos autores, se llevó a cabo un análisis más exhaustivo de la definición de Kenny, por tratarse de la más sistematizada hasta la fecha. Por último, se señalaron las coincidencias conceptuales entre los autores, siendo estas: el sentimiento de aprehensión subjetiva; las cuatro manifestaciones del constructo; la relativa independencia a la experiencia, edad u horas de práctica; y el posible peligro que la ADM puede representar para el desarrollo profesional de los músicos. En las siguientes secciones se desarrollarán los componentes de la ADM. Luego, se presentarán las consecuencias profesionales y personales.

\subsection{Componentes de la ansiedad ante el desempeño musical}

\subsubsection{Componentes fisiológicos de la ansiedad ante el desempeño musical}

Yoshie, et al. (2008). señalaron algunos componentes fisiológicos relacionados con la ADM. Entre ellos, estaría el ritmo cardíaco, el ritmo de sudoración, la actividad electromiográfica y el nivel de co-contracción muscular de los brazos.

Kim (2008), llevó a cabo una investigación para encontrar los efectos de dos aproximaciones terapéuticas en los niveles de la ADM: por un lado, la desensibilización en improvisación asistida; y por otro la relajación muscular progresiva asistida por música y la imaginería en estudiantes de piano. 
Luego de las seis semanas de intervención, se halló que ambos procedimientos tuvieron un efecto significativo en modificar ciertos componentes, entre ellos, la temperatura de los dedos de las participantes. Se encontró que esta última medida aumentó luego de la intervención, siendo un indicador más de la efectividad de ambos tratamientos.

En resumen, algunos de los componentes fisiológicos de la ADM son la aceleración del ritmo cardíaco, aumento del ritmo de sudoración, mayor actividad electromiográfica, el mayor nivel de co-contracción muscular de los brazos o la disminución de la temperatura de los dedos.

\subsubsection{Componentes conductuales de la ansiedad ante el desempeño musical}

Yoshie et al. (2008), reportaron cómo una situación de evaluación de la ejecución producía un aumento en la velocidad con la cual los pianistas evaluados tocaban una serie de arpegios en un teclado. Para ellos, se llevaron a cabo dos situaciones de medidas en las cuales se registraron una serie de datos provenientes de los pianistas: una situación de ensayo y otra de evaluación.

Otra medida llevada a cabo fue el nivel de co-contracción en los brazos. Esta co-contracción, según los autores, funciona como una forma de estabilización de las muñecas, ayudando a lograr una mayor precisión en las teclas; no obstante, bajo situaciones de estrés, esta co-contracción genera entumecimiento de los brazos, lo cual en parte puede explicar el temblor en las palmas, así como una falta de precisión en las teclas que se toquen.

Yoshie, et al. (2009), señalaron un aumento en la tensión muscular entre una situación de ensayo y otra de competencia. El aumento de la tensión muscular en un contexto de evaluación de la interpretación puede explicar el levantar los hombros como conducta de ansiedad.

En resumen, los componentes conductuales de la ADM son modificación involuntaria del tempo de ejecución, levantar los hombros, temblores en las manos o falta de coordinación motora fina.

\subsubsection{Componentes cognitivos de la ansiedad ante el desempeño musical}

Deniz (2007), presenta algunas de las manifestaciones asociadas al componente cognitivo de la ADM. Son comunes las cogniciones catastróficas, las creencias irracionales y los diálogos internos negativos. Asimismo, Kirchner et al. 
(2008), dieron cuenta de cómo los músicos pueden presentar autocrítica destructiva hacia su interpretación en casos en los que hay mayor presencia de ADM. Vinculado a esta autocrítica, otro síntoma cognitivo de esta ansiedad está en una falta de correspondencia percibida entre la calidad de interpretación y el estándar del músico (Ortiz, 2011a, p. 102).

En resumen, los componentes cognitivos de la ADM son cogniciones catastróficas, creencias irracionales, diálogos internos negativos, autocrítica destructiva o ausencia de correspondencia entre el nivel de interpretación percibido y el estándar asignado por el músico.

\subsubsection{Componentes afectivos de la ansiedad ante el desempeño musical}

Tal y como se presentó en la definición de Ortiz (2011a), uno de los componentes afectivos de la ADM es una marcada y persistente aprensión ansiosa relacionada a la presentación musical. Spielberger y Díaz-Guerrero (1970), también señalaron estos componentes de tensión y aprensión subjetivas.

Kirchner et al. (2008), afirman que la ansiedad puede manifestarse como preocupación. Nagel (2010) desarrolla más esta idea y agrega manifestaciones como el miedo al fracaso. Por último, en base a lo planteado por Ortiz (2011a), la falta de correspondencia entre el nivel de interpretación esperado y el real, podría ocasionar en las y los músicos culpa al respecto.

En resumen, algunos de los componentes afectivos de la ADM serían aprensión y tensión subjetivas, miedo al fracaso o culpa.

\subsection{Consecuencias profesionales y personales de la ansiedad ante el desempeño musical}

El estudio de la ADM tiene una investigación que es recurrentemente citada en las diferentes publicaciones acerca del tema. Se llevó a cabo un estudio con 2212 músicos de orquesta profesionales, pertenecientes a la International Conference of Symphony and Opera Musician (ICSOM), organización estadounidense que reúne a 4000 miembros entre EEUU y Puerto Rico (Fishbein y Middlestadt, 1988). Del total de encuestados, el $24 \%$ de la muestra sostuvo que el "miedo escénico" era un problema mayor. También se encontró que el $20 \%$ de la muestra empleaba betabloqueadores antes de presentaciones públicas importantes (Ortiz, 2011b; Yoshie et al., 2009). 
De este modo, se observa que a nivel profesional, aproximadamente 530 músicos de la ICSOM (el 24\% de encuestados) reconocen el fenómeno a estudiarse como una amenaza importante para el pleno desarrollo de su profesión. También, los músicos señalaron que el empleo de betabloqueadores era un modo común de afrontar el estrés que significa una presentación.

Kirchner et al. (2008), buscaron examinar la relación entre la ADM y la propensión al flow, por un lado, y por el otro si existe una correlación negativa entre la $\mathrm{ADM}$ y la habilidad para interpretar sin presencia de autocrítica negativa y destructiva. Tal y como se mencionó en los antecedentes, se encontró que mientras menor sea la ADM, mayor será la experiencia del flow; asimismo, mientras menor sea la presencia de la ADM, la habilidad para cantar o tocar sin una autocrítica destructiva aumentará. De este modo, esta investigación pone en manifiesto el impacto que puede tener esta ansiedad en el desarrollo profesional de las y los músicos.

Dentro de la literatura revisada, se ha ubicado una investigación en la cual se simuló una competencia musical con el fin de estudiar los efectos de las situaciones sociales de evaluación de la interpretación en las reacciones subjetivas, autonómicas y electromiográficas de jóvenes pianistas (Yoshie et al., 2009). A través de una serie de medidas tanto subjetivas como fisiológicas, se encontraron diferencias significativas en la calidad de interpretación entre una situación de ensayo (donde no había nadie presente) y la situación de competencia (donde se contó con un público, cinco jurados profesionales y un auditorio). Las medidas de la calidad de la interpretación se hicieron grabando la sesión de ensayo y luego mostrándosela al jurado, y la sesión en vivo fue calificada directamente por el jurado el día de la competencia. Al finalizar el experimento, se encontró que sí hubo disminuciones significativas en la calidad interpretativa entre una situación ensayo y otra de competencia. También, la medida de ansiedad subjetiva y la activación autonómica se vieron incrementadas entre las situaciones de ensayo (donde eran menores) y las de competencia (donde eran mayores).

Nagel (2010) señala que la profesión musical, a diferencia de otro tipo de carreras, tiene características involucradas íntimamente con el desarrollo personal de los músicos, pues "la mayoría de individuos que se preparan para ser intérpretes profesionales de adultos, empezaron a tener clases de su instrumento en la niñez" (Nagel, 2010, p. 142). Nagel agrega que el 90\% de encuestados iniciaron el estudio de 
su instrumento antes de los 12 años, y que el $46 \%$ se iniciaron antes de los 7 años, siendo la edad promedio de inicio de entrenamiento musical a los 10 años.

De este modo, la formación musical coincide con el desarrollo de la personalidad y ajuste social, en un contexto en el cual los maestros pueden asumir roles paternos o de gran admiración. Así, Nagel (2010), argumenta que el ejercicio profesional de los músicos está estrechamente relacionado con el desarrollo personal $\mathrm{y}$, por lo tanto, cualquier aspecto que altere el resultado esperado por los músicos acerca de su desempeño podría tener efectos muy perjudiciales para la autoestima, autoconcepto y autoeficacia de los músicos, o, al menos, los hace más vulnerables que el fracaso en otras profesiones.

\subsection{Teoría de la ansiedad de Barlow}

Es pertinente presentar la teoría de la ansiedad de Barlow, puesto que el IADM-K está construido sobre la base de esta teoría. Si bien la teoría de Barlow no fue construida pensando en un grupo humano como los músicos, Kenny tomó lo señalado por este autor para construir su inventario; por ello, la presente investigación se adherirá al mismo planteamiento teórico.

Barlow (2000) propone un conjunto de vulnerabilidades conformado por tres elementos que permiten explicar cómo se desarrollan los trastornos de la ansiedad o del estado de ánimo. Estos tres elementos son:

1. Vulnerabilidad biológica generalizada (factores de herencia)

2. Vulnerabilidad psicológica generalizada

3. Vulnerabilidades psicológicas específicas que son producto de la asociación entre un estímulo ambiental y la respuesta de ansiedad.

Las vulnerabilidades biológicas generalizadas se refieren a características genéticas heredables que conforman características del temperamento de la persona. Esta vulnerabilidad es lo que se ha conocido en la literatura como "neuroticismo" o “inhibición conductual”. De acuerdo a Barlow, la ansiedad y otros desórdenes emocionales comparten una base genética, a partir de las cuales los factores ambientales determinan las diferencias específicas de los desórdenes. Sin embargo, la predisposición genética no es suficiente por sí misma para devenir en ansiedad o afecto negativo. 
La vulnerabilidad psicológica generalizada se refiere a aquellas circunstancias o experiencias tempranas en la vida de la persona, usualmente negativas, que producen, por un lado, la creencia de que la vida es impredecible e incontrolable; y por otro lado, que uno no cuenta con los recursos de afrontamiento necesarios para manejar dichos eventos.

Las vulnerabilidades psicológicas específicas son producto de asociaciones que se dan entre la ansiedad y algún estímulo interno (como respuestas somáticas o pensamientos intrusivos) o ambiental (la evaluación de un jurado o de la audiencia, por ejemplo).

\subsection{Facilitación social}

La facilitación social es el aumento en el desempeño de un individuo frente a una tarea como consecuencia de la mera presencia de otras personas que bien pueden observarlo o participar activamente en la misma (Martínez y Paterna, 2010). Este fenómeno fue identificado por el estudio pionero de Triplett (1898) en el cual comparó el desempeño de ciclistas al montar solos en contraste con montar acompañados. Él halló que la presencia de otros concursantes generaba un aumento en la velocidad del pedaleo.

Zajonc (1965) profundizó en el concepto y estableció que la presencia de una audiencia aumenta el desempeño de una tarea dominada o sencilla (por ejemplo: acciones motoras simples, multiplicaciones sencillas o asociación de palabras). No obstante, la ejecución frente a una audiencia de una actividad poco aprendida o más compleja tendrá consecuencias perjudiciales en el nivel de desempeño, produciéndose una inhibición social (Martínez y Paterna, 2010).

Dado que los músicos instrumentistas se exponen a situaciones sociales (sean conciertos, recitales $\mathrm{u}$ / otras variantes), los conceptos de facilitación social e inhibición social resultan pertinentes para comprender los contextos a los cuales deben afrontar. Sin embargo, la delimitación de lo que es una "tarea sencilla" o "tarea compleja" no puede delimitarse objetivamente (Uziel, 2007). De acuerdo a Uziel (2007), la personalidad es una mejor base para entender y predecir si es que un individuo interpretará la presencia de una audiencia como algo positivo o negativo.

Para Uziel (2007), la relación entre la autoestima, la introversión y la extraversión está fuertemente relacionada con la orientación negativa o positiva que se pueda adoptar frente a la presencia social. La orientación positiva se caracteriza 
por una tendencia a la seguridad y entusiasmo hacia el ambiente social y como disposición general y se vincula con la extraversión y alta autoestima; mientras que la orientación negativa se caracteriza por una tendencia a la ansiedad y aprehensión hacia el ambiente social y como disposición general y se vincula con la introversión y baja autoestima. Por lo tanto, lo que mejor explicará la manera como se experimente serán las diferencias individuales.

De este modo, sería esperable que aquellos músicos con mayor tendencia al neurotisismo o introversión y una baja autoestima tenderán a presentar mayores niveles de ADM y sentir mayores niveles de aprehensión. Por el contrario, aquellos con una orientación hacia la extroversión y niveles de autoestima altos tenderán a experimentar el contexto de presentación musical con mayor entusiasmo, seguridad y sensación de control.

\subsection{Instrumentos de medición empleados para evaluar la ansiedad ante el desempeño musical}

La literatura en torno a la medición de la ADM da cuenta de instrumentos de medidas psicofisiológicas, auto-reportes y observaciones conductuales.

El antecedente más cercano a la realidad sudamericana es la investigación de Ana Elisa Medeiros por la Universidad de Sao Paulo, Brasil, en el año 2013. Ella llevó a cabo una validación transcultural de las interpretaciones y decisiones derivadas de las puntuaciones del IADM-K en una muestra de 230 músicos profesionales y amateur. El IADM-K empleado en su investigación fue la versión anterior a la que se emplea en la presente investigación. La versión anterior del instrumento cuenta con 26 ítems que se puntúan de acuerdo a una escala Likert de 7 valores.

Asimismo, se emplearon otros instrumentos para determinar evidencias convergentes y divergentes de las puntuaciones obtenidas del IADM-K: El Inventario de Ansiedad de Beck (IAB), el Inventario de Fobia Social (SPIN), la Escala de AutoEvaluación del Desempeño en Público (SSPS-D) y el Cuestionario sobre la Salud del Paciente-9 (PHQ-9). Medeiros reportó un tamaño del efecto grande entre el IADM-K y el IAB $(r=.50)$; y mediano entre el IADM-K y el SPIN $(r=.34)$; y el IADM-K y el PHQ-9 $(r=.48)$, de acuerdo a la clasificación de Ellis (2010). Mientras que el IADMK y el SSPS-D presentaron correlaciones moderadas y negativas entre la subescala positiva $(r=-.36)$ y la subescala negativa $(r=-.50)$ del SSPS-D. Estas dos últimas 
correlaciones reportadas corresponden a tamaños del efecto medio y grande, respectivamente (Ellis, 2010). De este modo, justificó la existencia de evidencias de validez vinculadas a otras variables. Además, al explorar las evidencias de validez vinculadas a la estructura interna, encontró un valor de consistencia interna de .82. En su conjunto, los datos obtenidos por Medeiros (2013) brindaron evidencias para sostener que el K-MPAI puede ser empleado para el contexto brasilero.

\subsection{Investigaciones previas relacionadas con alternativas de solución a la ansiedad ante el desempeño musical}

Las investigaciones en torno a medidas de solución para la ADM suelen encontrarse en modelos cuasi o pre experimentales. Los tipos de programas de intervenciones que se emplean suelen incluir técnicas de relajación (relajación progresiva, entrenamiento autógeno, visualización guiada, etc.) y otras estrategias psicológicas y psicofisiológicas (tales como el biofeedback). A continuación se presentarán algunas de las investigaciones que han propuesto soluciones a la ADM desorganizadora.

Kim (2008) investigó los efectos de dos aproximaciones terapéuticas: por un lado, la desensibilización en improvisación asistida; y por otro la relajación muscular progresiva asistida por música y la imaginería en la reducción de los componentes de la $\mathrm{ADM}$ en estudiantes de piano. Para ello se contó con la participación de 30 pianistas mujeres, dado que se ha encontrado que la ADM es más elevada entre las mujeres. Se les dividió en dos grupos al azar: 15 al grupo de desensibilización y 15 a la relajación progresiva e imaginería. Ambas intervenciones tuvieron una duración de seis semanas.

Se tomaron dos medidas de interpretación, una antes de iniciar el tratamiento y otra una semana después de culminado. Se midió la ansiedad por medio de cuatro tipos de escalas análogas visuales (ADM, estrés, tensión y comodidad), el Inventario de Ansiedad Estado (IDARE) y el Cuestionario de Ansiedad ante el Desempeño Musical (MPAQ), asimismo, se midió la temperatura de los dedos de los participantes.

En la condición de relajación progresiva e imaginería, seis de las siete medidas presentaron diferencias estadísticamente significativas; mientras que en la condición de desensibilización sistemática se encontraron diferencias estadísticamente significativas entre las medidas pre y post test en el nivel de tensión, 
ansiedad estado en el IDARE y en la temperatura de los dedos. Sin embargo, al contrastar los resultados obtenidos en ambos grupos, ninguna de las dos técnicas resultó significativamente mejor que la otra.

Nagel (2010) llevó a cabo una revisión de las diferentes propuestas psicológicas de tratamiento para la ADM. El autor presenta una revisión de la literatura cognitiva y psicodinámica acerca de la ADM. Una de las primeras conclusiones que se extraen es que la desensibilización sistemática, junto con otras estrategias tales como la reestructuración cognitiva y la práctica en el escenario, lograron reducir la ansiedad y aumentar la calidad de interpretación. Los efectos positivos de la desensibilización sistemática resulta un proceso más efectivo para tratar la ADM que el entrenamiento en análisis musical o un grupo control no entrenado. Otros efectos terapéuticos reportan un impacto positivo sobre los niveles de ansiedad al emplear otras técnicas tales como la relajación progresiva, la terapia cognitivo conductual y el entrenamiento en biofeedback de temperatura, con lo cual es posible lograr efectos terapéuticos para la ADM.

Dado que la ADM parece iniciarse en músicos jóvenes, se sugiere incorporar cursos preventivos en los currículos de las facultades de música a fin de disminuir problemas de salud física y psicológicos vinculados a la profesión musical.

En la literatura psicodinámica, se entiende a la MPA como un síntoma de conflictos no resueltos. Para Gabbard (1983) y Nagel (como se citó en Nagel, 2010), el miedo al fracaso oculta una culpa y miedo inconsciente a "ser muy bueno". La autora de esta revisión de literatura reconoce que la investigación empírica en la perspectiva psicodinámica es de reciente aparición. Además, agrega que la terapia psicodinámica es la que obtiene los efectos terapéuticos más prolongados.

Con respecto a las investigaciones que emplean técnicas de relajación, Mohamed y Parish (1998) llevaron a cabo un estudio en el cual se entrenaron a grupos de estudiantes de secundaria en técnicas de relajación: 1) relajación conductual y 2) relajación progresiva de los músculos. El propósito del estudio fue reducir los estados de ansiedad de los estudiantes, dado que estudios anteriores demuestran que los altos grados de ansiedad afectan gravemente en la capacidad de aprendizaje del alumno. Para ello, participaron 55 estudiantes (26 hombres y 29 mujeres), los cuales fueron divididos en tres grupos para ambas técnicas y un grupo control que no recibió tratamiento alguno. Los resultados obtenidos demostraron que ambas técnicas disminuyen significativamente la ansiedad, pero los valores no fueron 
significativos en cuanto al género y a la ansiedad rasgo. El grupo control con respecto a los otros grupos mostró un mayor estado de ansiedad, lo cual demuestra que ambas técnicas son útiles para reducir los estados de ansiedad en estudiantes de secundaria. Es importante mencionar que en el caso de ansiedad rasgo las técnicas de relajación pueden no ser suficientes, debido a que ésta forma parte de la personalidad del estudiante y podría llegar a necesitar más sesiones de entrenamiento o consejería individual.

Otra técnica de relajación empleada para el manejo de la ADM es la imaginación guiada. Su et al. (2010) buscaron examinar los efectos de aplicar ejercicios de relajación en los niveles de ADM en estudiantes de primaria. Se trabajó con 59 músicos impartiendo el entrenamiento de técnicas de respiración 10 minutos, dos veces por semana durante dos meses. Antes de reportar los hallazgos más relevantes, es importante señalar que en algunos casos Su et al. (2010) no reportaron los datos necesarios para calcular los tamaños del efecto y potencias estadísticas de sus medidas. Se encontró que practicar la respiración cinco minutos antes de tocar frente a un jurado $(M=39.53)$ disminuyó la ADM en comparación a los niveles registrados 30 minutos antes $(M=42.66)$. Al no presentar la desviación estándar no fue posible determinar el tamaño del efecto o la potencia estadística para este resultado. Asimismo, se calculó las diferencias de medias entre niñas y niños en el puntaje de ADM en los últimos cinco minutos antes de tocar frente a un jurado. Las niñas registraron niveles menores de ansiedad $(M=-4.09, D E=6.40)$ que los niños $(M=-1.92, D E=6.64)$. Los autores afirman que las diferencias no son estadísticamente significativas $(t=1.27, p>.05, d=.33,1-\beta=.24)$; sin embargo esta ausencia de significancia estadística puede deberse a la escasa potencia lograda (Cohen, 1992). Su et al. (2010) sostienen que no existen diferencias estadísticamente significativas en el nivel de ADM de acuerdo al grado de estudio $(F=0.39, p>.05)$, pero no reportan las desviaciones estándar necesarias para el cálculo del tamaño del efecto y la potencia estadística. Finalmente, la comparación en el nivel de ADM entre pianistas $(M=-3.91, D E=6.81)$ y violinistas $(M=-0.38, D E=4.72)$ no arrojó diferencias estadísticamente significativas, aunque sí se registró un tamaño del efecto mediano, pero con una potencia estadística inferior a .80 (Cohen, 1992), $t=-1.75, p>$ $.05, d=.60,1-\beta=.47$. En base a los resultados obtenidos, se concluye que la aplicación de las técnicas de respiración disminuye la ADM a corto plazo, pero no tienen un efecto significativo a largo plazo; no obstante, los resultados deben 
interpretarse con cautela puesto que no es posible estimar todas las propiedades estadísticas necesarias para evaluar el impacto real de esta investigación.

Si bien las técnicas de relajación han demostrado tener cierta efectividad en el contexto musical, existen investigaciones basadas en otros contextos, tales como el deportivo. Es importante presentar la investigación de Hashim y Ahmad (2011) puesto que el enfoque deportivo suele ser comparado análogamente con el contexto musical, dada la gran demanda y disciplina exigida en ambos campos. Hashim y Ahmad buscaron comparar los efectos de dos técnicas de relajación en el estado de ánimo en dos grupos de jugadores de fútbol adolescentes. Estas técnicas fueron la relajación muscular progresiva (RMP) y el entrenamiento autógeno (EA). La medición del estado de ánimo se llevó a cabo mediante el Perfil de estados de ánimo en adolescentes (Profile of Mood States-Adolescents), la cual es una prueba conformada por 24 ítems y con alternativas de tipo Likert. Esta prueba busca evaluar estados de ánimo positivos (vigorosidad) y negativos (depresión, enojo, confusión, entre otros). Dieciséis jugadores de fútbol adolescentes fueron separados en dos grupos de ocho personas, cada uno para pasar por el entrenamiento de una técnica de relajación durante 12 sesiones (tres veces por semana durante un mes). Tanto la RMP como la EA fueron instruidas mediante grabaciones con las indicaciones, y fueron acompañadas de otros equipamientos de relajación, tales como colchonetas y audífonos. Se encontró que tanto la RMP como la EA producen un estado anímico similar, por lo que no se encontraron diferencias estadísticamente significativas. Sin embargo, sí se encontraron reducciones estadísticamente significativas en cuatro de las sub-escalas de estados de ánimo negativos: confusión, depresión, fatiga y tensión. 


\section{CAPÍTULO III: OBJETIVOS}

\subsection{Objetivo general}

- Adaptar y determinar las propiedades psicométricas del IADM-K en una muestra de estudiantes de instituciones de enseñanza musical superior de Lima Metropolitana.

\subsubsection{Objetivos específicos}

- Adaptar lingüísticamente el IADM-K empleando el método de contratraducción.

- Obtener evidencias de validez vinculadas al contenido de la versión en español del K-MPAI por criterio de jueces.

- Obtener evidencias de validez vinculadas a la estructura interna de la versión en español de la traducción del IADM-K a través del análisis factorial exploratorio de primer y segundo orden.

- Obtener evidencias de validez vinculadas a la relación con otras variables de la versión en español de la traducción del IADM-K estableciendo la correlación con el Inventario de Ansiedad Rasgo-Ansiedad Estado (IDARE) y con el Inventario de Ansiedad de Beck (IAB).

- Obtener evidencias de confiabilidad de las puntuaciones derivadas de aplicar los ítems que conforman al IADM-K, usando el método de consistencia interna.

- Elaborar baremos locales de la traducción del K-MPAI para estudiantes de música de nivel superior. 


\subsection{Definición de variables}

\subsubsection{Definición conceptual de ansiedad ante el desempeño musical}

De acuerdo a Kenny (2011), la ADM se define como

La experiencia de una ansiedad aprensiva, marcada y persistente, que está vinculada a la ejecución musical y que puede originarse por vulnerabilidades biológicas o psicológicas, o por experiencias particulares de condicionamiento ansioso. Se manifiesta por una combinación de componentes afectivos, cognitivos, somáticos y conductuales. Puede ocurrir en diversos contextos de ejecución, pero suele ser más severa en contextos en los cuales hay mayor inversión del ego, existe la amenaza de ser evaluado (una audiencia), y en los cuales se tiene miedo al fracaso. Puede ser focal (i.e. presente solo en ejecuciones musicales), o ser comórbida con otros desórdenes de ansiedad, particularmente con la ansiedad social. Afecta a los músicos a lo largo de su vida y es parcialmente independiente de los años de entrenamiento, horas de práctica y nivel de logro musical. Puede o no perjudicar la calidad de la ejecución musical. (p. 61).

\subsubsection{Definición operacional de ansiedad ante el desempeño musical}

La ADM se define operacionalmente de acuerdo a los 40 ítems agrupados en las tres áreas que abarca el Inventario de Ansiedad Ante el Desempeño Musical de Kenny:

- $\quad$ Contexto de relaciones tempranas: abarca la transmisión generacional de la ansiedad; y la empatía de los padres.

- Vulnerabilidades psicológicas: abarca sentimientos de depresión/desesperanza; sentido de control; confianza; y una ansiedad muy marcada ante el desempeño.

- Preocupaciones asociadas a próximas presentaciones: abarca componentes corporales de la ansiedad debido a la existencia de próximas presentaciones; preocupación/pavor; rumiaciones o pensamientos repetitivos antes y después 
de una presentación; evaluación propia o de otros; costos de oportunidad y confianza en la memoria. 


\section{CAPÍTULO IV: MÉTODO}

\subsection{Tipo y diseño de investigación}

La presente investigación es de tipo aplicada y psicométrica. Es aplicada puesto que busca generar una tecnología que sirva como base para investigaciones futuras. Es psicométrica puesto que hará uso de los puntajes numéricos obtenidos en la aplicación del IADM-K para determinar las propiedades psicométricas derivadas de la interpretación y uso de las puntuaciones extraídas del mismo, así como generar baremos de acuerdo a determinadas características demográficas (Alarcón, 2008; Hernández et al., 2010; Sánchez y Reyes, 2006).

Además, la investigación corresponde a un diseño no experimental y transeccional correlacional. Es no experimental pues no habrá una manipulación deliberada de variables, observando la variable ansiedad ante el desempeño musical en su ambiente natural. Es transeccional correlacional puesto que la medición se llevará a cabo en un momento dado y con el fin de identificar la ocurrencia de los niveles de $\mathrm{ADM}$ en los estudiantes de música de nivel superior, así como encontrar relaciones entre los puntajes de los diferentes instrumentos que serán empleados (Hernández et al., 2010).

\subsection{Participantes}

La población objetivo de la presente investigación se conformó por estudiantes de música de nivel profesional que tenían como mínimo de edad 18 años y cuya especialidad era instrumental. Dado que el IADM-K está orientado hacia músicos instrumentistas (pianistas, violinistas, percusionistas, cantantes, etc.), los estudiantes pertenecientes a otras especialidades no fueron contemplados en el presente estudio (e.g. compositores, productores musicales, musicólogos, etc.). A nivel de Lima metropolitana, la población se compone de un total de 1712 estudiantes repartidos entre seis instituciones privadas y estatales de la siguiente manera: 
Tabla 4.1

Distribución poblacional de los estudiantes de música de Lima Metropolitana en las seis instituciones de formación musical más representativas

\begin{tabular}{|c|c|c|c|c|}
\hline & \multicolumn{4}{|c|}{ Institución } \\
\hline & \multicolumn{2}{|c|}{ Privada } & \multicolumn{2}{|c|}{ Estatal } \\
\hline & $n$ & $\%$ & $n$ & $\%$ \\
\hline A & $992^{\mathrm{a}}$ & $57.94^{\mathrm{a}}$ & 320 & 18.69 \\
\hline B & 260 & 15.19 & $33^{\mathrm{a}}$ & $1.93^{\mathrm{a}}$ \\
\hline $\mathrm{C}$ & $80^{\mathrm{a}}$ & $4.67^{\mathrm{a}}$ & & \\
\hline D & 27 & 1.58 & & \\
\hline Total & 1359 & 79.38 & 350 & 20.62 \\
\hline
\end{tabular}

Nota: $N=1712$.

${ }^{a}$ No fue posible determinar el número de estudiantes de acuerdo a la especialidad, pues la institución no contaba con el dato.

La muestra estuvo conformada por 455 estudiantes de música de tres instituciones de formación musical superior distribuidos de la siguiente manera:

\section{Tabla 4.2}

Distribución muestral de los estudiantes de música de Lima Metropolitana en tres instituciones de formación musical

\begin{tabular}{l|ccccc}
\hline \multirow{2}{*}{} & \multicolumn{4}{|c}{ Institución } \\
\cline { 2 - 5 } & \multicolumn{3}{|c}{ Privada } & Estatal & \% \\
\cline { 2 - 5 } & $\boldsymbol{n}$ & $50.54^{\mathrm{a}}$ & 141 & 30.99 \\
$\mathrm{~A}$ & $230^{\mathrm{a}}$ & 18.46 & & $\boldsymbol{n}$ \\
B & 84 & $\mathbf{6 9 . 0 1}$ & $\mathbf{1 4 1}$ & $\mathbf{3 0 . 9 9}$ \\
\hline
\end{tabular}

Nota: $N=455$.

${ }^{a}$ No fue posible determinar el número de estudiantes de acuerdo a la especialidad, pues la institución no contaba con el dato.

El método de muestreo fue no probabilístico y accidental puesto que se tomó la muestra a la cual se tenía acceso; a pesar de ello, se aseguró que los participantes cumplan con los requisitos de la investigación, a saber, que sean estudiantes de música de nivel superior en la especialidad instrumental y que tengan como mínimo de edad 18 años (Kerlinger y Lee, 2002). Todos los participantes firmaron un consentimiento informado (ver Anexo 9). 
El tamaño de la muestra se estableció de acuerdo al criterio propuesto por Nunnally (1987) para llevar a cabo un análisis factorial exploratorio. Este criterio consiste en emplear un tamaño de muestra equivalente a 10 veces el número de variables o ítems que conforman al instrumento $(N=10 \mathrm{k})$, con el propósito de minimizar el error de muestreo. Puesto que el Inventario de Ansiedad Ante el Desempeño Musical de Kenny cuenta con 40 ítems, se obtuvieron 455 pruebas, superando la cantidad mínima requerida por el criterio de Nunnally.

Para mantener una muestra representativa de la población, se distribuyeron las 400 pruebas mínimas requeridas entre las instituciones privadas A y B, y la institución estatal A. Los estudiantes de instituciones privadas representan al 79.38\% de la población; mientras que los estudiantes de instituciones estatales al $20.62 \%$. Finalmente, a nivel muestral y sobre el total de 455 pruebas recogidas, los estudiantes de instituciones privadas representaron al $69.01 \%$ de la muestra; mientras que los estudiantes de la institución estatal al 30.99\%.

Aunque el porcentaje muestral de estudiantes de instituciones privadas (69.01\%) no haya igualado al porcentaje poblacional del mismo tipo de gestión institucional (79.38\%), no fue un inconveniente. Los 1359 estudiantes que se emplearon para determinar el porcentaje poblacional de las instituciones privadas es en la realidad menor: Al no ser posible determinar la cantidad de estudiantes por especialidad, el total antes mencionado está compuesto por especialidades musicales que no son contemplados en la presente investigación (tales como composición, producción musical, pedagogía musical, etc.). Por esta razón, se asume que la muestra de estudiantes de instituciones privadas ha replicado adecuadamente la proporción poblacional de estudiantes del mismo tipo de gestión educativa.

\subsection{Técnicas de recolección de datos}

Para esta investigación se emplearon tres instrumentos: El Inventario de Ansiedad Ante el Desempeño Musical de Dianna Kenny (IADM-K, cuyo nombre en inglés es Kenny-Music Performance Anxiety Inventory); el Inventario de Ansiedad Rasgo - Estado de Charles Spielberger (IDARE); y el Inventario de Ansiedad de Aaron Beck (IAB). A continuación se presentará la descripción de cada instrumento así como sus propiedades psicométricas. 


\subsubsection{Inventario de Ansiedad Ante el Desempeño Musical de Kenny (IADM-}

K)

El IADM-K corresponde a la segunda versión del K-MPAI diseñada por Kenny en 2009. La prueba está dirigida a estudiantes de música de nivel profesional cuya especialidad sea ejecución instrumental o canto. No contempla a otras especialidades tales como composición, musicología, educación musical, etc. Contiene 40 ítems cuyo formato de respuesta es de escala Likert con siete opciones (que va desde el 0 que es totalmente en desacuerdo; hasta el 6 que es totalmente de acuerdo) e incluye 8 ítems con puntuaciones inversas (1, 2, 9, 17, 23, 33, 35 y 37). Puede ser aplicado de manera individual o colectiva y tarda aproximadamente entre 5 a 10 minutos en completarse.

El análisis factorial exploratorio llevado a cabo por Kenny (2009) contó con la participación de 151 estudiantes, de los cuales el $72 \%$ fueron músicos y el $28 \%$ estudiantes de danza. Asimismo, el rango de edad se extendió entre los 17 y 50 años; y la distribución de género fue 36\% de varones y el $64 \%$ restante de mujeres.

El análisis factorial con rotación ortogonal de tipo varimax reveló que la versión revisada de su inventario cuenta con 12 factores subyacentes que Kenny luego agrupó en tres grandes categorías:

- Contexto de relaciones tempranas: compuesto por 11 ítems.

- Vulnerabilidades psicológicas: compuesto por 33 ítems.

- $\quad$ Preocupaciones acerca de presentaciones futuras: compuesto por 34 ítems.

Esta estructura, concluye Kenny, coincide con el conjunto de vulnerabilidades señaladas por Barlow en su teoría de la ansiedad. Sin embargo, dado el bajo número de participantes empleados en su estudio, resulta necesario replicar el análisis factorial con una muestra más numerosa.

No existen evidencias de validez o de confiabilidad de las puntuaciones obtenidas mediante el IADM-K en contextos similares al peruano. Sin embargo, Medeiros (2013) llevó a cabo un estudio psicométrico sobre la versión anterior del IADM-K (Kenny, Davis y Oates, 2004) en la ciudad de Ribeirão Preto, Brasil. La muestra de Medeiros (2013) estuvo conformada por 230 músicos amateurs y 
profesionales, cuya mayoría contaba con un grado de instrucción superior (53.9\%). La media de edad fue de 39.17 años $(\mathrm{DE}=16.48)$.

Medeiros (2013) evaluó las evidencias de validez vinculadas a la relación con otras variables, particularmente a las evidencias convergentes y discriminantes. Específicamente correlacionó las puntuaciones obtenidas por medio del IADM-K junto con el IAB, el Inventario de Fobia Social (SPIN), la Escala de autoevaluación para el desempeño en público (SSPS-D), compuesta por una escala de autoevaluación positiva y otra negativa; y el Cuestionario sobre la Salud del Paciente-9 (PHQ-9).

A un nivel de significancia de $p<.01$, Medeiros (2013) reportó relaciones moderadas entre el IADM-K y tres de los instrumentos empleados: el BAI $(r=.50)$, el SPIN $(r=.34)$, y el PHQ-9 $(r=.48)$. Asimismo, reportó relaciones moderadas y negativas entre el IADM-K y el SSPS-D en su escala de autoevaluación positiva ( $r$ $=-.36)$ y en su escala de autoevaluación negativa $(r=-.50)$.

Medeiros (2013) brindó evidencias de validez vinculadas a la estructura interna a través de un análisis factorial exploratorio (AFE) sin especificar el método de rotación empleado. No obstante, la medida de adecuación muestral KaiserMeyer-Olkin obtenida fue de .81 y el test de esfericidad de Bartlett puntuó un valor por debajo del nivel de significancia $p<.000$, con lo cual reportó una adecuación a la muestra para el AFE del inventario. Identificó ocho factores que explicaban el $62.39 \%$ de la varianza compartida, siendo el primer factor el que reunía el mayor porcentaje $(23.09 \%)$.

Medeiros (2013) llevó a cabo otro AFE considerando a los ocho factores antes obtenidos con rotación ortogonal de tipo Varimax, dado que, teóricamente, se espera una independencia entre los ítems. Retuvo tres de los ocho factores, justificando la eliminación de los factores 6,7 y 8 por contener menos de dos ítems y el factor 4 por presentar una confiabilidad menor a .70. De este modo, concluyó que una estructura con tres factores presentaba el modelo más adecuado. Estos fueron: preocupaciones e inseguridad (vinculadas al desempeño musical), desesperación y desesperanza (vinculados a factores de autoestima y estabilidad emocional) y contexto de relaciones parentales temprana (vinculadas a la relación temprana con los padres), con un $\alpha$ de Cronbach igual a $.82 ; .77 ;$ y .57, respectivamente. 
En un reporte más reciente, Medeiros, Crippa y Osorio (2014) llevaron a cabo la estimación de la confiabilidad de las puntuaciones derivadas del IADM-K por medio del método de consistencia interna. Obtuvo un alfa de Cronbach de .91 (superando el criterio de .70 establecido por Nunnally y Bernstein, 1995). Asimismo, todos los ítems resultaron relevantes para la conformación de la escala.

\subsubsection{Inventario de Ansiedad Rasgo-Estado (IDARE)}

El IDARE fue creado por Spielberger, Gorsuch y Lushene (1970) y adaptado al español por Spielberger y Díaz-Guerrero (1970). Cuenta con 40 ítems repartidos entre la subprueba de Ansiedad Estado (A-Estado) y la subprueba de Ansiedad Rasgo (A-Rasgo). Ambas cuentan con un formato de respuesta de escala Likert de 4 opciones. Puede ser respondido por estudiantes de secundaria, universidad, pacientes neuropsiquiátricos, médicos y quirúrgicos. El modo de aplicación puede ser de manera individual o colectiva y tarda aproximadamente entre 5 y 10 minutos para ser completado. Los ítems con calificación inversa de la subprueba de A-Estado son: 1, 2, 5, 8, 10, 11, 15, 16, 19 y 20; mientras que los equivalentes de la subprueba de A-Rasgo son: 21, 26, 27, 30, 33, 36 y 39.

Ugarriza (1998) brindó evidencias de validez vinculadas a la relación con otras variables al explorar la convergencia entre el IDARE y diferentes escalas del Inventario Multicultural de la Expresión de Cólera-Hostilidad (IECH). Las escalas del IECH son: cólera estado $(\mathrm{CE})$, cólera temperamento $(\mathrm{Ct})$, reacción de cólera $(\mathrm{Cr})$, cólera manifiesta $(\mathrm{CM})$, cólera contenida $(\mathrm{CCM})$, control de la cólera manifiesta y control de la cólera contenida (CCC). A un nivel de significancia $p<$ .001 , la subprueba de A-Estado correlacionó significativamente con CE (.50), Ct (.33) y CR (.34); mientras que a un nivel de significancia $p<.05$, se evidenciaron correlaciones significativas entre A-Estado con $\mathrm{Cr}(.26)$ y CC (.27).

Con respecto a la subprueba de A-Rasgo, a un nivel de significancia $\mathrm{p}<$ .001 , se reportaron correlaciones significativas entre esta subprueba y las escalas CE (.37), Ct (.49), Cr (.40), CR (.51), CC (.43) y CCC (.35). A un nivel de significancia $\mathrm{p}<.05$, se encontraron correlaciones con CM (.28).

Ugarriza (1998) estimó la confiabilidad de las puntuaciones derivadas del IDARE, tanto para la subprueba de ansiedad estado, como de ansiedad rasgo, en 1502 estudiantes universitarios de una universidad pública $(n=1110)$ y una universidad privada $(n=392)$. Para ello, empleó el método de consistencia interna, 
obteniendo un alfa de Cronbach de .66 para A-Estado y de .71 para A-Rasgo (superando el criterio de .70 establecido por Nunnally y Bernstein, 1995).

\subsubsection{Inventario de Ansiedad de Beck (IAB)}

El IAB fue creado por Beck y Steer (1993) y adaptado al español por Robles, Varela, Jurado y Páez (2001, como se citó en Thornberry, 2011). Cuenta con 21 ítems cuyo formato de respuesta es de escala Likert de 4 opciones (yendo desde 0 que es en absoluto; hasta el 3 que es severamente). El inventario es aplicable a poblaciones generales a partir de los 13 años de edad sin alguna patología determinada y casos clínicos. El modo de aplicación puede ser de manera individual o colectiva y tarda aproximadamente entre 5 y 10 minutos para ser completado. El inventario carece de ítems con puntuaciones inversas.

Thornberry (2011) brindó evidencias de validez vinculadas a la estructura interna en 1119 estudiantes de pregrado de dos universidades privadas de Lima de entre 17 y 25 años, repartidos en 18 carreras distintas. Llevó a cabo un análisis factorial exploratorio (AFE) por medio del método de componentes principales con rotación oblicua de tipo Promax, dado que esperaba teóricamente que los ítems tengan relación entre ellos. La medida de adecuación muestral Kaiser-Meyer-Olkin obtenida fue de .94 y el test de esfericidad de Bartlett puntuó un valor por debajo del nivel de significancia $p<.001$, con lo cual reportó una adecuación a la muestra para el AFE del inventario.

Encontró tres factores que explicaban el $49.16 \%$ de la varianza compartida, siendo el primer factor el que reunía el mayor porcentaje (36.26\%). Sin embargo, el gráfico de sedimentación sugirió la existencia de un único factor.

Thornberry (2011) llevó a cabo un segundo AFE, hallando un único factor que explicaba el $36.26 \%$ de la varianza y todos los ítems obtuvieron una carga factorial mayor a .30, reafirmando la existencia de un factor común para todos los ítems.

Se llevó a cabo la estimación de la confiabilidad de las puntuaciones derivadas del IAB por medio del método de consistencia interna. Obtuvo un alfa de Cronbach de .91 (superando el criterio de .70 establecido por Nunnally y Bernstein, 1995). Asimismo, obtuvo una correlación ítem-test corregida con puntajes entre .43 y .69, evidenciando un buen nivel de relación entre los ítems del inventario al 
superar el criterio $r>.20$ de Kline (1995). Todos los ítems resultaron relevantes para la conformación de la escala.

\subsection{Procedimiento}

A fin de recolectar los datos de la aplicación definitiva, se contactó formalmente a las tres escuelas escogidas para el estudio. Durante la aplicación de los cuestionarios se llevó a cabo la lectura grupal del consentimiento informado y la aplicación de las pruebas (se incluyen ejemplos de estos documentos en la sección de Anexos). Las pruebas se presentaron en el siguiente orden: primero, el IADM-K; segundo, el IDARE; y tercero, el IAB. Todas fueron aplicadas sucesivamente sin pausa de por medio. A fin de minimizar resistencias a la evaluación, se les indicó a los participantes que sería un estudio de las emociones en los músicos y se reiteró el anonimato de las respuestas.

Para recolectar las pruebas de manera más eficiente, se contó con el apoyo de otros investigadores, previamente capacitados. Para ello, se elaboró un protocolo de aplicación del cuadernillo (consultar anexo $\mathrm{H}$ ).

Los datos recolectados fueron sistematizados en una base de datos empleando el SPSS en su versión 21. Asimismo, se utilizó el programa Factor en su versión 9.3.1 (Lorenzo-Seva y Ferrando, 2015) para llevar a cabo el análisis factorial exploratorio de segundo orden y el cálculo de las confiabilidades ordinales.

A fin de determinar las propiedades psicométricas del IADM-K, se ha partido de la teoría clásica de los test (TCT) cuya hipótesis fundamental plantea que toda puntuación observada tras la aplicación de una prueba será igual a una puntuación verdadera correspondiente al constructo en medición junto con un error de medición (Santisteban, 2009).

$$
\mathrm{X}=\mathrm{V}+\mathrm{e}
$$

Las pruebas estadísticas que se han empleado para estimar las propiedades psicométricas del IADM-K son:

- Coeficiente V de Aiken: establece el grado de acuerdo entre los jueces en el proceso de calificación de los ítems de acuerdo a la estructura propuesta (Escurra, 
1988). Este coeficiente se utilizó para obtener evidencias de validez vinculadas al contenido.

- A fin de obtener las evidencias de validez vinculadas a la estructura interna, primero se replicó el modelo ortogonal con rotación varimax efectuado por Kenny (2009) y a partir de los resultados de este análisis se evaluó la pertinencia de aplicar un análisis factorial exploratorio de segundo orden (AFESO) con la solución Schmid-Leiman (SSL). El AFESO es una técnica que permite reducir y agrupar una gran cantidad de variables en factores específicos de primer orden y factores generales o de orden superior (Wolff y Preising, 2005). Asimismo, la SSL permite transformar una solución factorial oblicua (o de dependencia teórica) con jerarquías o con factores de mayor orden, en una solución ortogonal (o de independencia teórica), preservando las características de la interpretación oblicua y mostrando las cargas factoriales de cada una de las variables o ítems en cada uno de los factores de diferentes niveles (Schmid y Leiman, 1957). Es decir, "la SLS estima las cargas factoriales directas de los ítems en los factores de primer y segundo orden" (Wolff y Preising, 2005, p. 49).

Para determinar la pertinencia de aplicar el AFESO, hace falta llevar a cabo la medida de adecuación muestral Kaiser-Meyer-Olkin (KMO) y la prueba de esfericidad de Bartlett. La medida de adecuación muestral KMO da cuenta de en qué proporción la varianza de las variables debe considerarse como varianza común compartida como consecuencia de factores subyacentes (Burga, 2006). Mientras que la prueba de esfericidad de Bartlett: "contrasta la hipótesis referida a que la matriz de correlaciones con la cual trabajamos es una matriz de identidad" (Burga, 2006, p. 63); es decir permite establecer si es que las variables guardan relación entre sí.

- Coeficiente alfa de Cronbach: indica la fuerza de correlación entre todas las puntuaciones obtenidas a partir de los ítems de un instrumento, sobre el supuesto de que se parte una matriz de correlaciones continua (Bonanomi, Ruscone y Osmetti, 2013; Gadermann, Guhn y Zumbo, 2012; Zumbo, Gadermann, Zeisser, 2007). Este coeficiente se reporta al emplearse la estimación de la confiabilidad por medio del método de consistencia interna. 
- Alfa ordinal: estimador de la confiabilidad por medio de la consistencia interna empleado para ítems policóricos o en formato de respuesta Likert que se basan en una matriz de correlaciones policóricas o politómicas (Bonanomi, Ruscone y Osmetti, 2013; Gadermann, Guhn y Zumbo, 2012; Zumbo, Gadermann y Zeisser, 2007). Este estimador se empleará para calcular la confiabilidad de cada uno de los factores obtenidos en la presente investigación.

- Coeficiente de correlación $r$ de Pearson: Es la medida de relación entre dos variables. Sus valores pueden abarcar desde el -1, el cambio de una variable en una dirección está acompañada por el cambio de la otra en dirección opuesta, 0, el cambio en el valor de una variable no genera cambios en la otra, y +1 , el cambio de una variable en una dirección está acompañada por el cambio de la otra en la misma dirección (Field, 2009). Este coeficiente se utilizará para obtener evidencias de validez vinculadas a la relación con otras variables, así como estimador del tamaño del efecto (Ellis, 2010; Ferguson, 2009; Field, 2009).

- Los baremos serán establecidos de acuerdo al uso de percentiles. Un percentil es un valor dentro de una escala de medida que deja por debajo de sí a un determinado porcentaje de las puntuaciones de una distribución (Pagano, 2011).

- Tamaño del efecto: es un estimador del grado de asociación entre dos o más variables a partir del cual pueden tomarse decisiones en una población real (Ellis, 2010; Ferguson, 2009). Además del coeficiente de correlación $r$ de Pearson antes mencionado, en esta investigación se empleará la $d$ de Cohen como estimador de la diferencia entre dos grupos (Ferguson, 2009); y $\eta^{2}$ como el grado en el cual la varianza en la variable dependiente es explicada por las variables independientes (Ellis, 2010).

- Potencia estadística: Ellis (2010) la define como "la probabilidad de que una prueba identifique correctamente a un efecto genuino" (p. 52). Se espera obtener valores superiores a .80 (Cohen, 1992) a fin de disminuir la probabilidad de cometer un error tipo II o $\beta$. 


\section{CAPÍTULO V: RESULTADOS}

\subsection{Adaptación del IADM-K}

Dado que no existe una versión en español del IADM-K, el proceso de adaptación lingüística se llevó a cabo mediante el método de contratraducción, o el traducir un texto de un idioma hacia otro y nuevamente hacia el idioma original para buscar equivalencias que permitan comprar resultados (APAb, 2010). Para este proceso de contratraducción, se tomó como base la propuesta del Appraisal of Guidelines for Research and Evaluation II (AGREE II), una guía cualitativa de traducción. A continuación se detallan los pasos seguidos en la presente investigación:

Se tradujo el instrumento del inglés al español por cuatro personas bilingües y cuya lengua materna era el español: una psicóloga especialista en metodología de investigación, un pianista y director de orquesta, y un filósofo de la ciencia y de la mente y el investigador. La traducción al español implicó la revisión de cada uno de los ítems y proponer un equivalente, lo más cercano posible, al español.

Las cuatro traducciones propuestas fueron posteriormente evaluadas simultáneamente por tres de los cuatro expertos en su especialidad y con conocimiento fluido del inglés para resolver discrepancias y ambigüedades de las traducciones hasta alcanzar una primera versión preliminar del instrumento en español. Los traductores buscaron similitudes y diferencias entre las propuestas de cada uno. Las diferencias fueron resueltas buscando traducciones que sintetizaran mejor las propuestas individuales y que se asemejaran más a la intencionalidad de la prueba original en inglés. Entre las diferencias en las traducciones de cada uno, cabe mencionar un ejemplo interesante ocurrido con la traducción de la palabra performance al español. La palabra performance puede adoptar distintos usos y significados en español (particularmente dentro de un contexto artístico), tales como: desempeño, presentación, concierto, recital, tocar, ejecutar o actuar. Por ello, se empleó la traducción de performance más acertada de acuerdo al contexto musical peruano y procurando no desviarse de la intencionalidad de la prueba en inglés.

Completada la primera versión preliminar en español, fue enviada a dos traductores oficiales cuya lengua materna era el inglés y que no estaban 
familiarizados con el AGREE II para ser traducida del español al inglés. Estos traductores llevaron a cabo la doble traducción o contratraducción del instrumento. Una vez que se contó con las dos versiones contratraducidas del español al inglés, estas fueron enviadas vía correo electrónico a Dianna Kenny, autora de la prueba, indicándole que ambas versiones en inglés procedían de la versión preliminar en español y que ella debía indicar si es que encontraba algún ítem que debía ser corregido o modificado.

La autora envió por correo electrónico ambas versiones contratraducidas al inglés, resaltando los ítems que se asemejaban más a la primera versión original en inglés construida por ella. Aquellos ítems que no fueron resaltados fueron los que, según su criterio, expresaban el mismo significado a su prueba original. Kenny señaló que para el ítem 9 en inglés: "My parents were mostly responsive to my needs", las palabras empleadas por los traductores sensitive (sensible) y aware of (conscientes de) no capturaban el significado completo de la palabra responsive, empleada originalmente por Kenny, quien sostuvo que la palabra responsive significa que los padres fueron sensibles de las necesidades del hijo o hija y que además respondieron apropiadamente a ellas. La autora sugirió que se escoja una palabra que abarque ambas acciones. A fin de mantener la intencionalidad original de la autora, se decidió corregir la redacción de ese ítem a: "Mis padres han sido generalmente sensibles a mis necesidades y han respondido a ellas". Asimismo, se siguió la sugerencia propuesta por ella para que se emplee la palabra ansioso para traducir anxious, en vez de emplear nervioso.

Tomando en cuenta la respuesta de Kenny, las dos versiones contratraducidas al inglés y la primera versión preliminar en español, se elaboró la versión final del IADM-K al español. Esta versión final consistió en cambiar la redacción de los ítems de acuerdo a las recomendaciones sugeridas por la autora. La versión final fue enviada a Kenny para contar con su aprobación previamente a proceder con el contacto con los jueces y la aplicación de la prueba piloto. Ella reconoció esta versión en español como la versión oficial en este idioma.

Paralelamente, se llevó a cabo el diseño de la ficha sociodemográfica y se agruparon los tres cuestionarios a aplicarse bajo un único formato. Una vez terminado el cuadernillo de preguntas, se llevó a cabo el contacto correspondiente con las autoridades de la institución privada de enseñanza musical para obtener los contactos con los docentes y la autorización para ingresar a la institución y las aulas. 
El estudio piloto se desarrolló en una facultad de música de una universidad privada de Lima Metropolitana, donde se aplicaron 62 cuestionarios. La muestra piloto estuvo conformada por 51 varones (82.3\%) y 11 mujeres (17.7\%). Asimismo, las edades del grupo de participantes está comprendido entre los 18 y 29 años $(M=$ 21.5). Este grupo de estudiantes estuvo comprendido entre el $4^{\circ}$ y $8^{\circ}$ ciclo de estudios, concentrándose la mayor frecuencia de ellos en el $6^{\circ}$ ciclo (38.2\%). De estos 62 estudiantes, $45(77.6 \%)$ señalaron el género contemporáneo como especialidad (incluye rock, pop, salsa, etc.).

La aplicación piloto permitió identificar algunos aspectos a mejorarse en la presentación del IADM-K en español. La versión aplicada consta de una escala Likert de 7 puntos, desde 0 hasta 6. Sin embargo, no todos los ítems coincidían en su gradación desde el extremo totalmente en desacuerdo al extremo totalmente de acuerdo. Esta particularidad hizo que varios participantes consultaran sobre cómo debían puntuar esos ítems en particular. Por ello, se corrigió la presentación de los ítems para la aplicación definitiva del instrumento, graduando a todos los reactivos desde el totalmente en desacuerdo (0) hasta totalmente de acuerdo (6). Asimismo, fue posible identificar el tiempo de aplicación promedio necesario para contestar a todo el cuadernillo, siendo, aproximadamente, 15 minutos.

\subsection{Evidencias de validez vinculadas al contenido}

Se llevó a cabo el análisis de las evidencias de validez vinculadas al contenido del IADM-K por medio de la calificación de ocho jueces (consultar apéndice F para observar la matriz de criterio de jueces). Los jueces correspondían a diferentes especialidades: psicólogos clínicos, psicólogos expertos en psicometría y estadística y un músico profesional. A partir de sus calificaciones, se estimó el coeficiente $\mathrm{V}$ de Aiken.

Los resultados sugieren que el ítem 27 (En la infancia, a menudo me sentía triste) no constituye un indicador del área "contexto de relaciones tempranas". Los ítems restantes sí presentaron niveles significativos para el coeficiente V de Aiken a un nivel $p<.05$. 
Tabla 5.1

Coeficiente V de Aiken para los ítems del IADM-K

\begin{tabular}{c|ccc}
\hline Ítem & $\mathbf{V}$ & Ítem & $\mathbf{V}$ \\
\hline Ítem 1 & $.98^{*}$ & Ítem 21 & $.90^{*}$ \\
Ítem 2 & $.95^{*}$ & Ítem 22 & $.98^{*}$ \\
Ítem 3 & $.98^{*}$ & Ítem 23 & $.85^{*}$ \\
Ítem 4 & $.93^{*}$ & Ítem 24 & $.95^{*}$ \\
Ítem 5 & $.98^{*}$ & Ítem 25 & $.98^{*}$ \\
Ítem 6 & $.98^{*}$ & Ítem 26 & $1.00^{*}$ \\
\hline Ítem 7 & $.95^{*}$ & Ítem 27 & .68 \\
Ítem 8 & $.88^{*}$ & Ítem 28 & $1.00^{*}$ \\
Ítem 9 & $.88^{*}$ & Ítem 29 & $.98^{*}$ \\
\hline Ítem 10 & $.98^{*}$ & Ítem 30 & $1.00^{*}$ \\
Ítem 11 & $.88^{*}$ & Ítem 31 & $.90^{*}$ \\
Ítem 12 & $1.00^{*}$ & Ítem 32 & $.98^{*}$ \\
Ítem 13 & $.93^{*}$ & Ítem 33 & $.83^{*}$ \\
\hline Ítem 14 & $1.00^{*}$ & Ítem 34 & $1.00^{*}$ \\
Ítem 15 & $.98^{*}$ & Ítem 35 & $.90^{*}$ \\
Ítem 16 & $.98^{*}$ & Ítem 36 & $1.00^{*}$ \\
\hline Ítem 17 & $.98^{*}$ & Ítem 37 & $1.00^{*}$ \\
Ítem 18 & $.90^{*}$ & Ítem 38 & $.98^{*}$ \\
\hline Ítem 19 & $.98^{*}$ & Ítem 39 & $.95^{*}$ \\
\hline Ítem 20 & $1.00^{*}$ & Ítem 40 & $.98^{*}$ \\
\hline < 05. & & & \\
\hline
\end{tabular}

\subsection{Evidencias de validez vinculadas a la estructura interna}

A fin de estimar las evidencias de validez vinculadas a la estructura interna del IADM-K, se ejecutó un análisis factorial exploratorio (AFE) a partir del cual resultó pertinente ampliar el análisis de las puntuaciones del instrumento por medio de un análisis factorial exploratorio de segundo orden (AFESO).

El AFE se llevó a cabo sobre los 40 ítems de la prueba con una rotación varimax (ortogonal), pues se asumió la independencia teórica de los componentes del IADM-K. La medida KMO indicó una correlación entre los ítems lo suficientemente alta para ejecutar el AFE, KMO = .91. El test de esfericidad de Bartlett también dio cuenta de la existencia de relaciones estadísticamente significativas, rechazándose la hipótesis nula referida a que la matriz muestral de correlaciones entre variables proviene de una matriz población tipo identidad, $X^{2}(780)=6322.20, p<.001$. El 
análisis de los autovalores superiores al criterio de Kaiser de 1 sugirió la existencia de cuatro factores que explican el $41.22 \%$ de la varianza común compartida. Un análisis paralelo corroboró la cantidad de factores. Los ítems con cargas factoriales mayores a .40 fueron retenidos para el análisis (Field, 2009).

Tras repetir el AFE bajo el mismo procedimiento y depurar los ítems necesarios se alcanzó una estructura factorial preliminar con 32 ítems. Tanto el KMO como el test de esfericidad de Bartlett señalaron que los datos son adecuados para realizar el análisis factorial, $\mathrm{KMO}=.91, X^{2}(496)=5281.36, p<.001$. La tabla 5.2 muestra las cargas factoriales luego de ser rotadas. 
Tabla 5.2

Matriz de factores rotados ortogonalmente para los ítems del IADM-K

\begin{tabular}{|c|c|c|c|c|}
\hline \multirow[b]{2}{*}{ Ítems } & \multicolumn{4}{|c|}{ Factor } \\
\hline & $\begin{array}{c}\text { Preocupaciones } \\
\text { asociadas a } \\
\text { próximas } \\
\text { presentaciones }\end{array}$ & $\begin{array}{l}\text { Vulnerabilidades } \\
\text { psicológicas }\end{array}$ & $\begin{array}{c}\text { Confianza en la } \\
\text { memoria }\end{array}$ & $\begin{array}{c}\text { Contexto de } \\
\text { relaciones } \\
\text { tempranas con } \\
\text { los padres }\end{array}$ \\
\hline 26 & .685 & & & \\
\hline 36 & .676 & & & \\
\hline 38 & .659 & & & \\
\hline 10 & .658 & & & \\
\hline 20 & .63 & & & \\
\hline 34 & .597 & & & \\
\hline 30 & .593 & & & \\
\hline 22 & .562 & & & \\
\hline 28 & .536 & .419 & & \\
\hline 15 & .528 & & & \\
\hline 11 & .527 & .402 & & $=4$ \\
\hline 21 & .496 & & & \\
\hline 39 & .485 & & & \\
\hline 12 & .485 & V & & \\
\hline 18 & .484 & & & \\
\hline 25 & .469 & & & \\
\hline 16 & .456 & & & \\
\hline 32 & .439 & & & \\
\hline 14 & .428 & & & \\
\hline 19 & .421 & & & 3 \\
\hline 13 & & .758 & & \\
\hline 6 & & .675 & & \\
\hline 31 & & .626 & & \\
\hline 3 & & .557 & & \\
\hline 1 & & .492 & & \\
\hline 4 & & .481 & & \\
\hline 27 & & .476 & & \\
\hline 37 & & & .794 & \\
\hline 35 & & & .762 & \\
\hline 9 & & & & .713 \\
\hline 23 & & & & .642 \\
\hline 33 & & & & .623 \\
\hline
\end{tabular}


La estructura factorial obtenida discrepó con la presentada en Kenny (2009) puesto que el factor "Confianza en la memoria" debía formar parte del factor "Preocupaciones asociadas a próximas presentaciones". A fin de profundizar en la estructura factorial del IADM-K, se llevó a cabo un primer análisis factorial exploratorio de segundo orden $\left(\mathrm{AFESO}_{1}\right)$ con la solución Schmid-Leiman (SSL, Schmid y Leiman, 1957).

El AFESO ${ }_{1}$ se llevó a cabo sobre los 40 ítems de la prueba con una rotación oblicua de tipo promin, pues la estimación de un factor de segundo orden o factor general $(G)$ supone la dependencia teórica entre los factores de primer orden del instrumento. Se factorizó la matriz de correlaciones mediante una correlación policórica, pues los ítems son variables ordinales y de respuesta policórica (Burga, 2006). Asimismo, se empleó la SLS para identificar la carga factorial de cada ítem para los factores de primer y segundo orden, $\mathrm{KMO}=.91, X^{2}(780)=6390.8, p<.001$. El análisis de los autovalores superiores al criterio de Kaiser de 1 indicó la existencia de cuatro factores que explican el $43.98 \%$ de la varianza común compartida. En esta ocasión, el análisis paralelo sugirió la existencia de 3 factores, en lugar de 4. Los ítems con cargas factoriales mayores a .30 fueron retenidos para el análisis, pues la ejecución de un AFESO tiende a disminuir las cargas factoriales (Wolff y Preising, 2005).

Tras repetir el $\mathrm{AFESO}_{1}$ bajo el mismo procedimiento y depurar los ítems necesarios se alcanzó una estructura de tres factores que explicaba el $64.87 \%$ de la varianza común compartida. Tanto el KMO como el test de esfericidad de Bartlett aún se mantuvieron en los valores adecuados, KMO $=.93, X^{2}(435)=4948.9, p<$ .001. Se eliminó el factor de contexto de relaciones tempranas con los padres, pues los ítems que lo constituyen: 9, 23 y 33, no presentaron cargas factoriales superiores a .30 en el factor $\mathrm{G}$ (ítem $9=.077$, ítem $23=.069$, ítem $33=.081$ ). Esto sugiere que el factor 4 no pertenece a la estructura del instrumento. Asimismo, tanto el ítem 35 como el 37, pertenecientes al factor de confianza en la memoria o factor 2 , fueron eliminados del $\mathrm{AFESO}_{1}$, pues se corroboró que no pertenecen a las preocupaciones asociadas a las próximas presentaciones. Por último, se empleó el criterio de .30 (Wolff y Preising, 2005) para eliminar los ítems que no aportaban las cargas factoriales necesarias. De este modo, los ítems que fueron eliminados de la escala fueron los siguientes: $2,8,9,22,23,25,33,35,37,40$; con lo cual de los 40 ítems que constituían la primera versión del instrumento, se obtuvo una nueva propuesta de 
prueba con 30 ítems. Así, el factor "Contexto de relaciones tempranas con los padres" (ítems 9, 23 y 33) también fue descartado pues sus cargas factoriales no superaban el valor de .30 (Wolff y Preising, 2005). En la tabla 5.3 se presenta la estructura final de segundo orden. 
Tabla 5.3

Análisis factorial exploratorio de segundo orden de los ítems del IADM-K con la solución Schmid-Leiman con tres factores de primer orden rotados oblicuamente

\begin{tabular}{|c|c|c|c|c|}
\hline \multirow{2}{*}{ Ítems } & \multicolumn{4}{|c|}{ Factor } \\
\hline & F1 & F2 & F3 & G \\
\hline 38 & .467 & & & .560 \\
\hline 20 & .457 & & & .472 \\
\hline 39 & .441 & & & .375 \\
\hline 19 & .419 & & & .432 \\
\hline 34 & .382 & & & .538 \\
\hline 29 & .376 & & & .375 \\
\hline 18 & .374 & & & .395 \\
\hline 30 & .342 & $\longrightarrow$ & & .557 \\
\hline 26 & .341 & & & .598 \\
\hline 21 & .326 & & & .443 \\
\hline 36 & .298 & & & .587 \\
\hline 32 & .287 & & & .392 \\
\hline 15 & .253 & & & .521 \\
\hline 10 & & .317 & & .626 \\
\hline 11 & & .379 & & .674 \\
\hline 12 & & .248 & & .514 \\
\hline 14 & & .415 & & .637 \\
\hline 16 & & .271 & & .577 \\
\hline 17 & & .278 & & .449 \\
\hline 24 & & .142 & & .473 \\
\hline 28 & & .303 & & .688 \\
\hline 1 & & & .311 & .426 \\
\hline 3 & & & .497 & .453 \\
\hline 4 & & & .343 & .415 \\
\hline 5 & & & .452 & .347 \\
\hline 6 & & & .594 & .452 \\
\hline 7 & & & .191 & .471 \\
\hline 13 & & & .604 & .561 \\
\hline 27 & & & .489 & .369 \\
\hline 31 & & & .390 & .562 \\
\hline
\end{tabular}


A pesar de obtener tres factores oblicuos de primer orden, el contenido teórico de los dos primeros factores no presentó mayor diferenciación. A fin de esclarecer esta discrepancia se llevó a cabo una correlación entre los puntajes totales del IADM$\mathrm{K}$ en su estructura factorial de segundo orden y los puntajes totales de los tres factores de primer orden.

Se obtuvieron niveles de correlación positivas entre el puntaje del IADM-K y las puntuaciones de los tres factores de primer orden, $p<.001$. Se reportaron niveles altos de correlación entre el IADM-K G con el IADM-K F1, $r=.91$ y entre el IADM$\mathrm{K}$ G con el IADM-K F2, $r=.87$; asimismo, la correlación entre el IADM-K G y el IADM-K F3 también evidenció un nivel de correlación alto, $r=.58$. Considerando a $r$ como tamaño del efecto (Ferguson, 2009; Field, 2009), todas las correlaciones antes presentadas corresponden a un tamaño del efecto grande (Ellis, 2010) y una potencia estadística mayor a .80 (Cohen, 1992).

\section{Tabla 5.4}

Matriz de correlación entre los puntajes del IADM-K, y los puntajes del F1, F2, y F3

\begin{tabular}{l|cccc}
\hline & IADM-K G & IADM-K F1 & IADM-K F2 & IADM-K F3 \\
\hline IADM-K G & - & $.91^{* * *}$ & $.87^{* * *}$ & $.78^{* * *}$ \\
IADM-K F1 & & - & $.72^{* * *}$ & $.51^{* * *}$ \\
IADM-K F2 & & & - & $.58^{* * *}$ \\
IADM-K F3 & & & & - \\
\hline
\end{tabular}

Nota: $N=455$.

$* * * p<.001$.

Tomando en cuenta estas correlaciones se llevó a cabo otro AFESO $\left(\mathrm{AFESO}_{2}\right)$. En esta ocasión se hipotetizó que si F1 y F2 se encontraban altamente correlacionados, entonces un AFESO con dos factores de primer orden y uno de orden superior deberían agrupar a F1 y F2 bajo un solo factor de primer orden y mantener a F3 como otro factor de primer orden. Tras repetir el $\mathrm{AFESO}_{2}$ bajo el mismo procedimiento de $\mathrm{AFESO}_{1}$ se alcanzó una estructura de dos factores que explicaba el $58.65 \%$ de la varianza común compartida. Tanto el KMO como el test de esfericidad de Bartlett aún se mantuvieron en los valores adecuados, $\mathrm{KMO}=.93$, $X^{2}(435)=4948.9, p<.001$. Más aún, la estructura factorial obtenida sugirió mantener los mismos 30 ítems obtenidos en el $\mathrm{AFESO}_{1}$ (tabla 5.3). Tal y como se hipotetizó, el 
F1 obtenido en el $\mathrm{AFESO}_{2}$ reunió a los ítems comprendidos en el F1 y F2 del $\mathrm{AFESO}_{1}$.

A partir de esta estructura factorial, el F1 refiere a "preocupaciones sobre la presentación musical" y el F2 a "vulnerabilidades psicológicas". Aunque el ítem 14 comparte la misma carga factorial para el F1 y el F2, se le consideró como perteneciente al primero al tomar en cuenta el contenido. Asimismo, el factor $\mathrm{G}$ se identificó como "ansiedad ante el desempeño musical". Los datos del $\mathrm{AFESO}_{2}$ se encuentran resumidos en la tabla 5.5. 


\section{Tabla 5.5}

Análisis factorial exploratorio de segundo orden de los ítems del IADM-K con la solución Schmid-Leiman con dos factores de primer orden rotados oblicuamente

\begin{tabular}{|c|c|c|c|}
\hline Ítems & $\begin{array}{c}\begin{array}{c}\text { Ansiedad ante el } \\
\text { desempeño musical }\end{array} \\
\text { (F1) }\end{array}$ & $\begin{array}{c}\text { Componentes } \\
\text { depresivos } \\
\text { (F2) }\end{array}$ & $\begin{array}{l}\text { Afectividad negativa } \\
\text { ante el desempeño } \\
\text { musical } \\
\text { (G) }\end{array}$ \\
\hline 10 & .479 & 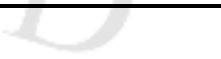 & .527 \\
\hline 11 & .264 & & .644 \\
\hline 12 & .335 & & .456 \\
\hline 15 & .385 & & .463 \\
\hline 16 & .286 & & .544 \\
\hline 17 & .165 & & .427 \\
\hline 18 & .396 & & .342 \\
\hline 19 & .274 & & .457 \\
\hline 20 & .566 & & .363 \\
\hline 21 & .405 & & .381 \\
\hline 24 & .193 & & .476 \\
\hline 26 & .496 & & .516 \\
\hline 28 & .269 & 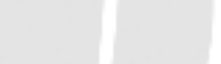 & .676 \\
\hline 29 & .227 & ( & .407 \\
\hline 30 & .423 & & .507 \\
\hline 32 & .331 & & .350 \\
\hline 34 & .463 & & .473 \\
\hline 36 & .516 & & .483 \\
\hline 38 & .535 & & .483 \\
\hline 39 & .406 & & .329 \\
\hline 14 & .185 & .185 & .618 \\
\hline 1 & & .233 & .494 \\
\hline 3 & & .251 & .569 \\
\hline 4 & & .216 & .490 \\
\hline 5 & & .203 & .456 \\
\hline 6 & & .403 & .613 \\
\hline 7 & & .171 & .494 \\
\hline 13 & & .413 & .714 \\
\hline 27 & & .257 & .493 \\
\hline 31 & & .308 & .646 \\
\hline
\end{tabular}


5.4 Estimación de la confiabilidad a partir de las puntuaciones derivadas de la aplicación de los ítems que conforman al IADM-K

Se llevó a cabo una estimación de la consistencia interna por medio del método clásico alfa de Cronbach y también por el alfa ordinal. El cálculo del error estándar de medida (EEM) se hizo a partir de los valores alfa ordinales obtenidos para las puntuaciones derivadas del factor G del IADM-K, así como del F1 y F2. Tanto los valores alfa de Cronbach como alfa ordinales obtenidos superan el criterio de .70 establecido por Nunnally y Bernstein (1995). Estos datos aparecen resumidos en la tabla 5.6.

Tabla 5.6

Alfa de Cronbach, alfa ordinal y EEM para las puntuaciones derivadas del factor $\mathrm{G}$ y de los factores de primer orden

\begin{tabular}{l|ccc}
\hline & $\boldsymbol{\alpha}$ de Cronbach & $\boldsymbol{\alpha}$ ordinal & EEM \\
\hline G (30 ítems) & .92 & .97 & 4.87 \\
F1 (21 ítems) & .91 & .93 & 6.11 \\
F2 (10 ítems) & .81 & .92 & 3.01 \\
\hline
\end{tabular}

Se calculó el alfa de Cronbach y alfa ordinal y el EEM para el grupo de varones $(n=337)$, obteniéndose un valor superior al criterio de .70 para todos los factores.

Tabla 5.7

Alfa de Cronbach, alfa ordinal y EEM para las puntuaciones derivadas del factor G y de los factores de primer orden para el grupo de hombres

\begin{tabular}{l|ccc}
\hline & a de Cronbach & $\boldsymbol{\alpha}$ ordinal & EEM \\
\hline G (30 ítems) & .91 & .97 & 4.60 \\
F1 (21 ítems) & .89 & .92 & 6.03 \\
F2 (10 ítems) & .83 & .92 & 2.95 \\
\hline Nota: $n=337$.
\end{tabular}


Adicionalmente, se reporta el alfa de Cronbach, el alfa ordinal y el EEM para el grupo de mujeres $(n=113)$, obteniéndose una consistencia interna superior al criterio de .70 para todos los factores. Para este grupo, fue necesario eliminar el ítem 29 perteneciente a F1 pues su carga factorial no superaba el criterio de 30 (Wolff y Preising, 2005) en ninguno de los factores de primer orden u orden superior.

\section{Tabla 5.8}

Alfa ordinal y EEM para las puntuaciones derivadas del factor $\mathrm{G}$ y de los factores de primer orden para el grupo de mujeres

\begin{tabular}{l|ccc}
\hline & $\boldsymbol{\alpha}$ de Cronbach & $\boldsymbol{\alpha}$ ordinal & EEM \\
\hline G (30 ítems) & .92 & .98 & 4.35 \\
F1 (20 ítems) & .91 & .91 & 6.28 \\
F2 (10 ítems) & .80 & .91 & 3.15 \\
\hline
\end{tabular}

Nota: $n=113$. Este cálculo excluyó el ítem 29 en F1.

\subsection{Evidencias de validez vinculadas a la relación con otras variables}

Se llevó a cabo una prueba Shapiro-Wilk de bondad de ajuste a la curva normal para cada una de las puntuaciones derivadas de la aplicación del IADM-K (considerando solo los ítems de la estructura final), el IDARE Rasgo y el IDARE Estado y el IAB. Solo el puntaje del IADM-K presentó evidencias empíricas insuficientes para rechazar la hipótesis nula, por lo que se asume que los datos provienen de una población en la cual se distribuyen normalmente, $D(450)=.03, p=$ .20 .

Tabla 5.9

Prueba Shapiro-Wilk de bondad de ajuste a la curva normal para el IADM-K, IDARE Estado, IDARE Rasgo y IAB

\begin{tabular}{l|ccc}
\hline \multicolumn{1}{c|}{ Pruebas } & $\boldsymbol{D}$ & $\boldsymbol{g l}$ & $\boldsymbol{p}$ \\
\hline IADM-K & .03 & 450 & .20 \\
IDARE Estado & .06 & 450 & $<.001^{* * *}$ \\
IDARE Rasgo & .05 & 450 & $.02 *$ \\
IAB & .09 & 450 & $<.001^{* * *}$ \\
\hline
\end{tabular}

Nota: $N=450$.

$* p<.05 . * * * p<.001$. 
A pesar de que las puntuaciones del IDARE y el IAB no presentaron evidencias de provenir de una población con distribución normal, es posible asumir su proximidad a una distribución normal, de acuerdo al teorema del límite central (Field, 2009). Al tener una muestra de 455 observaciones, es posible afirmar que las medias muestrales de las puntuaciones obtenidas a partir del IDARE y el IAB tenderán a aproximarse a una distribución normal. Esta tendencia a la normalidad puede apreciarse al apreciar los histogramas de las figuras 5.1, 5.2 y 5.3.

Figura 5.1

Histograma de las puntuaciones del IDARE-Estado

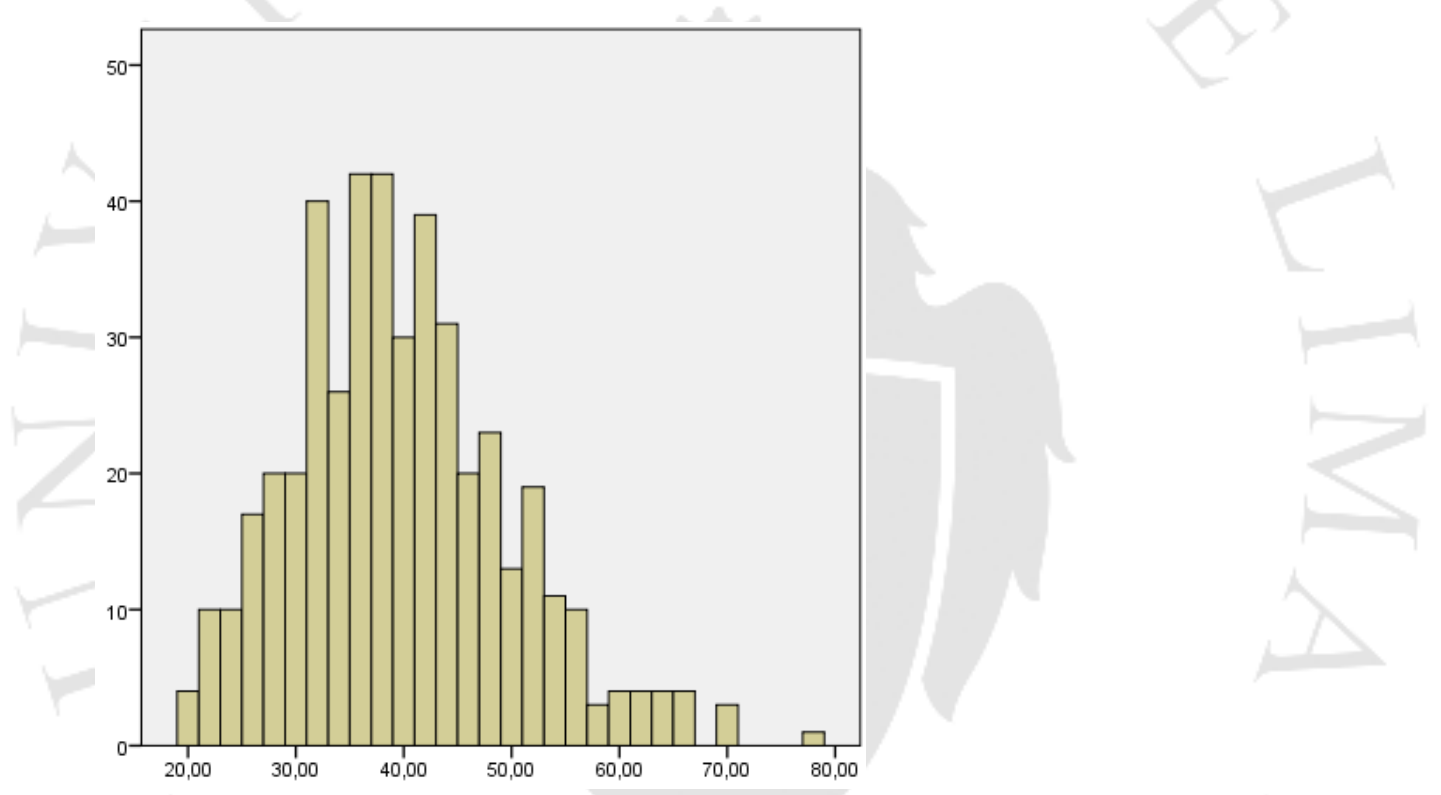

Nota: $N=450$. 
Figura 5.2

Histograma de las puntuaciones del IADRE-Rasgo

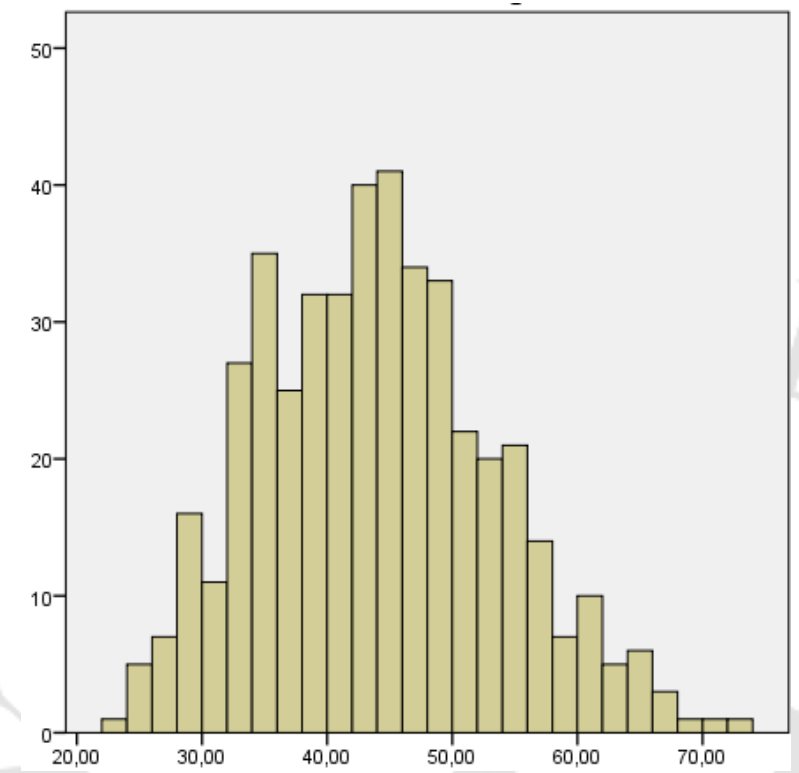

Nota: $N=450$.

Figura 5.3

Histograma de las puntuaciones del IAB

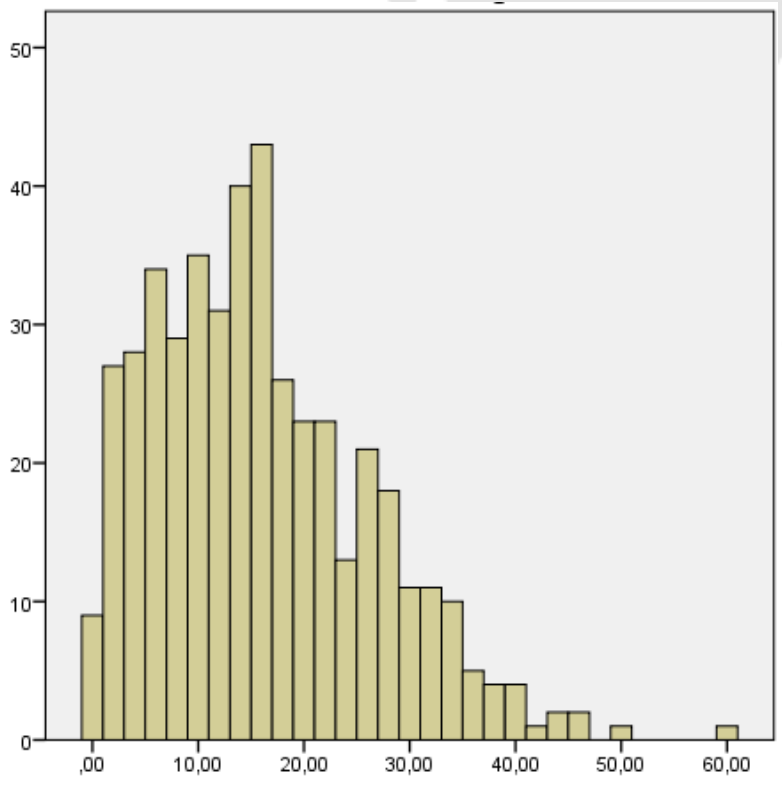

Nota: $N=452$. 
A fin de estimar las evidencias de validez vinculadas a la relación con otras variables, se llevó a cabo una correlación entre las puntuaciones totales del IADM-K, el IDARE Rasgo, el IDARE Estado y el IAB. Se encontraron evidencias positivas entre el puntaje del IADM-K y las otras pruebas empleadas para medir ansiedad a un nivel $p<.001$. El nivel de correlación más alto se presentó entre el IADM-K y el IDARE Rasgo, $r=.70$; mientras que el nivel de correlación más bajo se presentó entre el IDARE Estado y el IAB, $r=.53$. Tomando al coeficiente de correlación $r$ como estimador del tamaño del efecto (Ferguson, 2009; Field, 2009) puede reportarse un efecto moderado entre el IADM-K y el IDARE Estado; un efecto grande entre el IADM-K y el IDARE rasgo y un efecto igualmente grande entre el IADM-K y el IAB (Ellis, 2010). La potencia estadística obtenida superó en todos los casos al criterio de .80 (Cohen. 1992).

\section{Tabla 5.10}

Matriz de correlación entre los puntajes del IADM-K, IDARE Estado, IDARE Rasgo y el IAB

\begin{tabular}{l|cccc} 
& IADM-K & IDARE Estado & IDARE Rasgo & IAB \\
\hline IADM-K & - & $.48^{* * *}$ & $.70^{* * *}$ & $.57^{* * * *}$ \\
IDARE Estado & - & $.67^{* * *}$ & $.53^{* * * *}$ \\
IDARE Rasgo & & - & $.61^{* * *}$ \\
IAB & & & - \\
\hline
\end{tabular}

Nota: IADM-K, $N=455$; IDARE Estado y IAB, $N=452$; IDARE Rasgo, $N=450$.

$* * * p<.001$.

\subsection{Elaboración de baremos}

El análisis descriptivo del puntaje total del IADM-K con su estructura factorial de segundo orden presentó una media de 71.52 y una desviación estándar de $29.12(N=455)$. Asimismo, a partir de la prueba de normalidad Shapiro-Wilk se reportaron evidencias suficientes para asumir una distribución normal de las puntuaciones a nivel poblacional, $D(455)=.03, p=.19$. Se llevó a cabo la elaboración de los percentiles globales para las puntuaciones obtenidas a partir de la aplicación del IADM-K en las tres instituciones. 


\section{Tabla 5.11}

Percentiles globales para las puntuaciones obtenidas a partir del IADM-K

\begin{tabular}{c|c}
\hline Percentil & Puntaje \\
\hline 99 & 137 \\
95 & 122 \\
90 & 110 \\
85 & 101 \\
80 & 96 \\
75 & 90 \\
70 & 87 \\
65 & 82 \\
60 & 79 \\
55 & 75 \\
50 & 72 \\
45 & 70 \\
40 & 65 \\
35 & 61 \\
30 & 56 \\
25 & 52 \\
20 & 45 \\
15 & 39 \\
10 & 34 \\
5 & 24 \\
\hline
\end{tabular}

Nota: $N=455$.

El análisis descriptivo del puntaje total de "ansiedad ante el desempeño musical" (F1) presentó una media de 52.12 y una desviación estándar de $22.29(N=$ 455). La prueba de normalidad Shapiro-Wilk permitió asumir que existen evidencias empíricas suficientes para afirmar que las puntuaciones derivadas del F1 provienen de una población normal, $D(455)=.99, p=.64$. Se llevó a cabo la elaboración de los percentiles globales para las puntuaciones obtenidas a partir de la aplicación del F1 en las tres instituciones. 


\section{Tabla 5.12}

Percentiles globales para las puntuaciones obtenidas a partir del F1 (ansiedad ante el desempeño musical)

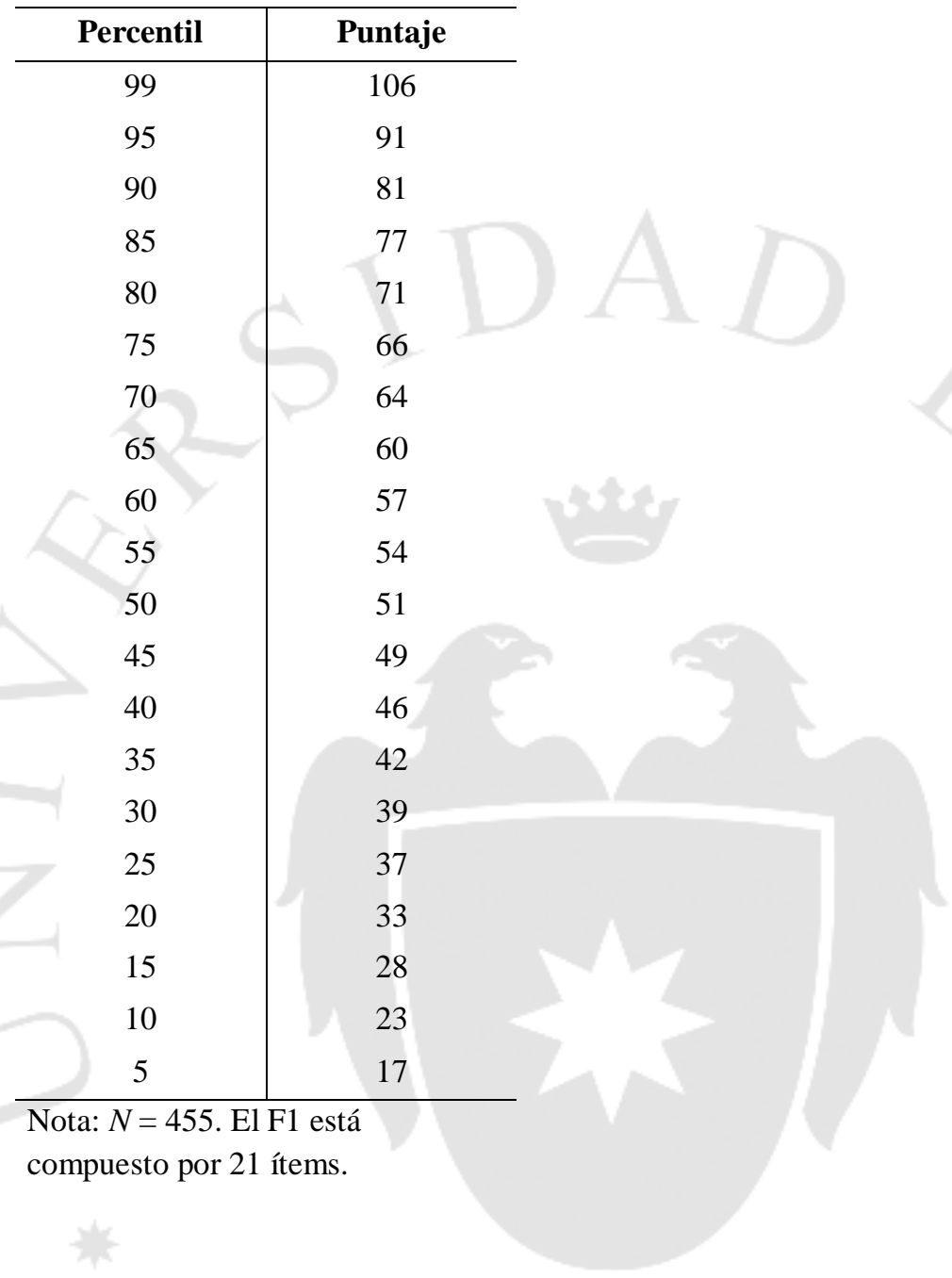

También se reportó el análisis descriptivo del puntaje total de "componentes depresivos" (F2). Este presentó una media de 20.85 y una desviación estándar de $10.73(N=455)$. La prueba de normalidad Shapiro-Wilk determinó que no existen evidencias empíricas suficientes para asumir una distribución normal de las puntuaciones de F2 a nivel poblacional $D(455)=.98, p<.000$. No obstante, es posible asumir su proximidad a una distribución normal, de acuerdo al teorema del límite central (Field, 2009). Se llevó a cabo la elaboración de los percentiles globales para las puntuaciones obtenidas a partir de la aplicación del F2 en las tres instituciones. 


\section{Tabla 5.13}

Percentiles globales para las puntuaciones obtenidas a partir del F2 (componentes depresivos)

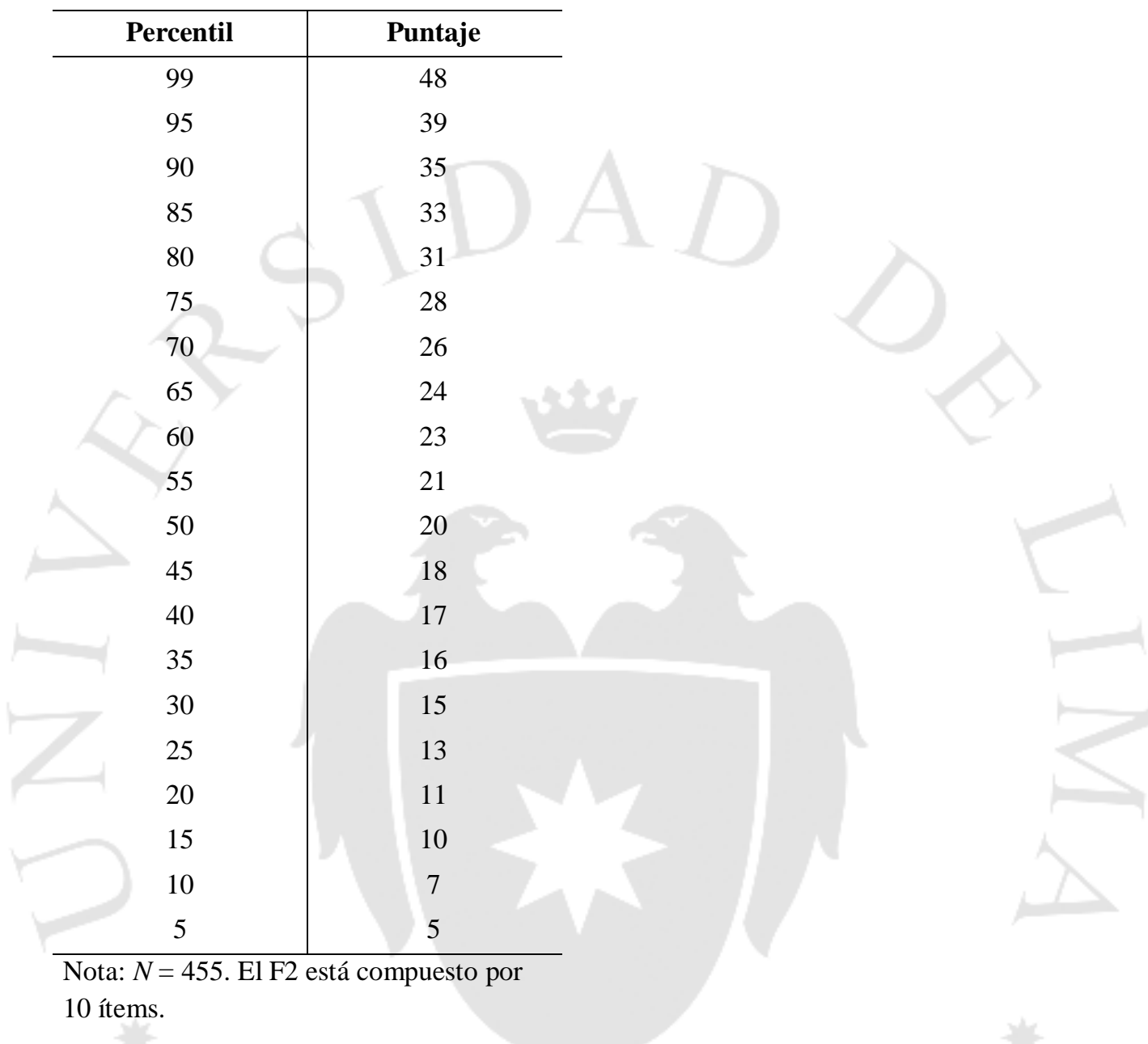

A fin de determinar la pertinencia de elaborar baremos de acuerdo a la institución educativa de procedencia, se llevó a cabo un análisis de varianza entre las tres instituciones educativas. Sin embargo, primero se reportan los resultados de la prueba Shapiro-Wilk de bondad de ajuste a la curva normal. A un nivel de significancia $p<.05$, las puntuaciones del IADM-K obtenidas en cada institución presentaron evidencias de provenir de una población con distribución normal. 


\section{Tabla 5.14}

Estadísticos descriptivos y prueba Shapiro-Wilk de bondad de ajuste a la curva normal para las instituciones educativas privadas A y B; y para la institución educativa estatal

\begin{tabular}{l|cccccc}
\hline \multicolumn{1}{c|}{$\begin{array}{c}\text { Institución } \\
\text { Educativa }\end{array}$} & $\boldsymbol{M}$ & $\boldsymbol{D E}$ & $\boldsymbol{n}$ & $\boldsymbol{D}$ & $\boldsymbol{g l}$ & $\boldsymbol{p}$ \\
\hline Privada A & 71.34 & 30.18 & 230 & .99 & 230 & .14 \\
Privada B & 75.93 & 26.54 & 84 & .98 & 84 & .39 \\
Estatal & 69.19 & 29.31 & 141 & .99 & 141 & .30 \\
\hline
\end{tabular}

Nota: $N=455$. $* p<.05$.

Puesto que existen evidencias empíricas que señalan que las puntuaciones obtenidas en las tres instituciones provienen de una población con distribución normal, se procedió con un análisis de varianza, mostrando que no existen diferencias estadísticamente significativas en las puntuaciones promedio del IADM-K de acuerdo a la institución educativa de procedencia. El tamaño del efecto $\eta^{2}$ no alcanza el mínimo de .01 para considerar que existe una significancia práctica (Ellis, 2010). Finalmente, la potencia estadística lograda está muy por debajo de .80 (Cohen, 1992), con lo cual no sería posible detectar este tamaño del efecto (Field, 2009; Mayr, Erdfelder, Buchner y Faul, 2007), $F(2,452)=1.42, p=.24, \eta^{2}=.006,1-\beta=.05$.

Adicionalmente, se procedió con un análisis de varianza entre las tres instituciones educativas tanto para F1 como para F2. 
Tabla 5.15

Media y desviación estándar para F1 y F2 de acuerdo a la institución educativa de pertenencia

\begin{tabular}{l|ccccc}
\hline \multirow{2}{*}{$\begin{array}{c}\text { Institución } \\
\text { Educativa }\end{array}$} & $\boldsymbol{n}$ & \multicolumn{3}{c}{$\boldsymbol{M}$} & \multicolumn{2}{c}{$\boldsymbol{D E}$} \\
\cline { 2 - 6 } & & 51.35 & 21.32 & 22.68 & 10.46 \\
\hline Privada A & 230 & 56.06 & 21.35 & 19.74 & 10.13 \\
Privada B & 84 & 51.02 & 19.79 & 22.98 & 11.48 \\
Estatal & 141 & & &
\end{tabular}

Nota: $N=455$

El procedimiento no evidenció diferencias estadísticamente significativas en las puntuaciones promedio de los factores de primer orden de acuerdo a la institución educativa de procedencia; asimismo, el tamaño del efecto y la potencia estadística obtenidas fueron muy pequeñas (Cohen, 1992; Ellis, 2010; Ferguson, 2009). Por ello, no se consideró pertinente elaborar baremos de acuerdo a cada institución.

Tabla 5.16

Análisis de varianza, tamaño del efecto y potencia estadística de las puntuaciones obtenidas de F1 y F2 para las tres instituciones educativas

\begin{tabular}{l|cccccc}
\hline & $\boldsymbol{F}$ & $\boldsymbol{g l 1}$ & $\boldsymbol{g l 2}$ & $\boldsymbol{p}$ & $\boldsymbol{\eta 2}$ & $\mathbf{1 - \beta}$ \\
\hline F1 & 1.62 & 2 & 452 & .19 & .007 & .05 \\
$\mathrm{~F} 2$ & 0.99 & 2 & 452 & .37 & .004 & .05 \\
\hline$* p<.05$. & & & & & &
\end{tabular}

También, se evaluó la viabilidad de generar baremos de acuerdo al sexo de los participantes. Para ello, se llevó a cabo una prueba de bondad de ajuste a la curva normal Shapiro-Wilk a un nivel de significancia $p<.05$. A partir de las evidencias empíricas, puede sostenerse que las puntuaciones obtenidas en el IADM-K tanto para el grupo de mujeres, $D(113)=.99, p=.78$, como para el grupo de hombres, $D(337)=$ $.99, p=.11$, provienen de una población con distribución normal.

Se procedió con una prueba $t$ de muestras independientes a fin de comparar las puntuaciones medias del grupo de mujeres y de hombres. Las varianzas del grupo de 
mujeres $(n=113, M=82.53, D E=31.14)$ y del grupo de hombres $(n=337, M=$ $67.57, D E=27.52)$ para las puntuaciones obtenidas en el IADM-K se asumen homogéneas a nivel de población, $F=2.71, p=.101$. Se reportaron diferencias estadísticamente significativas, un tamaño del efecto mediano (Ellis, 2010) y una potencia estadística mayor a .80 (Cohen, 1992) con lo cual es posible afirmar que sí sería posible detectar un tamaño del efecto (Field, 2009; Mayr et al., 2007) en el puntaje del IADM-K de acuerdo al sexo $t(448)=-4.83, p<.001, d=.51,1-\beta=.99$. Por ello, se consideró pertinente elaborar baremos de acuerdo al sexo.

Tabla 5.17

Percentiles de acuerdo al sexo de los participantes para las puntuaciones obtenidas a partir del IADM-K

\begin{tabular}{c|cc}
\hline \multirow{2}{*}{ Percentil } & Hombres & Mujeres \\
\cline { 2 - 3 } & $(\boldsymbol{n}=\mathbf{3 3 7})$ & $(\boldsymbol{n}=\mathbf{1 1 3})$ \\
\hline 99 & 128 & 152 \\
95 & 113 & 132 \\
90 & 103 & 122 \\
85 & 97 & 119 \\
80 & 90 & 111 \\
75 & 87 & 102 \\
70 & 81 & 101 \\
65 & 79 & 94 \\
60 & 75 & 89 \\
55 & 72 & 86 \\
50 & 70 & 82 \\
45 & 66 & 77 \\
40 & 63 & 74 \\
35 & 57 & 70 \\
30 & 54 & 65 \\
25 & 47 & 59 \\
20 & 41 & 55 \\
15 & 36 & 49 \\
10 & 31 & 35 \\
5 & 19 & \\
\hline
\end{tabular}

Nota: $N=450$.

Adicionalmente, se evaluó la pertinencia de generar baremos para el factor “Ansiedad ante el desempeño musical" (F1) de acuerdo al sexo de los participantes. La prueba de bondad de ajuste a la curva normal a un nivel de significancia $p<.05$ evidenció que las puntuaciones obtenidas en el F1 tanto para el grupo de mujeres, 
$D(113)=.99, p=.33$, como para el grupo de hombres, $D(337)=.99, p=.19$, provienen de una población con distribución normal.

Se procedió con una prueba $t$ de muestras independientes a fin de comparar las puntuaciones medias del grupo de mujeres y de hombres. Las varianzas del grupo de mujeres $(n=113, M=61.92, D E=24.22)$ y del grupo de hombres $(n=337, M=$ $48.70, D E=20.70$ ) para las puntuaciones obtenidas en el F1 se asumen homogéneas a nivel de población, $F=5.94, p=.02$. Se reportaron diferencias estadísticamente significativas, un tamaño del efecto mediano (Ellis, 2010) y una potencia estadística mayor a .80 (Cohen, 1992) con lo cual es posible afirmar que sí sería posible detectar este tamaño del efecto (Field, 2009; Mayr et al., 2007) en el puntaje del F1 de acuerdo al sexo $t(448)=-5.62, p<.001, d=.59,1-\beta=.99$. Por ello, se consideró pertinente elaborar baremos de acuerdo a esta variable para el F1. 


\section{Tabla 5.18}

Percentiles de acuerdo al sexo de los participantes para las puntuaciones obtenidas a partir del F1 (ansiedad ante el desempeño musical)

\begin{tabular}{c|cc}
\hline \multirow{2}{*}{ Percentil } & Hombres & Mujeres \\
\cline { 2 - 3 } & $(\boldsymbol{n}=\mathbf{3 3 7})$ & $(\boldsymbol{n}=\mathbf{1 1 3})$ \\
\hline 99 & 94 & 107 \\
95 & 83 & 102 \\
90 & 77 & 94 \\
85 & 71 & 88 \\
80 & 66 & 83 \\
75 & 63 & 79 \\
70 & 59 & 78 \\
65 & 56 & 74 \\
60 & 54 & 67 \\
55 & 51 & 66 \\
50 & 49 & 64 \\
45 & 47 & 59 \\
40 & 43 & 56 \\
35 & 40 & 51 \\
30 & 38 & 48 \\
25 & 36 & 43 \\
20 & 30 & 38 \\
15 & 26 & 33 \\
10 & 21 & 29 \\
5 & 15 & 26 \\
\hline
\end{tabular}

Nota: $N=450$. El F1 está compuesto por 21 ítems.

El mismo procedimiento se siguió para el factor "componentes depresivos" (F2) de acuerdo al sexo de los participantes. La prueba de bondad de ajuste a la curva normal a un nivel de significancia $p<.05$ evidenció que las puntuaciones obtenidas en el F2 tanto para el grupo de mujeres, $D(113)=.97, p=.13$, como para el grupo de hombres, $D(337)=.98, p<.000$, no provienen de una población con distribución normal; sin embargo, dado el teorema del límite central (Field, 2009), así como la robustez de la prueba $t$ ante la violación de la normalidad (Edgell y Noon, 1984), se asumió que las puntuaciones de F2 provienen de una población con distribución normal.

Se procedió con una prueba $t$ de muestras independientes a fin de comparar las puntuaciones medias del grupo de mujeres y de hombres. Las varianzas del grupo de 
mujeres $(n=113, M=22.23, D E=10.76)$ y del grupo de hombres $(n=337, M=$ $20.27, D E=10.69$ ) para las puntuaciones obtenidas en el F2 se asumen homogéneas a nivel de población, $F=.01, p=.92$. No se reportaron diferencias estadísticamente significativas en el puntaje del F2 de acuerdo al sexo $t(448)=-1.68, p=.09, d=.18$, $1-\beta=.50$; asimismo, el tamaño del efecto reportado no alcanzó el mínimo de .20 para representar un efecto práctico a nivel poblacional (Ellis, 2010) y la potencia estadística obtenida no permite identificar este efecto. Por ello, no se consideró pertinente elaborar baremos de acuerdo al sexo para el F2. 


\section{CAPÍTULO VI: DISCUSIÓN}

Este capítulo se dividirá en dos secciones. La primera implicará una discusión sobre la adaptación del instrumento y una interpretación de las propiedades psicométricas elaboradas en la sección de Resultados. La segunda identificará los criterios con los cuales cumple el análisis psicométrico de esta investigación, de acuerdo a los Estándares para la Evaluación Educativa y Psicológica (American Educational Research Association [AERA], American Psychological Association [APA] y National Council on Measurement in Education [NCME], 2014).

\subsection{Adaptación y propiedades psicométricas}

El proceso de contratraducción empleado para la adaptación del IADM-K respondió al procedimiento establecido por el AGREE II. Sin embargo, es importante señalar que la traducción del término performance pudo interferir con una traducción adecuada del instrumento.

Tal y como se señaló en la sección de Resultados, la palabra performance puede adoptar distintos usos y significados en español. A pesar de que se buscó emplear la traducción más acertada de acuerdo al contexto peruano, otras formas de traducir la palabra son posibles. No obstante, luego del AFESO, se eliminaron 10 de los 40 ítems que inicialmente conformaban la prueba, de los cuales cinco contenían la palabra performance. Sin embargo, de los 10 ítems eliminados, el ítem 35 y el ítem 37 , correspondientes a la confianza en la memoria, fueron retirados de la prueba debido a que teóricamente no pertenecían a la dimensión de preocupaciones asociadas a próximas presentaciones y no por tratarse de un error de traducción.

Más aún, de los 40 ítems que conformaban la primera versión del instrumento, 21 de ellos empleaban la palabra performance, de los cuales se eliminaron 3 ítems (los dos restantes son los ítems de confianza en la memoria). Es decir, proporcionalmente, al solo eliminar 3 de 21 ítems conteniendo alguna traducción de performance, se afirma que la traducción de este término no ha interferido significativamente con el análisis psicométrico del instrumento. 
Asimismo, la autora de la prueba en inglés consideró al método de traducción escogido como riguroso, con lo cual reconoció a la versión en español aquí presentada como la autorizada en español (D. T. Kenny, comunicación personal, 8 y 16 de octubre, 2013). Por ello, puede afirmarse que se ha elaborado un adecuado proceso de adaptación lingüística del IADM-K.

Se reportaron favorables evidencias de validez vinculadas al contenido del IADM-K de acuerdo a la estructura teórica presentada por Kenny (2009), quien se basó en la teoría de la triple vulnerabilidad de Barlow (2000). Es decir, los ítems que constituyen al IADM-K y los constructos a los cuales responden son congruentes con los propósitos de la prueba (Kenny, 2009; Sireci y Faulkner-Bond, 2014). No obstante, estas evidencias no son convergentes con las evidencias basadas en la estructura interna aportadas por el AFE aquí reportado. De hecho, se evidenció la existencia de 4 factores donde el factor 1 representa a las preocupaciones asociadas a próximas presentaciones, el factor 2 representa a las vulnerabilidades psicológicas, particularmente a una tendencia a la depresión, el factor 3 representa a la confianza en la memoria durante la ejecución musical y el factor 4 a la relación temprana con los padres. Más aún, se esperaba que los ítems del factor 3, confianza en la memoria, se encuentren comprendidos en el factor 1, preocupaciones asociadas a próximas presentaciones.

El AFE con rotación ortogonal de tipo varimax llevado a cabo por Kenny (2009) empleó un tamaño de muestra muy pequeño $(N=151)$ y por ello insuficiente para llevar a cabo un AFE satisfactorio. La diferencia en el tamaño de muestra puede explicar las estructuras disímiles entre Kenny (2009) y la presente investigación. En lugar de suscribir una estructura conformada por "contexto de relaciones tempranas", "vulnerabilidades psicológicas" y "preocupaciones asociadas a próximas presentaciones", el AFESO propone una estructura unidimensional de segundo orden basada en el modelo tripartito de la ansiedad y depresión, el cual cuenta con un respaldo empírico mayor a dos décadas (Anderson y Hope, 2008; Brown, Chorpita y Barlow, 1998; Clark y Watson, 1991).

De acuerdo a este modelo teórico, la recurrente correlación entre los desórdenes de ansiedad y depresión (y el tratamiento farmacológico y psicoterapéutico muy similar para ambos trastornos) se debe a un componente heredable de orden superior no específico común a ambos que se ha denominado como afectividad negativa ([AN], Clark y Watson, 1991). Este factor de orden 
superior es definido como el grado en el cual un individuo percibe malestar o displacer acompañado de un alto distrés, en lugar de paz y comprende estados afectivos tales como malestar, enojo, culpa, miedo, etc. (Anderson y Hope, 2008; Clark y Watson, 1991).

Otro de los postulados teóricos del modelo tripartito plantea que si bien la AN es común tanto a la ansiedad como a la depresión, esta última puede distinguirse mejor de la primera por una baja afectividad positiva (AP), un segundo factor de orden superior. La AP se define como el grado de entusiasmo de una persona por la vida y comprende estados afectivos tales como energía y placer, actividad, deslumbre, interés, entusiasmo, etc. (Clark y Watson, 1991). Mientras que una alta hiperactividad fisiológica (HF) subyace y caracteriza a los desórdenes de ansiedad. Es decir, mientras que la AN es común a la ansiedad y depresión, la AP es específica únicamente a la depresión y la HF subyace específicamente a los desórdenes de ansiedad.

La revisión estructural de Brown et al. (1998) por medio de un análisis factorial confirmatorio aun suscribe la existencia de un modelo tripartito donde la depresión y la ansiedad están vinculadas por la AN, pero plantea que la HF distingue únicamente al trastorno de pánico con agorafobia y no a todos los desórdenes de ansiedad como afirma Clark y Watson (1991). Es decir, cada desorden de ansiedad contiene un componente específico y único que los diferencia del resto de trastornos y que deben ser identificados. Esta diferencia en la estructura del modelo permite comprender por qué a pesar de que la ansiedad y la depresión compartan un factor común general de orden superior, los trastornos de ansiedad se diferencian tanto uno del otro en su sintomatología (Barlow, 2000).

Actualmente, el modelo tripartito ha experimentado algunas variantes con respecto a su planteamiento original (Clark y Watson, 1991). En lugar de proponer a la HF como un componente subyacente a todos los desórdenes de ansiedad, se le considera como un factor de orden inferior subyacente solo al trastorno de pánico; asimismo, la AN, si bien está vinculada a los diversos trastornos de ansiedad, guarda una relación más fuerte con el desorden de ansiedad generalizada en comparación con otros desórdenes. Es decir, el modelo tripartito no funciona de manera similar y homogénea entre todos los desórdenes de ansiedad y depresión; por el contrario, hace falta delimitar claramente la dirección en las relaciones, el grado de asociación 
específico a cada tipo de trastorno de ansiedad y los componentes específicos a cada uno (Anderson y Hope, 2008; Mineka, Watson y Clark, 1998).

Para Barlow (2000), la diferencia entre los distintos tipos de trastornos de ansiedad estará determinada por el estímulo que desencadene la AN o, tal y como él la define, ansiedad aprehensiva. Barlow (2000) propone el modelo de triple vulnerabilidad para explicar el origen de los trastornos ansiosos o depresivos; sin embargo, el AFESO aquí elaborado descarta este planteamiento teórico. Por ello, el IADM-K se sostiene bajo el modelo tripartito de ansiedad y depresión. Se propone llamar al factor $\mathrm{G}$ como afectividad negativa ante el desempeño musical, la cual subyace tanto a la ansiedad ante el desempeño musical (F1) como al componente depresivo (F2). Las puntuaciones derivadas de esta estructura jerárquica cuentan con niveles altos de confiabilidad, haya sido calculada por medio del alfa de Cronbach o por el alfa ordinal. Los valores obtenidos para este último fueron de .97 para G; y valores alfa ordinales de .93 y .92 para F1 y F2 respectivamente. Puesto que el instrumento cuenta con un formato de respuesta policórica (escala Likert), es necesario interpretar la confiabilidad de las puntuaciones a partir del alfa ordinal (Bonanomi et al., 2013; Gadermann et al., 2012; Zumbo et al., 2007). Dados los niveles de confiabilidad de cada factor y el contenido diferenciado de cada uno, podría plantearse la posibilidad de recoger información sobre alguno de los factores de primer orden, de ambos o de los tres factores, de acuerdo a los requerimientos de la persona evaluadora. Sin embargo, para afirmar la existencia de evidencias de validez discriminante, será necesario complementar el análisis psicométrico del IADM-K junto con otras medidas que permitan explorar si acaso F1 y F2 pueden medirse independientemente. Tomando en cuenta estos resultados, se plantea una nueva propuesta de prueba llamada Inventario de Afectividad Negativa Ante el Desempeño (IANDM, Anexo D). Los 30 ítems que conforman este nuevo modelo fueron ordenados al azar, de acuerdo a un programa en línea generador de listas al azar (Haahr, 1998).

Basándose en Clark y Watson (1991), la afectividad negativa ante el desempeño musical puede interpretarse como el grado en el cual un individuo percibe malestar o displacer ante un contexto de ejecución musical próximo, presente o futuro acompañado de un alto distrés, en lugar de paz, y comprende estados afectivos tales como malestar, culpa, miedo, etc. en torno a su desempeño musical. 
A partir de Kenny (2011), es posible redefinir el factor de ADM como un conjunto de componentes fisiológicos (p.e. boca seca, náuseas, falta de sueño, sensaciones de pánico, etc.), cognitivos (preocupación por la evaluación de la audiencia, incertidumbre ante las consecuencias de la ejecución, pensamientos intrusivos, distracción de la atención y concentración, etc.) y conductuales (dejar pasar oportunidades de presentarse, tensión muscular, temblores, etc.) que pueden presentarse sobre todo en contextos de evaluación y en los cuales se teme fracasar, con el posible riesgo de interferir con la calidad de la interpretación y el disfrute de la misma.

Mientras que el factor depresivo puede definirse como componentes afectivos vinculados a una falta de control y preocupación general en la vida del individuo, acompañado de una valía personal disminuida, recuerdos tristes de la infancia y con pocas expectativas futuras.

Las correlaciones estadísticamente significativas a un nivel $p<.001$, los tamaños del efecto moderados a altos y los altos niveles de potencia estadística entre el puntaje total del IANDM y el IDARE Rasgo, el IDARE Estado y el IAB permiten afirmar que existen evidencias de validez vinculadas a la relación con otras puntuaciones que miden ansiedad. Es decir, las otras pruebas de ansiedad empleadas en esta investigación guardan relación con la AN.

Con respecto a la elaboración de baremos, esta prueba permite identificar niveles de afectividad negativa ante el desempeño musical para toda la muestra del estudio, independientemente de la institución educativa, del género musical de especialidad o de la especialidad de estudios cursada. Esto está sustentado en los análisis estadísticos presentados en la sección de Resultados. Asimismo, tal y como se encuentra en la literatura, (APA, 2010a; Barlow, 2000) se justificó la elaboración de baremos de acuerdo al sexo, pues se presentaron diferencias estadísticamente significativas entre hombres y mujeres así como también un tamaño del efecto mediano (Ellis, 2010) y una potencia estadística mayor a .80 (Cohen, 1992). De esta manera, esta investigación aporta baremos generales y de acuerdo al sexo.

A raíz de las evidencias empíricas reunidas, es posible afirmar que las interpretaciones y decisiones que se tomen a partir de la aplicación del IANDM son válidas y confiables bajo una perspectiva tripartita de la ansiedad y depresión en estudiantes de música de nivel profesional de Lima Metropolitana. Por ello, los usos de las puntuaciones del INADM deberán limitarse hacia esta población y con el 
propósito de identificar niveles de afectividad negativa ante el desempeño musical. Todo uso distinto a este deberá atravesar un nuevo proceso de estimación de las propiedades psicométricas pertinentes. A esta discusión teórica se añadirá una en torno a los estándares con los cuales cumple esta adaptación y estimación de propiedades psicométricas.

\subsection{Estándares para la Evaluación Educativa y Psicológica (AERA, APA y NCME, 2014)}

En esta sección se enlistarán únicamente los estándares con los cuales cumple la presente investigación. Estos corresponden a los criterios de validez, confiabilidad, diseño y desarrollo de la prueba, elaboración de normas y documentación adjunta de las pruebas. Se presentará el estándar y a continuación una justificación de porqué esta investigación cumple con aquel.

\subsubsection{Estándares para la validez}

1.0. Una articulación clara de cada interpretación propuesta de las puntuaciones de la prueba para un uso específico debe ser presentado y evidencias de validez apropiadas para cada interpretación que se desee formular deben ser provistas (p. 23): El IANDM pretende medir afectividad negativa ante el desempeño musical, la cual subyace tanto a la ADM como a componentes depresivos. Esta prueba está diseñada para utilizarse en estudiantes instrumentistas de música de nivel profesional de Lima Metropolitana, con el propósito de plantear estrategias de intervención futuras y acordes a cada caso.

1.1. El creador de la prueba debe especificar la manera en la cual los puntajes de esta se interpretarán y utilizarán. La población para la cual se destinará la prueba debe delimitarse claramente y el constructo o constructos que la prueba pretender evaluar deben describirse claramente (p. 23): Los puntajes derivados de la aplicación del IANDM permitirán medir el nivel de afectividad negativa ante el desempeño musical en estudiantes de música de nivel profesional de Lima Metropolitana. Tal y como se ha definido en la sección anterior de la Discusión, cada componente de la prueba, los dos factores de primer orden y el factor de orden superior, ha sido definido. 
1.6. Cuando se recomienda el uso de una prueba para producir beneficios indirectos, además de la utilidad informada de las interpretaciones de los puntajes, se debe argumentar esta anticipación de beneficios indirectos con evidencias empíricas y también señalando efectos no esperados o contradictorios (p. 24): El IANDM puede ser empleado a futuro para establecer mediciones pre y post test de programas que tengan como objetivo disminuir los niveles de ADM y, de manera más global, de afectividad negativa ante el desempeño musical. En la sección de Antecedentes se han reportado dos grandes tipos de intervenciones para disminuir la ADM: las técnicas de relajación (Kim, 2008; Mohamed y Parish, 1998; Su et al., 2010) y las técnicas cognitivo-conductuales y programas de prevención en edades de formación (Nagel, 2010). Independientemente de la aproximación que se escoja, es necesario contar con instrumentos psicológicos que permitan cuantificar el impacto de estos programas sobre la afectividad negativa ante el desempeño musical.

1.8. La composición de cualquier muestra de evaluados a partir de los cuales se obtienen las evidencias de validez deben describirse de la manera más detallada posible, incluyendo datos socioeconómicos relevantes y características de desarrollo (p. 25): Tal y como se especificó en la sección de Método, los participantes fueron estudiantes de música de nivel profesional que tenían como mínimo de edad 18 años y cuya especialidad es instrumental, es decir, se excluyó a los compositores, productores musicales, musicólogos y pedagogos musicales. Una limitación a tomarse en cuenta es que la muestra se reunió mediante un muestreo no probabilístico y accidental. Se detallaron los datos poblacionales de los estudiantes profesionales de música en Lima Metropolitana. Con respecto a la muestra escogida, esta estuvo conformada por 455 estudiantes (hombres $=337$, mujeres $=113$ ) de tres instituciones de formación musical superior: institución privada A, $n=230$; institución privada B, $n=84$; e institución estatal A, $n=141$.

1.9. Especificar el proceso de selección de los expertos así como el medio por el cual se pueden registrar sus juicios (matriz de jueces). Presentar sus calificaciones y experiencia. Reportar entrenamientos e instrucciones provistas y reportar el grado de acuerdo (p. 25): Se empleó la calificación de ocho jueces 
los cuales eran psicólogos clínicos, psicólogos expertos en psicometría y estadística y un músico profesional. A partir de sus calificaciones, se estimó el coeficiente V de Aiken, superando un grado de acuerdo de .70 para 39 de los 40 ítems. Los jueces completaron la matriz a partir de las indicaciones especificadas en este documento (consultar anexo F).

1.10. Cuando las evidencias de validez incluyen análisis estadísticos de los resultados de la prueba junto con los datos de otras variables, las condiciones en las que se recolectó la información debe describirse en detalle (p. 26): el proceso de recolección de datos ha sido especificado de acuerdo a estos lineamientos y se pueden consultar en la sección de Método, particularmente en la subsección de Procedimiento.

1.13. Si la argumentación para las interpretaciones de las puntuaciones de una prueba para un uso particular depende de la relación entre los ítems o entre partes del test, se debe reportar la estructura interna (p. 26): Tanto en la sección de Resultados como en la primera sección de la Discusión, se han presentado evidencias de unidimensionalidad y que permiten comprender a la ADM de manera más global que ateniéndose a un AFE de primer orden. Sin embargo, también se presentaron datos que permiten interpretar las puntuaciones desde los factores de primer orden.

1.16. Cuando se incluyen análisis empíricos de los puntajes de una prueba junto con datos de otras variables se debe especificar el razonamiento empleado para seleccionar estas otras variables. Reportar las especificaciones técnicas de las otras pruebas (p. 27): El IDARE y el IAB fueron empleados para explorar la convergencia en la medida de ansiedad con el IANDM. Ambas pruebas fueron escogidas por su extendido respaldo en la literatura, así como por presentar evidencias de validez y confiabilidad pertenecientes al contexto peruano y que han sido detalladas en la sección de Método. 


\subsubsection{Estándares para la confiabilidad}

2.0. Proveer evidencias de confiabilidad apropiadas para las interpretaciones de cada uso de las puntuaciones (p. 42): Se han reportado índices de confiabilidad elevados tanto para el factor $\mathrm{G}$ como para los factores de primer orden. Estos niveles altos son adecuados sobre todo porque se está midiendo un constructo que puede tener consecuencias clínicas.

2.3. Para cada puntaje total y subpuntaje, se deben reportar índices relevantes de confiabilidad (p. 43): Los niveles de confiabilidad para F1, F2 y G han sido debidamente reportados en la sección de Resultados.

2.5. La estimación de la confiabilidad debe ser consistente con la estructura de la prueba (p. 43): Guardando relación con la estructura factorial obtenida a partir del AFESO, se llevó a cabo una estimación de la confiabilidad para los dos factores de primer orden y el factor de segundo orden.

2.11. Reportar la confiabilidad estimada para cada subgrupo relevante para el cual se recomienda la prueba (p. 45): El nivel de confiabilidad estimado para el grupo de varones y mujeres se reporta en la sección de Resultados.

2.13. El EEM, tanto general y condicional (de ser reportado), debe proveerse en unidades para cada puntuación reportada (p. 45): Los EEM tanto para el puntaje de toda la muestra, como para el especificado de acuerdo al sexo se reportan en la sección de Resultados.

\subsubsection{Estándares para el diseño y desarrollo de la prueba}

4.0. Las pruebas deben desarrollarse de tal modo que sustenten la validez de las interpretaciones de las puntuaciones de una prueba para los usos propuestos. El elaborador de la prueba debe documentar los pasos tomados durante el diseño y el desarrollo del proceso (p. 86): Los pasos seguidos para adaptar y analizar las propiedades psicométricas del IADM-K están claramente documentadas tanto en la sección de Método, así como en la de Resultados. Asimismo, el Anexo B, C y D presentan la versión en inglés, la versión en español y la nueva propuesta 
de instrumento respectivamente, de tal manera que otra $\mathrm{u}$ otro investigador pueda comparar las versiones.

4.1. Especificar el propósito de la prueba, la definición del constructo, a quiénes está dirigida y las interpretaciones de sus usos (p. 85): Estos datos se encuentran detallados en la sección de Método, especificados en la ficha técnica del IADM-K; así como en la sección de Marco Teórico (para la definición original de ADM) y en la sección de Discusión (para la definición de afectividad negativa ante el desempeño musical).

4.2. La prueba debe especificar el contenido, la duración, el formato de los ítems, las propiedades psicométricas de los ítems y la prueba, y el ordenamiento de los ítems y secciones; así como procedimientos a usarse para su administración (p. 85): Las especificaciones requeridas se encuentran la ficha técnica del anexo D. Los ítems de la nueva propuesta de prueba fueron ordenados al azar mediante un programa computacional. La administración de la prueba corresponde al procedimiento especificado en la sección de Método.

4.10. Cuando se evalúan las propiedades psicométricas de los ítems, hay que especificar el modelo psicométrico del cual se parte. Describir la muestra empleada para estimar estas propiedades y debe ser de adecuado tamaño y diversidad (p. 89): El análisis psicométrico del IADM-K partió de la TCT. Asimismo, la muestra ha sido claramente descrita en la sección de Método, estimando el tamaño requerido de acuerdo al criterio 10k de Nunnally (1987). Por último, la prueba fue aplicada en tres escuelas de música distintas, con el propósito de ampliar la utilidad del instrumento.

4.15. Incluir las pautas de administración para que otros puedan replicar las condiciones en las cuales se obtuvieron los datos de confiabilidad, validez y normas (p. 90): El procedimiento seguido para aplicar las pruebas que permitieron estimar las propiedades de confiabilidad, validez y las normas están especificados en la sección de Método. Adicionalmente, las indicaciones, matrices de jueces y capacitaciones a los aplicadores colaboradores están comprendidos en los Anexos. 
4.17. Si la prueba o parte de esta se usa para investigar, se debe mostrar afirmaciones sobre ese fin en todos los materiales de administración e interpretación entregados al usuario de la prueba (p. 91): Durante la lectura del consentimiento informado, ubicado en el Anexo I, se especificó claramente el uso de los datos para un fin de investigación, se garantizó el anonimato de los participantes y se informó que los resultados se compartirían en contextos académicos.

\subsubsection{Estándares para la elaboración de normas}

5.8. Las normas deben referirse a poblaciones claramente descritas. Estas poblaciones deben incluir individuos o grupos con los cuales los evaluadores querrían comparar a sus examinados (p. 104): A partir de los análisis estadísticos presentados en la sección de Resultados (particularmente en la elaboración de baremos), se establecieron dos baremos: de acuerdo al puntaje total obtenido en la prueba y de acuerdo al sexo de los participantes. Otro tipo de baremos resultaron no ser necesarios (por ejemplo de acuerdo a la escuela de procedencia, de acuerdo al género musical o de acuerdo al instrumento) pues las pruebas estadísticas no presentaron diferencias estadísticamente significativas, así como tamaños del efecto y potencias estadísticas muy bajas.

\subsubsection{Estándares para la administración, puntuación, reporte e interpretación}

6.1. Los evaluadores deben seguir cuidadosamente los procedimientos estándar para administrar y puntuar especificados por el desarrollador de la prueba y otras instrucciones que dé (p. 114): Los evaluadores que colaboraron en el proceso de recojo de información fueron debidamente capacitados previamente a las fechas de aplicación. El formato utilizado se encuentra en el Anexo J.

6.4. El ambiente de evaluación debe ser cómodo y con distracciones mínimas para evitar varianza irrelevante al constructo (p. 116): La aplicación se llevó a cabo en los salones de clase de cada institución. El docente o la docente encargada del aula apoyó al proceso solicitando la colaboración de los estudiantes. 


\section{CONCLUSIONES}

- El IADM-K fue correctamente adaptado al contexto peruano mediante el método de contratraducción. Asimismo, la autora de la prueba original reconoció a la presente adaptación como la versión oficial en español.

- Se obtuvieron buenas evidencias de validez vinculadas al contenido mediante ocho jueces; sin embargo, el análisis de la estructura interna del instrumento reveló una estructura distinta a la calificada por los jueces.

- A partir del AFESO se obtuvo una estructura interna distinta a la planteada por Kenny (2009); diferenciándose principalmente en la naturaleza unidimensional de la prueba, lo cual llevó a elaborar una nueva propuesta de instrumento que mide afectividad negativa ante el desempeño musical, la cual subyace tanto a la ADM como a componentes depresivos. Sin embargo, es posible interpretar las puntuaciones tanto para F1 como para F2.

- La afectividad negativa ante el desempeño musical correlacionó significativamente con el IDARE y el IAB, reportando evidencias de validez vinculadas a la relación con otras variables.

- Se elaboraron baremos para los puntajes globales, construyendo un baremo para cada factor (de primer y segundo orden). Adicionalmente, se repitió este procedimiento pero con la muestra de sexo masculino, pues estadísticamente no se justificaba la construcción de baremos para las mujeres. La construcción de otros baremos de acuerdo a la institución educativa no se justificó estadísticamente.

- El planteamiento teórico seguido por Kenny (2009) para construir su escala fue distinto al encontrado en esta investigación. La nueva estructura factorial obtenida puede interpretarse mejor bajo el modelo tripartito de la ansiedad y depresión (Anderson y Hope, 2008; Brown, Chorpita y Barlow, 1998; Clark y Watson, 1991). 
- Se propuso una nueva prueba llamada Inventario de Afectividad Negativa Ante el Desempeño Musical (INADM) compuesta por 30 ítems.

- Tomando en cuenta los resultados obtenidos se afirma que existen evidencias de validez y confiabilidad para los usos e interpretaciones derivadas de la aplicación del INADM en estudiantes de música de nivel profesional de Lima Metropolitana. Todo uso o decisión nueva que quiera tomarse a partir de la aplicación de este instrumento y con otras poblaciones deberá estar sujeto a una nueva estimación de sus propiedades psicométricas. 


\section{RECOMENDACIONES}

- A fin de reunir mayores evidencias de validez que soporten las interpretaciones y decisiones tomadas a partir de la aplicación del INADM deberán incluir evidencias discriminantes.

- Se recomienda repetir un proceso de criterio de jueces con la nueva estructura factorial, de tal manera que las evidencias de validez vinculadas al contenido puedan sumarse a las presentadas en esta investigación.

- Se recomienda añadir pruebas de depresión a fin de poner a prueba la relación entre ansiedad y depresión con el modelo de este instrumento.

- Se recomienda emplear un análisis factorial confirmatorio con el propósito de evaluar el grado de ajuste de las dimensiones propuestas en el INADM con los datos obtenidos tras la aplicación del instrumento. 


\section{REFERENCIAS}

Alarcón, R. (2008). Métodos y diseño de investigación del comportamiento (2 $2^{\mathrm{a}}$ ed.). Lima: Universidad Ricardo Palma.

American Educational Research Association, American Psychological Association, \& National Council on Measurement in Education (2014). Standards for educational and psychological testing. Washington D.C.: American Educational Research Association.

American Psychological Association. (2010a). Diccionario conciso de psicología. México D.F.: El Manual Moderno.

American Psychological Association (2010b). Manual de publicaciones ( $3^{\mathrm{a}}$ ed.). México D.F.: El Manual Moderno.

Anderson, E. R., \& Hope, D. A. (2008). A review of the tripartite model for understanding the link between anxiety and depression in youth. Clinical Psychological Review, 28, 275287. doi: 10.1016/j.epr.2007.05.004

Asociación Psiquiátrica Americana (2002). Manual diagnóstico y estadístico de los trastornos mentales (DSM-IV-TR). Barcelona: Autor.

Barlow, D. (2000). Unraveling the mysteries of anxiety and its disorders from the perspective of emotion theory. American Psychologist, 55(11), 1247-1263. doi: 10.1037/0003066X.55.11.1247

Beck, A., \& Steer, R. (1993). The Beck Anxiety Inventory. San Antonio: Psychological Corporation.

Bonanomi, A., Ruscone, M. N., \& Osmetti, S. A. (2013). The Polychoric Ordinal Alpha, measuring the reliability of a set of polytomous ordinal items. In Advances in Latent Variables-Methods, Models and Applications. Recuperado de http://meetings.sisstatistica.org/index.php/sis2013/ALV/paper/viewFile/2651/424

Burga, A. (2006). La unidimensionalidad de un instrumento de medición: Perspectiva factorial. Revista de Psicología de la PUCP, 24(1), 54-80.

Brown, T. A., Chorpita, B. F., \& Barlow, D. H. (1998). Structural relationships among dimensions of the DSM-IV anxiety and mood disorders and dimensions of negative affect, positive affect, and autonomic arousal. Journal of Abnormal Psychology, 107(2), 179-192.

Cohen, J. (1992). A power primer. Psychological Bulletin, 112(1), 155-159. doi: 10.1037/0033-2909.112.1.155 
Churchland, P. (1995). El materialismo eliminativista y las actitudes proposicionales. En E. Rabossi (Ed.), Filosofía de la mente y ciencia cognitiva (pp. 43-68). Barcelona: Paidós Ibérica.

Clark, L. A., \& Watson, D. (1991). Tripartite model of anxiety and depression: Psychometric evidence and taxonomic implications. Journal of Abnormal Psychology, 100(3), 316336.

Craske, M. G., \& Craig, K. D. (1984). Musical performance anxiety: The three-systems model and self-efficacy theory. Behaviour Research and Therapy, 22(3), 267-280.

Davey, G. (2008). Psychopathology: Research, assessment, and treatment in clinical psychology. Massachusetts: Blackwell Publishing.

Deniz, Z. (2007). Performance anxiety, dysfunctional attitudes and gender in university music students. Social Behavior and Personality, 35(10), 1415-1426.

Edgel, S. E. \& Noon, S. M. (1984). Effect of violatioin of normality on the $t$ test of the correlation coefficient. Psychological Bulletin, 95(3), 576-583. doi: 10.1037/00332909.95.3.576

Ellis, P. D. (2010). The essential guide to effect sizes: Statistical power, meta-analysis, and the interpretation of research results. UK: Cambridge University Press.

Escurra, L. M. (1988). Cuantificación de la validez de contenido por criterio de jueces. Revista de Psicología de la PUCP, 6(1-2), 103-111.

Fernández-Ballesteros, R., y Dolores, M. (2004). Garantías científicas y éticas de la evaluación psicológica. En Fernández-Ballesteros, R. (Ed.), Evaluación psicológica: Conceptos, métodos y estudio de casos (pp.121-161). Madrid: Pirámide.

Ferguson, C. J. (2009). An effect size primer: A guide for clinicians and researchers. Professional Psychology: Research and Practice, 40(5), 532-538. doi: 10.1037/a0015808

Field, A. (2009). Discovering statistics using SPSS (and sex and drugs and rock ' $n$ ' roll) ( $3^{\mathrm{a}}$ ed.). Dubay: Sage.

Fishbein, M., \& Middlestadt, S. (1988). Medical problems among ICSOM: Overview of a national survey. Medical Problems of Performing Arts, 3(1), 1-8.

Gabbard, G. O. (1983). Further contributions to the understanding of stage fright: Narcissistic issues. Journal of the American Psychoanalytic Association, 31, 423-441. doi: 10.1177/000306518303100203

Gadermann, A. M., Guhn, M., \& Zumbo, B. D. (2012). Estimating ordinal reliability for Likert-type and ordinal item response data: A conceptual, empirical, and practical guide. Practical Assessment, Research \& Evaluation, 17(3), 1-13. Recuperado de http://www.pareonline.net/getvn.asp?v=17\&n=3 
Haahr, M. (1998). Random.org. Irland: Trinity College - School of Computer Science and Statistics. Recuperado de https://www.random.org/

Hambleton, R. K. (1996). Adaptación de tests para su uso en diferentes idiomas y culturas: Fuentes de error, posibles soluciones y directrices prácticas. En J. Muñiz (Ed.), Psicometría (pp. 207-238). Madrid: Universitas.

Hashim, H. A., \& Hanafi, H. (2011). The effects of progressive muscle relaxation and autogenic relaxation on younger soccer players' mood states. Asian Journal of Sports Medicine, 2(2), 99-105.

Hernández, R., Fernández, C., y Baptista, P. (2010). Metodología de la investigación (5ª ed.). Lima: McGraw-Hill.

Kaspersen, M., \& Gotestam, K. G. (2002). A survey of music performance anxiety among Norwegian music students. European Journal of Psychiatry, 16(2), 69-80.

Kenny, D. T. (diciembre, 2009). The factor structure of the revised Kenny Music Performance Anxiety Inventory. Trabajo presentado en el International Symposium on Performance Science, Auckland, Nueva Zelandia. Recuperado de http://www.legacyweb.rcm.ac.uk/cache/f10019647.pdf

Kenny, D. T. (2011). The psychology of music performance anxiety. New York: Oxford University Press.

Kenny, D. T., Davis, P., \& Oates, J. (2004). Music performance anxiety and occupational stress amongst opera chorus artists and their relationship with state and trait anxiety and perfectionism. Anxiety Disorders, 18, 757-777.

Kerlinger, F. N., y Lee, H. B. (2002). Investigación del comportamiento (4a ed.). México D.F.: McGraw-Hill.

Kim, Y. (2008). The effect of improvisation-assisted desensitization, and music-assisted progressive muscle relaxation and imagery on reducing pianists' music performance anxiety. Journal of Music Therapy, 45(2), 165-191.

Kirchner, J., Bloom, A., \& Skutnick-Henley, P. (2008). The relationship between performance anxiety and flow. Medical Problems of Performing Artists, 23, 59-65.

Kline, P. (1995). The handbook of psychological testing. Londres: Routledge.

Lorenzo-Seva, U., y Ferrando, P. J. (2015). Factor (Versión 9.3.1) [Software de computación]. Recuperado de http://psico.fcep.urv.es/utilitats/factor/Download.html

Martínez, M. C., y Paterna, C. (2010). Manual de psicología de los grupos. Madrid: Síntesis.

Mayr, S., Erdfelder, E., Buchner, A., \& Faul, F. (2007). A short tutorial of GPower. Tutorials in Quantitative Methods for Psychology, 3(2), 51-59. Recuperado de http://www.tqmp.org/RegularArticles/vol03-2/p051/p051.pdf 
Medeiros, A. E. M. (2013). Ansiedade de performance musical: validacao transculutral de instrumento de avaliacao. (Tesis de licenciatura). Universidad de Sao Paulo.

Medeiros, A. E. M., Crippa, J. A. S., \& Osorio, F. L. (2014). Kenny Music Performance Anxiety Inventory (K-MPAI): Transcultural adaptation for Brazil and study of internal consistency. Journal of Depression and Anxiety, 3(4), 1-3. doi: 10.4172/21671044.1000167

Mineka, S., Watson, D., \& Clark, L. A. (1998). Comorbidity of anxiety and unipolar mood disorders. Annual Review of Psychology, 49, 377-412.

Morales, P. (2007). La fiabilidad de los test y escalas. Recuperado de http://www.upcomillas.es/personal/peter/estadisticabasica/Fiabilidad.pdf

Mohamed, Z., \& Parish T. S. (1998). The effects of two types of relaxation training on students' levels of anxiety. Adolescence, 33, 99-101.

Nagel, J. (2010). Treatment of music performance anxiety via psychological approaches: A review of selected CBT and psychodynamic literature. Medical Problems of Performing Artists, 25, 141-148.

Nunnally, J. C. (1987). Teoría psicométrica. México D.F.: Trillas.

Nunnally, J. C., y Bernstein, I. H. (1995). Teoría psicométrica (2ª ed.). México D.F.: McGraw Hill.

Pagano, R. (2011). Estadística para las ciencias del comportamiento (9a ed.). México D.F.: Cengage Learning.

Ortiz, A. (2011a). Music performance anxiety-Part 1: A review of its epidemiology. Medical Problems of Performing Artists, 26(2), 102-105.

Ortiz, A. (2011b). Music performance anxiety-part 2: A review of treatment options. Medical Problems of Performing Artists, 26(3), 164-171.

Osborne, M. S., \& Kenny, D. T. (2005). Development and validation of a music performance anxiety inventory for gifted adolescent musicians. Anxiety Disorders, 19, 725-751. doi: 10.1016/j.kanxdis.2004.09.002

Sandín, B., y Chorot, P. (2009). Síndromes clínicos de la ansiedad. En A. Belloch, B. Sandín y F, Ramos (Eds.), Manual de psicopatología, edición revisada (Vol. II) (pp. 65-90). Madrid: McGraw Hill.

Sánchez, C. H., y Reyes, M. C. (2006). Metodología y diseños de la investigación científica. Lima: Visión Universitaria.

Santisteban, C. (2009). Principios de psicometría. Madrid: Síntesis.

Schmid, J., \& Leiman, J. M. (1957). The development of hierarchical factor solutions. Psychometrika, 22(1), 53-61. 
Sireci, S., \& Faulkner-Bond, M. (2014). Validity evidence based on test content. Psicothema, 26(1), 100-107. doi: 10.7334/psichotema2013.256

Sireci, S., \& Padilla, J. L. (2014). Validating assessments: Introduction to the special section. Psicothema, 26(1), 97-99. doi: 10.7334/psicothema2013.255

Spielberger, Ch., y Díaz-Guerrero, R. (1970). Inventario de Ansiedad: Rasgo-Estado (IDARE). Florida: University of South Florida.

Su, Y., Luh, J., Chen, H., Lin, C., Liao, M., \& Chen, H.S. (2010). Effects of using relaxation breathing training to reduce music performance anxiety in $3^{\text {rd }}$ to $6^{\text {th }}$ graders. Medical Problems of Performing Artists, 5, 82-86.

Taylor, A., \& Wasley, D. (2004). Physical fitness. En A. Williamon (Ed.), Musical excellence: Strategies and techniques to enhance performance (pp. 163-178). New York: Oxford University Press.

Tolbert, G. L. (2009). Effects of anxiety reducing interventions on performance anxiety in graduate nurses (Tesis doctoral). De la base de datos de ProQuest. (UMI No. 3392121)

Thornberry, G. L. M. (2011). El rol de las creencias irracionales en la relación entre los eventos activadores, y las consecuencias emocionales y conductuales en estudiantes de dos universidades privadas de Lima (Tesis de doctorado inédita). Universidad San Martín de Porres: Lima.

Triplett, N. (1898). The dynamogenic factors in pacemaking and competition. American Journal of Psychology, 9, 507-533. doi: 10.2307/1412188

Ugarriza, N. (1998). Normalización del Inventario Multicultural de la Expresión de CóleraHostilidad en estudiantes universitarios. Revista de Investigación en Psicología, 1(1), 59-88. Recuperado de http://sisbib.unmsm.edu.pe/bvrevistas/investigacion_psicologia/v01_n1/pdf/a03v1n1.p df

Uziel, L. (2007). Individual differences in the social facilitation effect: A review and metaanalysis. Journal of Research in Personalitym 41, 579-601. doi:

10.1016/j.jrp.2006.06.008

West, R. (2004). Drugs and musical performance. En A. Williamon (Ed.). Musical excellence: Strategies and techniques to enhance performance (pp. 271-290). New York: Oxford University Press.

Wolff, H. G., \& Preising, K. (2005). Exploring item and high order factor structure with the Schmid-Leiman solution: Syntax codes for SPSS and SAS. Behavior Research Methods, 37(1), 48-58.

Yoshie, M., Kudo, K., Murakoshi, T., \& Ohtsuki, T. (2009). Music performance anxiety in skilled pianists: Effects of social-evaluative performance situation on subjective, 
autonomic, and electromyographic reactions. Experimental Brain Research, 199, 117126.

Yoshie, M., Kudo, K., \& Ohtsuki, T. (2008). Effects of psychological stress on state anxiety, electromyographic activity, and arpeggio performance in pianists. Medical Problems of Performing Artists, 23, 120-132.

Zajonc, R. B. (1965). Social facilitation. Science, 149(3681), 269-274. Recuperado de http://www2.psych.ubc.ca/ schaller/Psyc591Readings/Zajonc1965.pdf

Zumbo, B. D., Gadermann, A. M., \& Zeisser, C. (2007). Ordinal versions of coefficients alpha and theta for Likert Rating Scales. Journal of Modern Applied Statistical Methods, 6(1), 21-29. Recuperado de http://digitalcommons.wayne.edu/jmasm/vol6/iss1/4 


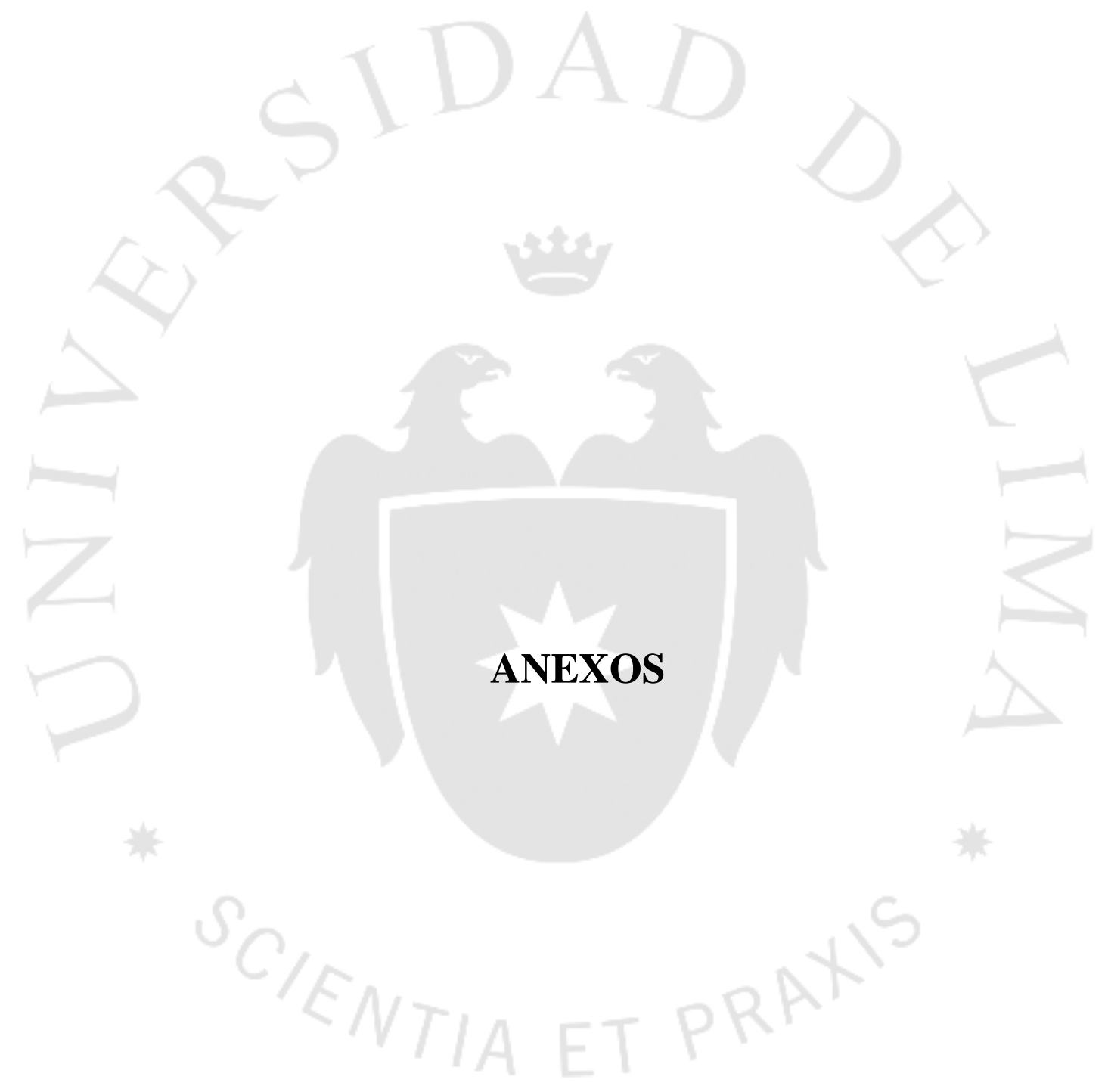




\section{Anexo 1: Ficha Sociodemográfica}

Sexo:

$M()$

$F()$

Edad:

Lugar de nacimiento:

Lima ( )

Provincia ( )

Extranjero ( )

Institución educativa en la que estudias música:

Ciclo o nivel de estudio:

Género musical de especialidad (escoge solo uno):
1) Clásico ( )
3) Folklórico ( )
2) Moderno ( )
4) Otros:

Instrumento o especialidad (escoge solo el principal):
1) Canto ( )
4) Percusión ( )
7) Vientos de madera ( )
2) Composición ( )
5) Piano ( )
8) Vientos de metal ( )
3) Cuerdas ( )
6) Producción ( )
9) Otros:

¿Hace cuántos años te dedicas a la música?

Además de música, ¿estudias o has estudiado otra carrera?

Estudió otra carrera （） Estudié otra carrera（） Solo estudio música（）

Actualmente, además de estudiar música, ¿trabajas?
1) Sí
2) No

Actualmente, ¿recibes tratamiento psicológico, psiquiátrico, ambos o ninguno?
1)Psicológico ( )
3) Ambos ( )
2) Psiquiátrico ( )
4) Ninguno ( ) 


\section{Anexo 2: IADM-K}

A continuación se presentan algunas afirmaciones acerca de cómo te sientes generalmente y cómo te sientes durante o antes de una presentación. Por favor, encierra en un círculo el número que indique cuán de acuerdo o en desacuerdo estás con cada afirmación.

Totalmente en

desacuerdo
Totalmente

de acuerdo

K_1 En general, me siento en control de mi vida

K_2 Me es fácil confiar en los demás.....

K_3 Algunas veces me siento deprimido(a) sin saber por qué .........

$\begin{array}{lllllll}0 & 1 & 2 & 3 & 4 & 5 & 6\end{array}$

$\begin{array}{lllllll}0 & 1 & 2 & 3 & 4 & 5 & 6\end{array}$

K_4 A menudo me es difícil reunir la energía para hacer cosas ....

$\begin{array}{lllllll}0 & 1 & 2 & 3 & 4 & 5 & 6\end{array}$

K_5 Preocuparse en exceso es una característica de mi familia .....

K_6 A menudo siento que la vida no tiene mucho qué ofrecerme ...

K_7 Aun cuando me esfuerce mucho en la preparación para una presentación, seguramente voy a cometer errores

K_8 Me cuesta depender de otras personas

K_9 Mis padres han sido generalmente sensibles a mis necesidades $y$ han respondido a ellas.

K_10 Durante o antes de una presentación, tengo sensaciones parecidas al pánico.

K_11 Antes de un concierto nunca sé si mi desempeño será bueno.

K_12 Durante o antes de una presentación, siento la boca seca.

K_13 A menudo siento que no valgo mucho como persona

$\begin{array}{lllllll}0 & 1 & 2 & 3 & 4 & 5 & 6\end{array}$

$\begin{array}{lllllll}0 & 1 & 2 & 3 & 4 & 5 & 6\end{array}$

K_14 Durante un concierto me pregunto a veces si lograré llegar hasta el final de una pieza

$\begin{array}{lllllll}0 & 1 & 2 & 3 & 4 & 5 & 6\end{array}$

K_15 Pensar acerca de la evaluación que pueda obtener interfiere con mi desempeño

K_16 Durante o antes de una presentación tengo nauseas o

siento que me voy a

desmayar.

$\begin{array}{lllllll}0 & 1 & 2 & 3 & 4 & 5 & 6\end{array}$ 
K_17 Aun en las presentaciones más estresantes, tengo la seguridad de que tendré un buen desempeño

K_18 A menudo me preocupa una reacción negativa de la audiencia

K_19 Algunas veces me pongo ansioso(a) sin ninguna razón aparente.

K_20 Desde una etapa temprana de mis estudios musicales recuerdo sentir ansiedad respecto de tocar en público

K_21 Me preocupa que un mal concierto pueda arruinar mi carrera

K_22 Durante o antes de una presentación, experimento un aumento en el ritmo cardiaco como si fueran golpes en el pecho.

K_23 Mis padres casi siempre me escuchaban

K_24 Dejo pasar valiosas oportunidades de presentación

$\begin{array}{lllllll}0 & 1 & 2 & 3 & 4 & 5 & 6\end{array}$

K_25 Después de una presentación, me preocupa si toqué lo suficientemente

bien.

K_26 La preocupación y nerviosismo sobre mi desempeño interfieren con mi atención y concentración.

K_27 En la infancia, a menudo me sentía triste

K_28 A menudo me preparo para un concierto con una sensación de temor y de desastre inevitable

K_29 Uno o dos de mis padres eran sumamente ansiosos.

K_30 Durante o antes de una presentación, tengo mayor tensión muscular.

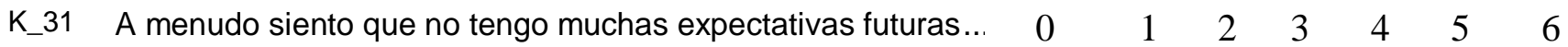

K_32 Después de una presentación, la repito en mi mente una y $\quad \begin{array}{llllllllll}0 & 0 & 1 & 2 & 3 & 4 & 5 & 6\end{array}$ otra vez.

K_33 Mis padres me alentaron a probar cosas nuevas

$\begin{array}{lllllll}0 & 1 & 2 & 3 & 4 & 5 & 6\end{array}$

K_34 Me preocupo tanto por una presentación que no puedo dormir

$\begin{array}{lllllll}0 & 1 & 2 & 3 & 4 & 5 & 6\end{array}$


K_35 Mi memoria es confiable cuando toco sin partitura......

$\begin{array}{lllllll}0 & 1 & 2 & 3 & 4 & 5 & 6 \\ 0 & 1 & 2 & 3 & 4 & 5 & 6\end{array}$

K_36 Durante o antes de una presentación me siento tembloroso(a) o

tambaleante.

K_37 Tengo confianza al tocar de memoria

$\begin{array}{lllllll}0 & 1 & 2 & 3 & 4 & 5 & 6\end{array}$

K_38 Me preocupa ser observado(a) y analizado(a) por

$\begin{array}{lllllll}0 & 1 & 2 & 3 & 4 & 5 & 6\end{array}$ otros

K_39 Me preocupa mi propio juicio acerca de mi

desempeño

$\begin{array}{lllllll}0 & 1 & 2 & 3 & 4 & 5 & 6\end{array}$

K_40 Me mantengo con el compromiso de tocar aun cuando me cause gran

$\begin{array}{lllllll}0 & 1 & 2 & 3 & 4 & 5 & 6\end{array}$ ansiedad. 


\section{Anexo 3: K-MPAI-R}

Below are some statements about how you feel generally and how you feel before or during a performance. Please circle one number to indicate how much you agree or disagree with each statement.

\section{Strongly \\ Disagree}

Strongly

Agree

K_1 I generally feel in control of my life.

K_2 I find it easy to trust others

K_3 Sometimes I feel depressed without knowing why.

6

54

43

6

5

43

0

1

$2 \quad 3$

K_4 I often find it difficult to work up the energy to do things

0

K_5 Excessive worrying is a characteristic of my family

K_6 I often feel that life has not much to offer me

K_7 Even if I work hard in preparation for a performance, I am likely to make mistakes

K_8 I find it difficult to depend on others

K_9 My parents were mostly responsive to my needs

K_10 Prior to, or during a performance, I get feelings akin to panic

K_11 I never know before a concert whether I will perform well

K_12 Prior to, or during a performance, I experience dry mouth

K_13 I often feel that I am not worth much as a person

K_14 During a performance I find myself thinking about whether I'll even get through it

K_15 Thinking about the evaluation I may get interferes with my performance.

K_16 Prior to, or during a performance, I feel sick or faint or have a churning in my stomach $\begin{array}{lllllll}0 & 1 & 2 & 3 & 4 & 5 & 6\end{array}$

$\begin{array}{lllllll}0 & 1 & 2 & 3 & 4 & 5 & 6\end{array}$

$\begin{array}{lllllll}0 & 1 & 2 & 3 & 4 & 5 & 6\end{array}$

$\begin{array}{lllllll}0 & 1 & 2 & 3 & 4 & 5 & 6 \\ 0 & 1 & 2 & 3 & 4 & 5 & 6\end{array}$

$\begin{array}{lllllll}0 & 1 & 2 & 3 & 4 & 5 & 6\end{array}$

$\begin{array}{lllllll}0 & 1 & 2 & 3 & 4 & 5 & 6\end{array}$ 
K_17 Even in the most stressful performance situations, I am confident that I will perform well.

K_18 I am often concerned about a negative reaction from the audience

K_19 Sometimes I feel anxious for no particular reason

K_20 From early in my music studies, I remember being anxious about performing

K_21 I worry that one bad performance may ruin my career

K_22 Prior to, or during a performance, I experience increased heart rate like pounding in my chest

K_23 My parents almost always listened to me

K_24 I give up worthwhile performance opportunities

K_25 After the performance, I worry about whether I played well enough

K_26 My worry and nervousness about my performance interferes with my focus and concentration

K_27 As a child, I often felt sad.

K_28 I often prepare for a concert with a sense of dread and impending disaster

K_29 One or both of my parents were overly anxious

K_30 Prior to, or during a performance, I have increased muscle tension

K_31 I often feel that I have nothing to look forward to

K_32 After the performance, I replay it in my mind over and over

K_33 My parents encouraged me to try new things

K_34 I worry so much before a performance, I cannot sleep

K_35 When performing without music, my memory is reliable

$\begin{array}{lllllll}0 & 1 & 2 & 3 & 4 & 5 & 6\end{array}$

$\begin{array}{lllllll}0 & 1 & 2 & 3 & 4 & 5 & 6\end{array}$

$\begin{array}{lllllll}0 & 1 & 2 & 3 & 4 & 5 & 6\end{array}$

$\begin{array}{lllllll}0 & 1 & 2 & 3 & 4 & 5 & 6\end{array}$

$\begin{array}{lllllll}6 & 5 & 4 & 3 & 2 & 1 & 0\end{array}$

$\begin{array}{lllllll}0 & 1 & 2 & 3 & 4 & 5 & 6\end{array}$

$\begin{array}{lllllll}0 & 1 & 2 & 3 & 4 & 5 & 6\end{array}$

$\begin{array}{lllllll}1 & 2 & 3 & 4 & 5 & 6\end{array}$

$\begin{array}{lllllll}0 & 1 & 2 & 3 & 4 & 5 & 6\end{array}$

$\begin{array}{lllllll}0 & 1 & 2 & 3 & 4 & 5 & 6\end{array}$

$\begin{array}{lllllll}0 & 1 & 2 & 3 & 4 & 5 & 6\end{array}$

$\begin{array}{llllllll}0 & 1 & 2 & 3 & 4 & 5 & 6\end{array}$

$\begin{array}{lllllll}0 & 1 & 2 & 3 & 4 & 5 & 6 \\ 0 & 1 & 2 & 3 & 4 & 5 & 6\end{array}$

$\begin{array}{lllllll}6 & 5 & 4 & 3 & 2 & 1 & 0\end{array}$

$\begin{array}{lllllll}0 & 1 & 2 & 3 & 4 & 5 & 6\end{array}$

$\begin{array}{lllllll}6 & 5 & 4 & 3 & 2 & 1 & 0\end{array}$ 
K_36 Prior to, or during a performance, I experience shaking or trembling or tremor

$\begin{array}{lllllll}0 & 1 & 2 & 3 & 4 & 5 & 6\end{array}$

K_37 I am confident playing from memory.

$\begin{array}{lllllll}6 & 5 & 4 & 3 & 2 & 1 & 0\end{array}$

K_38 I am concerned about being scrutinized by others

$\begin{array}{lllllll}0 & 1 & 2 & 3 & 4 & 5 & 6\end{array}$

K_39 I am concerned about my own judgement of how I will perform

$\begin{array}{lllllll}0 & 1 & 2 & 3 & 4 & 5 & 6\end{array}$

K_40 I remain committed to performing even though it causes me great anxiety

$\begin{array}{lllllll}0 & 1 & 2 & 3 & 4 & 5 & 6\end{array}$

CKenny, D.T. (2009). Kenny Music Performance Anxiety Inventor-Revised (K-MPAI-R) 


\section{Anexo 4: Ficha Técnica y Propuesta de Prueba}

Tabla A41

Ficha técnica del IANADM

\begin{tabular}{|c|c|}
\hline \multicolumn{2}{|c|}{ Ficha Técnica } \\
\hline \multirow{3}{*}{ Nombre de la prueba } & Inventario de Afectividad \\
\hline & Negativa Ante el Desempeño \\
\hline & Musical (INADM) \\
\hline \multicolumn{2}{|l|}{ Autor } \\
\hline \multirow[t]{2}{*}{ Basado en } & IADM-K, Kenny, 2009 \\
\hline & Estudiantes profesionales de \\
\hline \multirow[t]{2}{*}{ Población objetivo } & música especializados en \\
\hline & ejecución instrumental o canto \\
\hline \multirow{2}{*}{ Constructo evaluado } & Afectividad negativa ante el \\
\hline & desempeño musical \\
\hline Modo de aplicación & Individual o colectivo \\
\hline Tiempo de aplicación & Aproximadamente 10 minutos \\
\hline Tipo de respuesta & Escala Likert \\
\hline Número de ítems & 30 \\
\hline Ítem con calificación & \\
\hline inversa & \\
\hline
\end{tabular}


IANADM - Propuesta de Prueba

A continuación se presentan algunas afirmaciones acerca de cómo te sientes generalmente y cómo te sientes durante o antes de una presentación musical. Por favor, encierra en un círculo el número que indique cuán de acuerdo o en desacuerdo estás con cada afirmación.

Después de una presentación, la repito en mi mente una y otra vez.

2

A menudo siento que no valgo mucho como persona....

Totalmente

en

desacuerdo

Totalmente de acuerdo

Pensar acerca de la evaluación que

3 pueda obtener interfiere con mi desempeño.

4

Durante $o$ antes de una presentación,

tengo mayor tensión muscular.$$
0
$$

0

2

Desde una etapa temprana de mis

5 estudios musicales recuerdo sentir ansiedad respecto de tocar en público...

6 Antes de un concierto nunca sé si mi desempeño será bueno.

${ }_{7}$ A menudo me es difícil reunir la energía para hacer cosas.

8 Durante o antes de una presentación, siento la boca seca.

9 Me preocupa mi propio juicio acerca de mi desempeño.
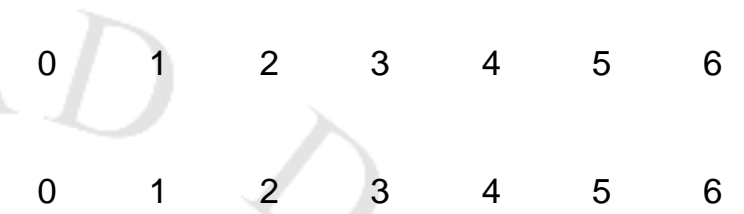

${ }_{10}$ A menudo siento que no tengo muchas expectativas futuras.

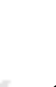

${ }_{11}$ A menudo siento que la vida no tiene

11 mucho qué ofrecerme

Durante un concierto me pregunto a

12 veces si lograré llegar hasta el final de una pieza.

13

Dejo pasar valiosas oportunidades de presentación.

$\begin{array}{lllllll}0 & 1 & 2 & 3 & 4 & 5 & 6\end{array}$

$\begin{array}{llllllll}0 & 1 & 2 & 3 & 4 & 5 & 6\end{array}$

$\begin{array}{lllllll}0 & 1 & 2 & 3 & 4 & 5 & 6\end{array}$

$\begin{array}{llllllll}0 & 1 & 2 & 3 & 4 & 5 & 6\end{array}$

$\begin{array}{lllllll}0 & 1 & 2 & 3 & 4 & 5 & 6\end{array}$

14 Durante o antes de una presentación me siento tembloroso(a) o tambaleante......

A menudo me preparo para un concierto

15 con una sensación de temor y de desastre inevitable. 
La preocupación y nerviosismo sobre mi

17 desempeño interfieren con mi atención y concentración.

${ }_{18}$ Algunas veces me pongo ansioso(a) sin ninguna razón aparente.

19

En general, me siento en control de mi vida.

$\begin{array}{lllllll}0 & 1 & 2 & 3 & 4 & 5 & 6\end{array}$

Durante o antes de una presentación

20 tengo nauseas o siento que me voy a desmayar.

21 Me preocupa ser observado(a) y analizado(a) por otros.

22 Algunas veces me siento deprimido(a) sin saber por qué.

$\begin{array}{lllllll}0 & 1 & 2 & 3 & 4 & 5 & 6\end{array}$

${ }_{23}$ Me preocupo tanto por una presentación que no puedo dormir.

$\begin{array}{lllllll}0 & 1 & 2 & 3 & 4 & 5 & 6\end{array}$

Preocuparse en exceso es una

característica de mi familia.

25 En la infancia, a menudo me sentía triste

Aun en las presentaciones más

26 estresantes, tengo la seguridad de que tendré un buen desempeño

27 Durante $o$ antes de una presentación, tengo sensaciones parecidas al pánico...

28 Uno o dos de mis padres eran sumamente ansiosos

Aun cuando me esfuerce mucho en la

29 preparación para una presentación, seguramente voy a cometer errores. A menudo me preocupa una reacción negativa de la audiencia. 


\section{Anexo 5: IDARE - Ansiedad Estado}

Algunas expresiones que la gente usa para describirse aparecen abajo. Lea cada frase y encierre en un círculo el número que indique cómo se siente ahora mismo, o sea, en este momento. No hay respuestas buenas o malas. No emplee mucho tiempo en cada frase, pero trate de dar la respuesta que mejor describa sus sentimientos ahora.

\section{No en lo absoluto \\ Un poco Bastante Mucho}

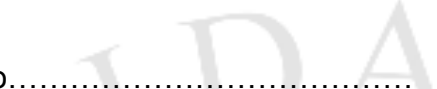

1. Me siento calmado

2. Me siento seguro.

3. Estoy tenso.

4. Estoy contrariado

5. Estoy a gusto.

6. Me siento alterado

7. Estoy preocupado actualmente por algún posible contratiempo.

\section{1}

1

1

1

1

1

1

8. Me siento descansado

9. Me siento ansioso.

10. Me siento cómodo.

11. Me siento con confianza en mí mismo.

12. Me siento nervioso

13. Me siento agitado.

14. Me siento "a punto de explotar".

15. Me siento reposado.

16. Me siento satisfecho.

17. Estoy preocupado.

18. Me siento muy excitado y aturdido

19. Me siento alegre.

20. Me siento bien... 


\section{Anexo 6: IDARE: Ansiedad Rasgo}

Algunas expresiones que la gente usa para describirse aparecen abajo. Lea cada frase y encierre en un círculo el número que indique cómo se siente generalmente. No hay respuestas buenas o malas. No emplee mucho tiempo en cada frase, pero trate de dar la respuesta que mejor describa cómo se siente generalmente.

Casi

nunca veces

Frecuentemente

Casi siempre

21. Me siento bien

22. Me canso rápidamente.

23. Siento ganas de llorar

24. Quisiera ser tan feliz como otros parecen serlo Pierdo oportunidades por no poder decidirme

25. rápidamente.

26. Me siento descansado.

27. Soy una persona "tranquila, serena y sosegada". Siento que las dificultades se me amontonan al punto de no

28. poder superarlas.

Me preocupo demasiado por cosas sin

29. importancia.

30. Soy feliz

31. Tomo las cosas muy a pecho

32. Me falta confianza en mí mismo.

33. Me siento seguro

34. Trato de sacarle el cuerpo a las crisis y dificultades....

35. Me siento melancólico.

36. Me siento satisfecho

37. Algunas ideas poco importantes pasan por mi mente y me molestan.

38. Me afectan tanto los desengaños que no me los puedo quitar de la cabeza.

39. Soy una persona estable.

40. Cuando pienso en los asuntos que tengo entre manos me pongo tenso y alterado.
2

2

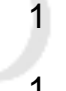

\section{1}

1

1

1

3

3

3

3

2

3

2
2

\section{3}

4

4

4

4

政

4

4

4

4

4

4

4

4

4

4

4 


\section{Anexo 7: IAB}

A continuación se presenta una lista de síntomas comunes de ansiedad. Lea cuidadosamente cada ítem de la lista. Indique marcando con un aspa (x) cuánto le ha molestado cada uno de estos síntomas durante estos últimos 30 días incluyendo el día de hoy.

\section{En \\ Levemente Moderadamente Severamente \\ Absoluto}

1

Entumecimiento muscular $\mathrm{u}$

hormigueo.

2. Acalorado.

3. Con temblor en las piernas.

4. Incapaz de relajarme

Con temor de que pase lo

peor

6. Mareado

Con latidos del corazón fuertes y

acelerados

8. Inestable

9. Atemorizado o asustado

10. Nervioso

11. Con sensación de asfixia.

12. Con temblores en las manos...

13. Inquieto o inseguro

14. Con miedo a perder control

15. Con sensación de ahogo

16. Con temor a morir

17. Con miedo

18. Con problemas digestivos

19

Con desvanecimientos o

debilidad

20. Con rubor facial

Con sudores fríos o calientes (no debido

21. a la temperatura del

0

ambiente)

0

0

0

0

0

0
1

2

3

0

0

2

3

3

2

2

3

2

3

3

3

2

3

3

3

3

3

3

3

3

3

3

3

3

2

1

2

3

.

3 


\section{Anexo 8: Criterio de Jueces}

Estimado(a),

Le escribo para solicitar su apoyo en el proceso de validación del "Kenny Music Performance Anxiety Inventory". Se llevó acabo la adaptación lingüística del inventario a través de un proceso de traducción inversa en la cual la versión original en inglés fue traducida al español y nuevamente traducida al inglés, con el propósito de analizar la equivalencia de ambas versiones. La versión final en español ya ha sido reconocida por la autora de la prueba original, Dianna Kenny, como la traducción autorizada en español.

Este inventario tiene como objetivo medir los niveles de ansiedad ante el desempeño musical en músicos adultos. La ansiedad frente al desempeño musical puede ser definida como el temor o preocupación anticipada y excesiva frente a situaciones de ejecución musical que son interpretadas como una amenaza (por miedo a la evaluación de la audiencia o al fracaso). El inventario cuenta con 40 ítems y se agrupan bajo tres áreas:

- Contexto de relaciones tempranas: abarca la transmisión generacional de la ansiedad; y la empatía de los padres.

- Vulnerabilidades psicológicas: abarca sentimientos de depresión/desesperanza; sentido de control; confianza; y una ansiedad muy marcada ante el desempeño.

- Preocupaciones asociadas a próximas presentaciones: abarca componentes corporales de la ansiedad debido a la existencia de próximas presentaciones; preocupación/pavor; rumiaciones o pensamientos repetitivos antes y después de una presentación; evaluación propia o de otros; costos de oportunidad y confianza en la memoria.

En la tabla adjunta, se le presentarán los ítems agrupados de acuerdo a las tres áreas antes descritas y que deberán calificar de acuerdo a los siguientes criterios:

- Representación del área: los ítems pertenecen al área en la que han sido agrupados. Deberá calificar este criterio con un puntaje que va del 1 al 5, donde 1 significa que el ítem es "poco representativo del área"; y 5 significa que es "muy representativo del área".

- Claridad en la redacción: los ítems tienen una sintaxis y semántica que permiten entenderlos fácilmente. Deberá calificar este criterio con un puntaje que va del 1 al 5 , donde $\underline{1}$ significa que el ítem "no es claro en su redacción"; y 5 significa que el ítem es "bastante claro en su redacción".

En caso de considerar que un ítem es poco representativo del área o no es claro en su redacción, o si tiene alguna observación que hacer, por favor indicar su razón o duda en la casilla de "Observaciones". Por favor, sírvase enviar sus respuestas por el mismo medio electrónico.

Muchas gracias por su tiempo y valioso apoyo.

Atentamente,

Álvaro Chang Arana 


\begin{tabular}{|l|l|}
\hline \multicolumn{1}{|c|}{ Consigna en español } & Observaciones \\
\hline $\begin{array}{l}\text { A continuación se te presentan algunas afirmaciones acerca de cómo } \\
\text { te sientes generalmente y cómo te sientes durante o antes de una } \\
\text { presentación. Por favor, encierra en un círculo el número que indique } \\
\text { cuán de acuerdo o en desacuerdo estás con cada afirmación. }\end{array}$ & \\
\hline \multicolumn{1}{|c|}{ Consigna original en inglés } & \\
\hline $\begin{array}{l}\text { Below are some statements about how you feel generally and how you } \\
\text { feel before or during a performance. Please circle one number to } \\
\text { indicate how much you agree or disagree with each statement. }\end{array}$ & \\
\hline
\end{tabular}

Contexto de relaciones tempranas: abarca la transmisión generacional de la ansiedad; y la empatía de los padres.

\begin{tabular}{|c|c|c|c|c|c|c|c|c|c|c|c|}
\hline \multirow[b]{2}{*}{5} & \multirow{2}{*}{$\begin{array}{l}\text { Contexto de relaciones tempranas } \\
\text { Preocuparse en exceso es una característica } \\
\text { de mi familia }\end{array}$} & \multicolumn{5}{|c|}{$\begin{array}{c}\text { Representativo } \\
\text { del área }\end{array}$} & \multicolumn{4}{|c|}{$\begin{array}{c}\text { Claridad en la } \\
\text { redacción }\end{array}$} & \multirow[t]{2}{*}{ Observaciones } \\
\hline & & 1 & 2 & 3 & 4 & 5 & 1 & 23 & 4 & 5 & \\
\hline 9 & $\begin{array}{l}\text { Mis padres han sido generalmente sensibles a } \\
\text { mis necesidades y han respondido a ellas }\end{array}$ & 1 & 2 & 3 & 4 & 5 & 1 & 23 & 4 & 5 & \\
\hline 23 & Mis padres casi siempre me escuchaban & 1 & 2 & 3 & 4 & 5 & 1 & 23 & 4 & 5 & \\
\hline 27 & En la infancia, a menudo me sentía triste & & 2 & 3 & 4 & 5 & 1 & 23 & 4 & 5 & \\
\hline 29 & $\begin{array}{l}\text { Uno o dos de mis padres eran sumamente } \\
\text { ansiosos }\end{array}$ & & & 3 & 1 & & & 2 & 4 & 5 & \\
\hline 33 & $\begin{array}{l}\text { Mis padres me alentaron a probar cosas } \\
\text { nuevas }\end{array}$ & 1 & 2 & 3 & 4 & 5 & 1 & 23 & 4 & 5 & \\
\hline
\end{tabular}


Vulnerabilidades psicológicas: abarca sentimientos de depresión/desesperanza; sentido de control; confianza; y una ansiedad muy marcada ante el desempeño.

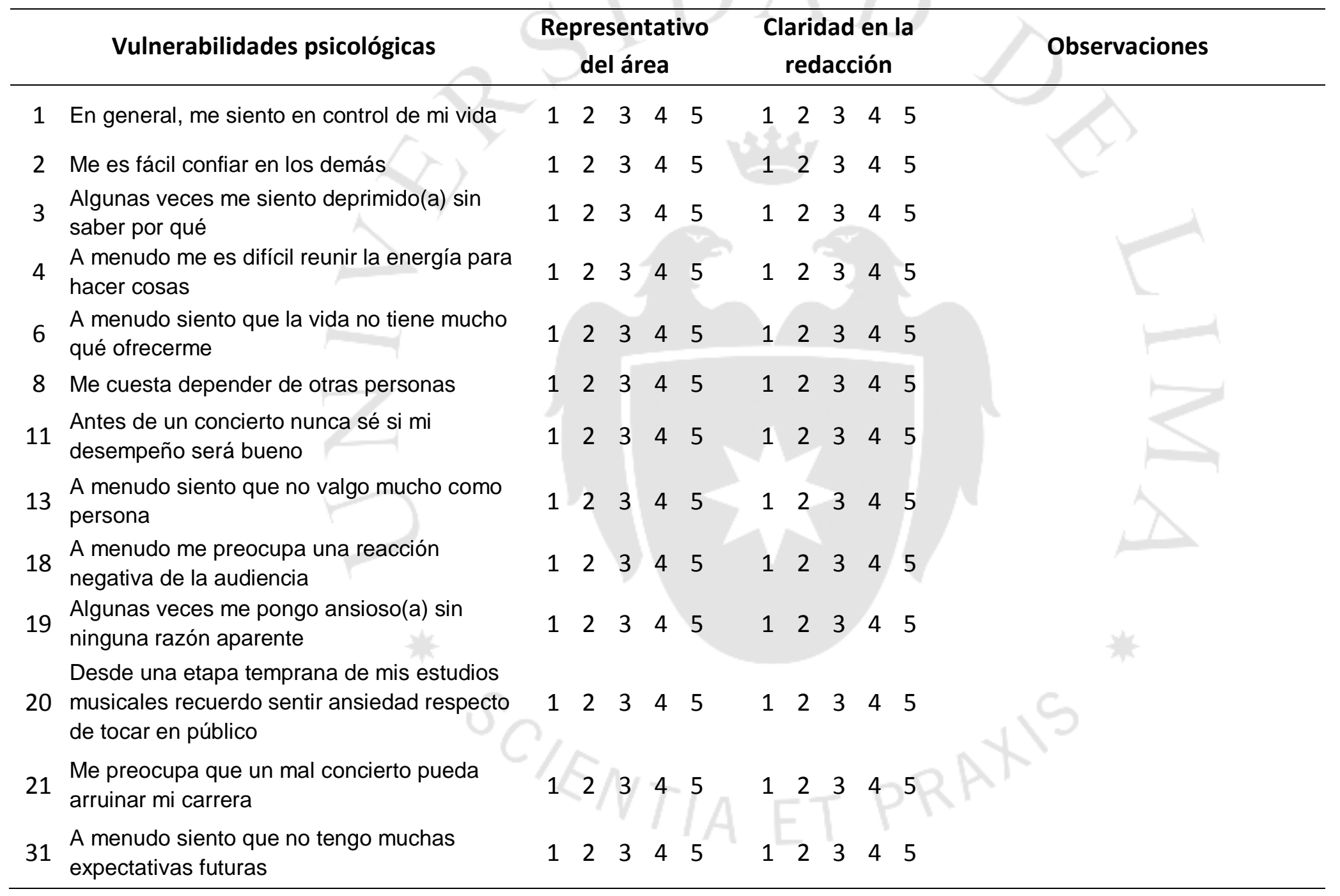


Preocupaciones asociadas a próximas presentaciones: abarca componentes corporales de la ansiedad debido a la existencia de próximas presentaciones; preocupación/pavor; rumiaciones o pensamientos repetitivos antes y después de una presentación; evaluación propia o de otros; costos de oportunidad y confianza en la memoria.

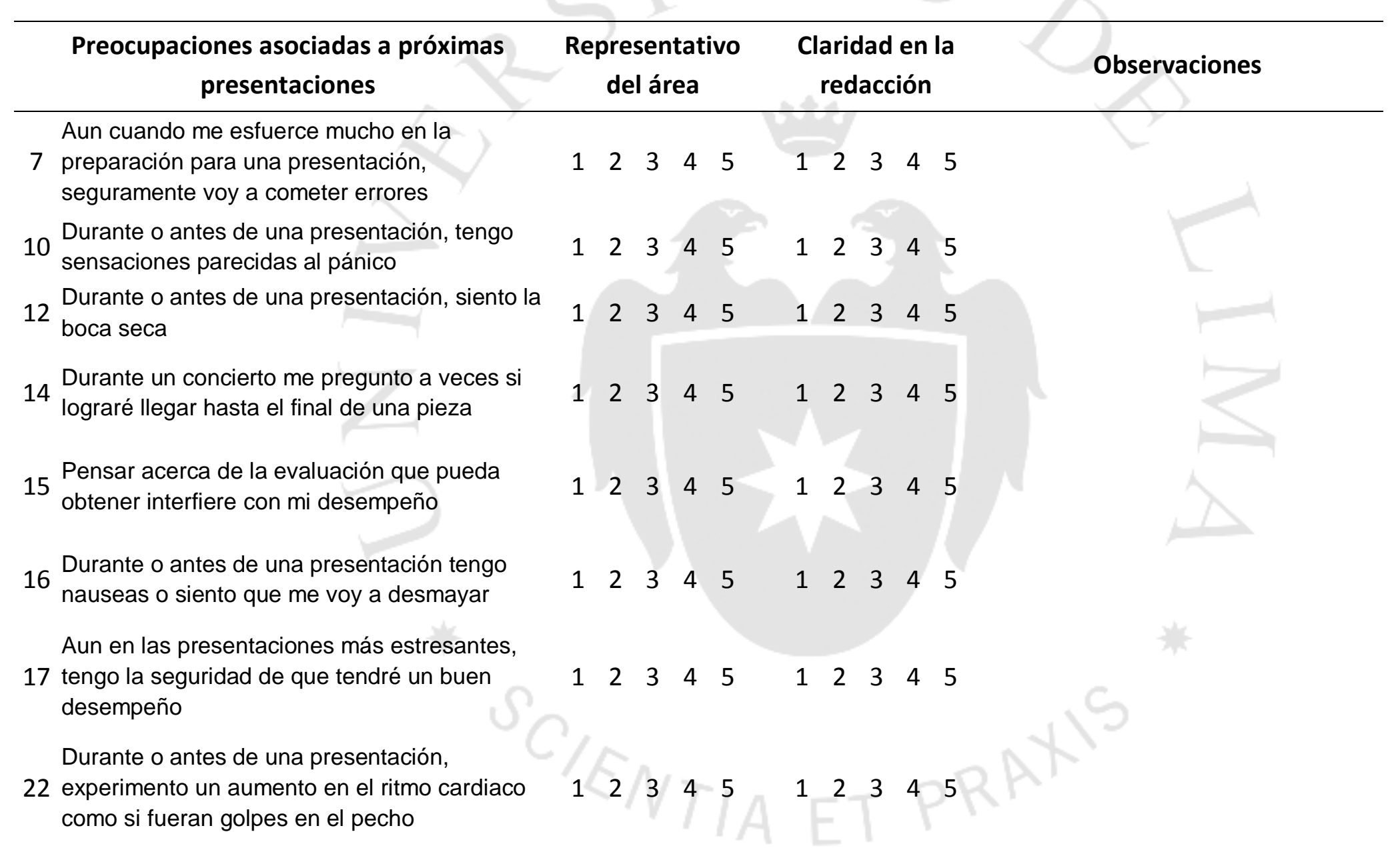


24 Dejo pasar valiosas oportunidades de presentación

$\begin{array}{llllllllll}1 & 2 & 3 & 4 & 5 & 1 & 2 & 3 & 4 & 5\end{array}$

25 Después de una presentación, me preocupa si

toqué lo suficientemente bien

$\begin{array}{llllllllll}1 & 2 & 3 & 4 & 5 & 1 & 2 & 3 & 4 & 5\end{array}$

La preocupación y nerviosismo sobre mi

26 desempeño interfieren con mi atención y concentración

A menudo me preparo para un concierto con

28 una sensación de temor y de desastre inevitable

30 Durante o antes de una presentación, tengo mayor tensión muscular

$\begin{array}{llllllllll}1 & 2 & 3 & 4 & 5 & 1 & 2 & 3 & 4 & 5\end{array}$

32 Después de una presentación, la repito en mi mente una y otra vez

Me preocupo tanto por una presentación que no puedo dormir

$\begin{array}{llllllllll}1 & 2 & 3 & 4 & 5 & 1 & 2 & 3 & 4 & 5\end{array}$

$\begin{array}{llllllllll}1 & 2 & 3 & 4 & 5 & 1 & 2 & 3 & 4 & 5\end{array}$

$\begin{array}{llllllllll}1 & 2 & 3 & 4 & 5 & 1 & 2 & 3 & 4 & 5\end{array}$

$\begin{array}{llllllllll}1 & 2 & 3 & 4 & 5 & 1 & 2 & 3 & 4 & 5\end{array}$

Mi memoria es confiable cuando toco sin partitura

$\begin{array}{llllllllll}1 & 2 & 3 & 4 & 5 & 1 & 2 & 3 & 4 & 5\end{array}$

Durante o antes de una presentación me siento

36 tembloroso(a) o tambaleante

$\begin{array}{llllllllll}1 & 2 & 3 & 4 & 5 & 1 & 2 & 3 & 4 & 5\end{array}$

37 Tengo confianza al tocar de memoria

$\begin{array}{llllllllll}1 & 2 & 3 & 4 & 5 & 1 & 2 & 3 & 4 & 5\end{array}$

38 Me preocupa ser observado(a) y analizado(a) por otros

Me preocupa mi propio juicio acerca de mi desempeño

$\begin{array}{llllllllll}1 & 2 & 3 & 4 & 5 & 1 & 2 & 3 & 4 & 5\end{array}$

$\begin{array}{llllllllll}1 & 2 & 3 & 4 & 5 & 1 & 2 & 3 & 4 & 5\end{array}$

$40 \begin{aligned} & \text { Me mantengo con el compromiso de tocar aun } \\ & \text { cuando me cause gran ansiedad }\end{aligned}$
1

$\begin{array}{llllllllll}1 & 2 & 3 & 4 & 5 & 1 & 2 & 3 & 4 & 5\end{array}$




\section{Anexo 9: Consentimiento Informado}

Estimada alumna o alumno,

Ante todo muchas gracias por tu tiempo y atención. La presente investigación está conducida por Álvaro Mario Chang Arana bachiller de la carrera de Psicología de la Universidad de Lima e identificado con el DNI: 46503560. El objetivo del estudio es conocer algunas características de las emociones en estudiantes de música.

De aceptar formar parte del estudio, se te solicitará que respondas algunas preguntas de un cuestionario, para lo cual necesitarás aproximadamente 15 minutos. Es importante que tengas en cuenta que tu participación durante todo el proceso es completamente voluntaria y que las respuestas que des serán absolutamente anónimas. Esto significa que no se te podrá identificar y los resultados que obtengas no se compartirán con ninguna persona. Por ello, puedes sentirte tranquila o tranquilo en contestar a las preguntas que se presentarán.

Los resultados obtenidos a nivel grupal tienen un fin estrictamente de investigación, por lo cual podrán ser publicados o compartidos en contextos académicos. Por ello es importante que respondas con la mayor sinceridad posible y que preguntes en cualquier momento si tienes alguna duda. Esta investigación es relevante pues permitirá identificar algunos aspectos emocionales que puedan influir en tu desempeño musical y a partir de ello plantear alternativas de solución. De este modo, podría ser de ayuda futura para aquellos estudiantes de música que así lo requieran, por lo cual tu participación será muy valorada y apreciada.

Si posteriormente tienes alguna duda o deseas mayor información con respecto a esta investigación, puedes escribir a: chang_03_09@ hotmail.com. A través de este medio se te contestará gustosamente.

Nuevamente, muchas gracias por tu colaboración.

Álvaro Mario Chang Arana

Luego de haber sido informada o informado acerca de la investigación conducida por Álvaro Mario Chang Arana, acepto participar voluntariamente en el proceso. Entiendo que la información que proporcione será estrictamente anónima y que los datos obtenidos serán utilizados exclusivamente para fines académicos.

Nombre y Apellido

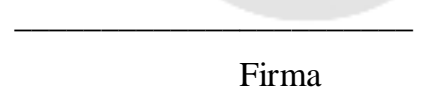

Fecha 


\section{Anexo 10: Protocolo de Aplicación}

\section{Instrucciones}

Buenas tardes, mi nombre es y vengo a apoyar a Álvaro Chang Arana, estudiante de psicología responsable de la aplicación de un cuestionario para su tesis de licenciatura. Cualquier consulta que tengan en cualquier momento háganmela saber. Ahora voy a repartirles un conjunto de hojas. Una es una hoja de consentimiento informado (se muestra la hoja) y el resto es un cuadernillo engrapado conteniendo el cuestionario (se muestra el cuadernillo engrapado).

\section{Consentimiento informado}

Por favor, vamos a leer juntos el consentimiento informado (se da lectura de todo el consentimiento informado). Si están de acuerdo con participar, por favor coloquen sus datos donde indica la hoja. Cuando acaben de responder, me entregarán el talonario de la hoja y ustedes se quedan con esta parte (se señala cada parte) ¿Tienen alguna pregunta con respecto al consentimiento informado?

\section{Cuadernillo}

El cuadernillo con el cuestionario está hecho de dos partes. En la primera página se les solicita unos cuantos datos personales y las siguientes 5 páginas contienen el cuestionario. Vamos a revisar las indicaciones para que puedan empezar. En la primera página se les pregunta... (Se lee solo los títulos de cada ítem sociodemográfico). Por favor, no dejen sin responder ningún ítem. Si no entienden algún término o no están seguros de algo levanten la mano y me acercaré.

Con respecto al cuestionario, por favor, vean que está enumerado en la esquina inferior derecha del 1 al 5, impreso por el anverso y reverso de la hoja (se muestran las caras del cuestionario). No desglosen las hojas, déjenlas engrapadas. Las indicaciones de lo que deben hacer y cómo contestar están explicadas en los rectángulos ubicados en el encabezado de la hoja. Vamos a leer juntos las indicaciones de cada uno (se da lectura de las indicaciones de cada cuestionario). ¿Alguien tiene alguna pregunta? Si no es así, por favor, pueden comenzar. No dejen ninguna respuesta en blanco. Me avisan cuando terminen. 


\section{Preguntas y respuestas frecuentes}

¿Si firmo acá, ya no va a saber quién soy?

No. Colocar esos datos no romperá el anonimato, puesto que al final de la evaluación me entregarán ese pedazo de la hoja cortada y yo la colocaré en una bolsa indistintamente del orden, por lo que no podré saber a quién corresponde el cuadernillo que me entreguen. Solo se mantienen los talonarios con sus nombres y firmas por si alguno de ustedes desea hacerle una consulta puntual a Álvaro, pero no servirá de ninguna manera para romper el acuerdo de anonimato. Es parte rutinaria de un proceso de investigación.

¿Qué es contrariado?

Disgustado

\section{¿Tendremos resultados de esto?}

No, pues esta investigación busca, justamente, tener una prueba que permita ayudar a los músicos, pero para eso debe pasar antes por un minucioso análisis estadístico. Sería irresponsable darles algún tipo de devolución de resultados sin que la prueba pase por este análisis estadístico. 